


\section{LIBRARY}

Brigham Young University

Gift of

John Eastmond

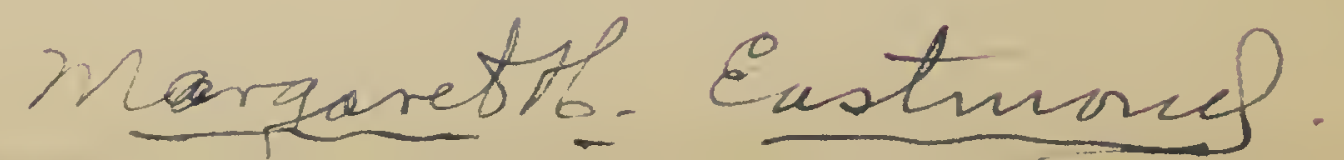






\title{
First Lessons \\ in Bacteriology for Nurses
}

\author{
By \\ M. E. Morse, M. D. \\ Pathologist to the Boston State Hospital
}

Illustrated

Philadelphia and London

W. B. Saunders Company 
Copyright, I9I9, by W. B. Saunders Company

Reprinted March, I920

PRINTED IN AMERICA

PRESS OF

W. B. BAUNDERS COMPANY

PHILADELPHIA

THE LORARY

BRIGHAM YOUNG UUIVERSITY

PROVO, UTAH 


\section{INTRODUCTION}

THE present work is the result of a number of years' experience in teaching bacteriology to nurses. A textbook is desirable to supplement and emphasize the material presented in lectures, but the writer has found the text-books examined difficult for beginners who have not had an extended preliminary education. The amount of material presented and the technical terms bewilder and discourage them. In the beginning they should grasp clearly a few general ideas in untechnical language and gradually build on them. It is less important for them to learn disconnected scientific facts than to realize vividly that the connection between the symptoms seen at the bedside and the material shown in the class-room is immediate and vital.

An effort has therefore been made to reduce technical terms to a minimum, to include nothing merely for the sake of systematic completeness, and to point out the application of bacteriological principles not only to conditions inside the hospital, but to household life, social movements, and particularly to preventive medicine. Subjects which are adequately treated in text-books of nursing, such as methods of sterilization and disinfec- 
tion, have been merely touched upon, and only the commonest organisms and diseases have been discussed. The chapters on immunity and vaccine and serum therapy are intended for senior nurses. The material in this book should be understood by pupils who have had a grammar school education.

Suggestions for demonstrations are appended to each chapter. If a projection apparatus is available it is preferable to the microscope for demonstrating bacteria to persons who are not used to microscopic technic. Use should be made for class purposes of such cultures as come into the hospital laboratory, with short explanations of their clinical bearings, and the cultures made in class should be incubated and demonstrated at the next meeting. If practicable, visits to a public health laboratory, a milk establishment, and, for the second year class, an antitoxin station should be undertaken in connection with class work. Reproductions of charts used in public health work are easily made, and are valuable for illustrating the lectures.

This book, as its title implies, is intended only as an introduction, with the idea that it might be supplemented later by the more extended bacteriologies for nurses, or the latter used as reference books by students whose needs are more advanced.

Boston, Mass. 


\section{CONTENTS}

InTrODUCTION................................

\section{CHAPTER I}

What Bacteria Are and How They Grow.............. 13

Bacteria are the simplest forms of living things. Belong to the vegetable kingdom. Consist of a single cell. Classification of bacteria according to shape: cocci, bacilli, and spirilla. Characteristics of bacteria: 1. Size: largest, $\frac{1}{2000}$ inch long; smallest, $\overline{5} \frac{1}{10 \overline{0}}$ inch. 2. Food, animal or vegetable matter. Disease-producing bacteria live on the fluids of the body. 3 . Multiplication by simple division. 4. Require moisture. 5 . Temperature. Lowest temperature at which bacteria can multiply $54^{\circ} \mathrm{F}$; highest, $110^{\circ} \mathrm{F}$. Sterilization by heat. 6 . Liglit unfavorable to bacteria. 7. Formation of spores. Bacteria present everywhere in nature; on the surface of the body and in the intestines. Not present in the deeper parts of the body. How bacteria are studied in the laboratory. Taking cultures.

\section{CHAPTER II}

The Work of Bacteria in the OUtside World. Bacteria in RELATION TO FOOD......................... 26

Classification of bacteria according to their activities: 1 . Harmless, live in the outside world and cause putrefaction. 2. Harmful, live in the human body and produce disease. Distribution of bacteria in nature; in soil, water, and air. Bacteria and food preservation. Spoiling of food caused by the growth of bacteria in it. Principles underlying canning, pickling, drying and smoking, and cold storage. Bacteria and milk. Souring of milk. Numbers of bacteria in milk. 
Growth of disease germs in milk. Pasteurization. Laws regulating the sale of milk. Bacteria and eggs.

\section{CHAPTER III}

Bacteria in Relation to the Human Body and the Production of Disease. Infection. How Bacteria Enter the Body

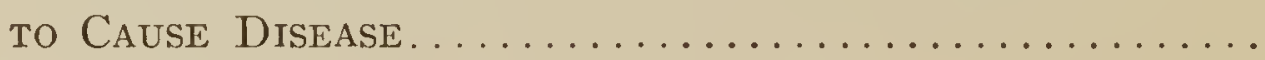

Two classes of diseases: 1 . Those arising from causes within the body-constitutional diseases. 2. Those produced by living organism-sinfections. Distribution of bacteria on and in the healthy human body: 1. On the skin. 2. In the nose, throat, and lungs. 3. In the mouth. Importance of cleanliness of the mouth and teeth. 4. In the stomach and intestines. In the feces. The colon bacillus. Infection is the reaction of the body to the injury produced by bacteria growing within it. Mild and severe infections. How bacteria enter the body to produce disease: 1 . Through breaks in the skin. Wounds. Importance of care of wounds. 2. Through the air breathed in: colds, pneumonia, and tuberculosis. 3. Through the mouth and infected food and drink. Infections of the intestines, typhoid, diarrhea, and dysentery. Food handlers. Putting unclean articles in the mouth. 4. Through the genital tract: Infection following child-birth.

\section{CHAPTER IV}

How Bacteria Are Cast Off from the Body.............

Bacteria are cast off in the excretions: in the feces in infections of the intestines; in sputum in infections of the lungs; in nasal discharge and saliva in infections of the nose and throat; in urine in infections of the kidneys and bladder; in pus and the discharges from sores and ulcers. How disease-producing bacteria are carried from person to person. Do not live long outside the body. Are carried by: 1. Direct contact with infected person or thing. The most important method of infection: Bacteria carried passively. 2. Carriers: Typhoid, dysentery, diphtheria, and other diseases. 3. Insects. Flies: Typhoid, dysentery, summer diarrhea. Mosquito: Malaria. Body lice. Prevention of infections in hospitals: "Food, fingers and flies, and food handlers." 


\section{CHAPTER V}

How Bacteria Injure the Body. Acute and Chronic Infections. Conditions Favoring Infections...............

Bacteria injure the body by producing poisonous substances which are distributed throughout the system, damaging the organs and thus producing symptoms. Acute and chronic infections. Stages of an acute infection: incubation, fever, convalescence. Conditions favoring infection: 1. Age. 2. Poor physical condition (underfeeding, overwork, etc.). 3. Unhygienic living conditions (overcrowding, etc.).

\section{CHAPTER VI}

The Bacteria Most Commonly Found in Pus. Inflammation Staphylococcus aureus and streptococcus. Characteristics of the Staphylococcus aureus. Found in abscesses, boils, and infected wounds. Characteristics of the streptococcus. Found in tonsillitis, erysipelas, peritonitis, puerperal fever, and blood-poisoning. The most dreaded organism in surgery and obstetrics. Inflammation is the local reaction to the injury produced by bacteria. Signs of inflammation. Acute and chronic inflammation.

\section{CHAPTER VII}

The Tubercle Bacillus and Tuberculosis...............

Prevalence of tuberculosis. The most wide-spread and destructive of diseases. Curability. Decrease of the disease. Discovery of the tubercle bacillus. Characteristics of the organism: slow growth, long life outside the body, resistance to disinfectants and drying. Tuberculosis of the different organs. How tuberculosis is spread: by excretions of the tuberculous patient, especially sputum. Importance of care of sputum. Infection from spray during coughing. Contamination of food. Importance of infection during childhood. Predisposing influences to infection. Early symptoms of pulmonary tuberculosis. Importance of early diagnosis. Measures for the control of tuberculosis.

\section{CHAPTER VIII}

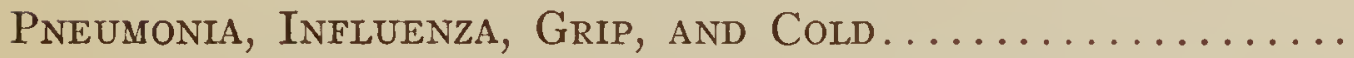

Pneumonia is an acute inflammation of the lung. Lobar and bronchopneumonia. Lobar pneumonia caused by the pneumo- 
coccus. Prevalence. Characteristics of the pneumococcus. Delicate organism; does not live long outside the body. Sources of infection, sputum of pneumonia patient. Pneumococci in throats of recovered patients. Carriers. Importance of care of sputum and of articles used by patient. Dangers of coughing and sneezing without covering nose and mouth. Grip or influenza; method of spread. Common colds, precautions against spread. Importance of colds as predisposing to more serious infections.

\section{CHAPTER IX}

Typhoid Fever, Dysentery, and Summer Diarrhea.........

Prevalence of typhoid fever. Preventable. Characteristics of the typhoid bacillus: Has power of motion, can live for some time outside body, easily killed by drying, disinfectants, and pasteurization. Features of typhoid fever: Bacilli in blood; intestinal ulcers. Sources of infection: Feces and urine of typhoid patient. Methods of transmission: By water, milk, direct contact with patient, flies, carriers. Responsibility of nurse for disinfection of patient's excretions. Widal reaction. Antityphoid inoculation. Measures for the reduction of typhoid. Dysentery bacillus: Cause of dysentery of adults and summer diarrhea of infants. Cast off in feces. Life outside body. Spread by direct contact, carriers, and flies. Prevention of infection.

\section{CHAPTER X}

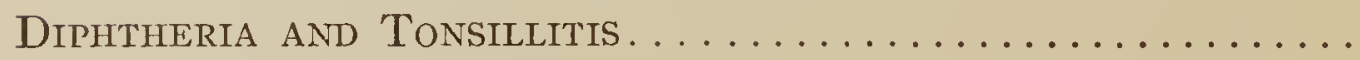

Diphtheria bacillus. Characteristics: Grows easily; quickly killed by heat when moist, resistant when dried. Diphtheritic membrane. Methods of infection: Direct contact; articles contaminated by patient; light unrecognized cases, and carriers. Importance of taking cultures from all cases of sore throat. Carriers in schools. Diphtheria antitoxin. Ordinary sore throat and tonsillitis, caused by streptococci, staphylococci, or pneumococci. Method of spread. Inflamed tonsils as a starting-point for infections in other parts of the body, rheumatism, etc.

\section{CHAPTER XI}

Contagious Diseases: Measles; Scarlet Fever; Whoopingcough; Mumps; Chicken-pox....................

Contagious diseases are those especially easily transmitted by direct contact. Organisms causing several of them still 
unknown. Usually affect children. Several are associated with rashes. One attack protects for life. Measles: most common of all infectious diseases. Organism undiscovered, but present in secretions of nose and throat and in blood. Spread by droplets of secretion. Incubation period. Infective period. Complications. Death-rate. Measles in army. Scarlet Fever: Possible discovery of cause. Organism present in secretions from throat and nose; can remain alive for some time outside body. Incubation period. Infective period long. Whoopingcough: bacillus of, present in sputum. Disease spread by infected droplets thrown out during coughing. Incubation period. Complications. Seriousness of the disease in young children. Mumps and Chicken-pox: Causes and methods of spread unknown. Incubation periods. General measures to be taken in every case of contagious disease. Care of secretions of nose and mouth. Attention to mouth and teeth. Disinfection of linen. Dishes. Precautions for doctor and nurse. Care of patient and sick room at end of quarantine. Importance of early isolation. Daily medical inspection of school children. Care of contagious cases in special hospitals.

\section{CHAPTER XII}

Syphilis and Gonorrhea: The Venereal Diseases.......... 104

Spread chiefly by sexual immorality. Frequency. Farreaching effects in nervous and mental diseases, internal diseases, obstetrics, and gynecology. Infection of innocent persons. Syphilis caused by the Spirochreta pallida. Features of syphilis, infection through breaks in the skin or mucous membranes; organism in the blood; may remain alive in body for years. Syphilis as a cause of nervous and mental diseases, diseases of heart and arteries, and miscarriages. Congenital syphilis. Idiocy and feeble-mindedness. Disease spread by direct contact and by articles used by patient. Length of infective period. Wassermann reaction in blood and cerebrospinal fluid. Routine Wassermann reactions on hospital patients. Salvarsan: intravenous and intraspinous injection. Gonorrhea, caused by the gonococcus. Acute inflammation later becoming chronic. Importance in gynecology and obstetrics. Characteristics of the gonococcus. Source of infection. Measures for the reduction of venereal diseases. 


\section{CHAPTER XIII}

How the Body Protects Itself Against Infection. Immuntty. Ways of Producing Immunity.................. 112

Protective substances produced in the course of an infectious disease. Circulate in blood. Length of time which they persist varies with the disease. As long as they are present a person is unlikely to have a second attack of the disease. Immunity is resistance to infection. Length of immunity varies in different diseases. Methods of acquiring immunity: 1. By recovering from the disease (the natural method). 2. By the injection of dead bacteria (bacterial vaccines). 3. By injection of the blood-serum of an immunized animal. 4. By the inoculation of living organisms which give the disease in a very mild form.

\section{CHAPTER XIV}

Bacterial Vaccines............................ 116

Injections of dead bacteria of the kind which it is desired to protect against. Autogenous and stock vaccines. Vaccines stimulate the body to produce substances injurious to the bacteria causing the infection. Preparation of vaccines. Dosage. Cases most suitable for vaccine treatment. Prophylactic use of vaccines. Immunization against typhoid. Dosage. Length of protection. Not an absolute prevention, and precautions against typhoid must not be relaxed. Results of inoculation in armies and institutions. Advisable also for travelers, persons in communities where typhoid is prevalent, and families of typhoid patients.

\section{CHAPTER XV}

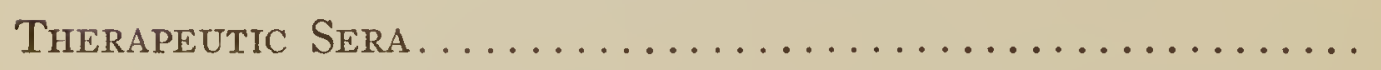

Definition. Most efficient sera are those against diphtheria, tetanus, and cerebrospinal meningitis. Protection given by sera immediate but transient; that given by vaccines slowly produced but lasting. Curative and protective uses of sera. Diphtheria antitoxin. Lowering of death-rate from diphtheria since its introduction. Action of diphtheria toxin. Antitoxin counteracts toxin. Method of preparation of antitoxin. Method of administration. Dosage. Importance of giving antitoxin early in the disease. Protective use of antitoxin. Dosage. Length of immunity. "Serum sickness." 
Tetanus antitoxin. Characteristics of tetanus bacillus. Cases likely to develop tetanus. Tetanus toxin. Curative value of tetanus antitoxin slight; protective value great. Antimeningococcus serum. Characteristics of meningococcus. Preparation of the serum. Results of treatment. Method of administration and dosage.

\section{CHAPTER XVI}

Vaccination against Small pox.................. 130

Small-pox the first disease to which immunity was obtained artificially. Principles underlying vaccination. Introduction of vaccination with cowpox virus by Jenner in 1798. Elimination of small-pox by vaccination. Preparation of vaccine virus. Method of inoculation. Reaction. Length of protection. Rules for vaccination and re-vaccination.

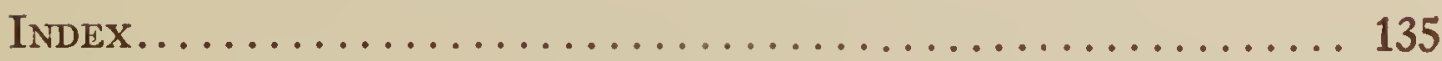





\section{FIRST LESSONS IN BACTERIOLOGY FOR NURSES}

\section{CHAPTER I}

\section{WHAT BACTERIA ARE AND HOW THEY GROW}

BACTERIA, germs, microbes, or micro-organisms are the lowest or simplest forms of living things. They are somewhat like the lowest kinds of both plants and animals, but, on the whole, they resemble more the simplest plants, and are, therefore, classed in the vegetable kingdom. A lowly plant with which we are familiar and which somewhat resembles bacteria is the common green mold that grows on bread.

Each germ consists of a single cell or extremely small bit of vegetable matter. It is inconceivably small measured by our every-day standards, so small, in fact, that it can be seen only with the highest powers of the microscope. An idea of its size may be obtained from the facts that the smallest bacteria are about $1 / 51,000$ inch long, and the largest only about 1/2000; that $1,700,000,000$ might easily be contained in a single drop of water; and that 30,000,000,000 would be required to weigh 1 gram. There is proof also that there are bac- 
teria which are too small to be seen with even the strongest microscopes.

Bacteria are divided into three groups, according to their shape: 1. Cocci (plural, singular coccus), which have the form of balls or spheres. The word coccus is Latin for ball. 2. Bacilli (singular bacillus, a Latin word for rod), which are rod-shaped bacteria. 3. Spirilla (singular spirillum), shaped like corkscrews. The cocci and bacilli are the common forms, while spirilla are rare among disease-producing germs.

The cocci when seen under the microscope are arranged in various ways. Some are in masses resembling a bunch of grapes; others form chains, and others are always in pairs. We shall meet examples of each of these in our study of disease germs. The bacilli vary in shape, some being short and plump, others long and slender, and still others curved (Fig. 1).

There are many different kinds of cocci and bacilli. Each germ has its own special characteristics, with which the bacteriologist is familiar, just as the botanist knows the different plants. We shall study in this book only a few of the commonest disease-producing bacteria.

In their natural state bacteria appear under the microscope as colorless balls or rods which are difficult to see clearly; so that in order to study them closely they are stained with colored dyes.

Some bacilli have the power of motion, and in a drop of fluid under the microscope may be seen darting, roll- 
ing, and squirming about, bumping into one another, clinging together for an instant, and then separating again. These bacilli, however, can move only in fluid. They cannot move through the air or on solid substances, but they may be carried as "passengers" on dust particles, hands, clothing, etc. None of the common forms of cocci have the power of movement.

Bacteria carry on the same processes of life as do the higher plants and animals. They grow by taking in

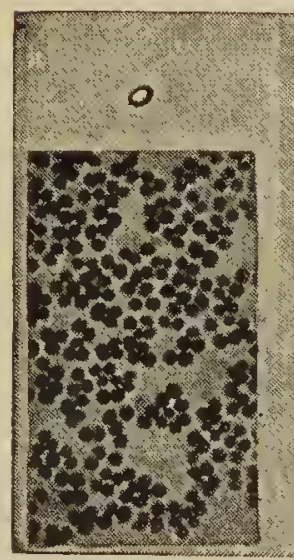

$a$

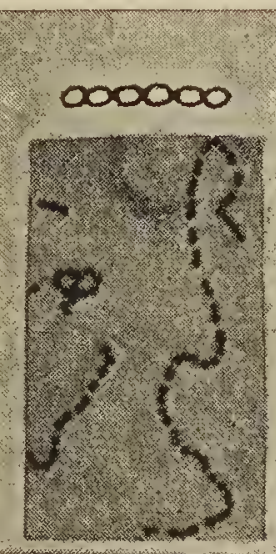

$b$

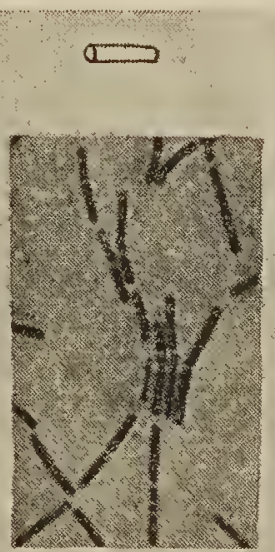

c

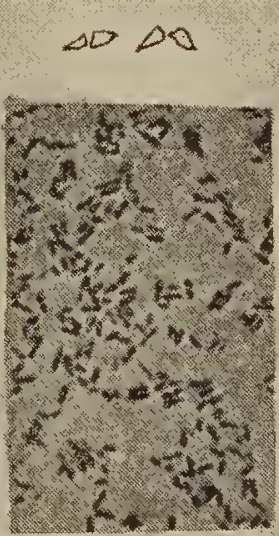

d

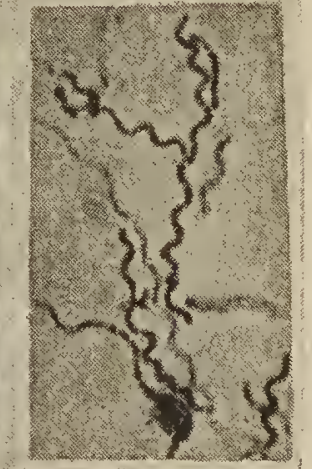

$e$

Fig. 1.-How bacteria look under the microscope. Cocci, bacilli, and spirilla, magnified 1000 times: $a$ and $b$, Cocci arranged in bunches and chains; $c$ and $d$, two forms of bacilli, one large, long, and slender; the other small, short, and plump; $e$, spirilla. (Park and Williams.)

food, they cast off their waste products, they reproduce their kind, and when conditions are unfavorable they die. In addition, they require for their growth certain conditions of temperature, moisture, and light.

The food of those bacteria which live in the outside world is dead animal or vegetable matter, which they break up, causing decay or putrefaction. The germs which live in or on the human body and produce disease 
subsist on the fluids and tissues of the body. In growing bacteria in the laboratory various substances are used, such as beef-broth, gelatin, potato, and milk. Some germs are very particular about their food and can live on only a few substances; some grow only with great difficulty outside the body; others are vigorous and can live on a great variety of nourishment.

Bacteria multiply in the simplest possible way, that is, each organism merely divides in the middle, forming two individuals. Each of these two divides again, and so on, as long as conditions are favorable. When the food-supply is abundant and conditions of moisture and temperature suitable, bacteria multiply with great rapidity. A single germ under these circumstances may divide in twenty or thirty minutes, in which case simple calculation will show that in twenty-four hours a single organism could give rise to $17,000,000$. If conditions were always suitable the earth would be overrun with bacteria, but they, like all other living things, have to struggle for existence, and when conditions are not right they multiply slowly or not at all. Their growth is checked by drying, lack of proper food, too high or too low a temperature, sunlight, and antiseptics. When conditions become absolutely unfavorable they die, like all other living things. Each germ when it multiplies reproduces its own kind, that is, the bacillus of tuber-. culosis produces only tubercle bacilli; the diphtheria bacillus, only diphtheria bacilli, etc. 
Bacteria resemble other living things in requiring moisture for their growth. Some are killed quickly by drying, others can withstand it for a considerable time, but none can multiply in the absence of moisture. Therefore, if we wish to prevent the growth of germs, one of the ways to do it, when possible, is to avoid moisture. There are many applications of this principle in medicine and nursing. For instance, bed-sores are caused by bacteria, and to prevent them it is most important to keep the skin dry by washing with alcohol and putting on a dusting-powder.

Bacteria must also have a suitable temperature for growth, each kind having a temperature at which it flourishes best. The germs which live in the outside world and cause putrefaction grow best at the temperature of warm summer weather $\left(68^{\circ}-75^{\circ} \mathrm{F}\right.$.); while those which live in the body and produce disease require more warmth and grow best at about body temperature $\left(95^{\circ}-102^{\circ} \mathrm{F}\right.$.). The lowest temperature at which bacteria can multiply is about $54^{\circ} \mathrm{F}$. and the highest $110^{\circ} \mathrm{F}$. This does not mean that they are killed at these temperatures, for some bacteria are very resistant to both heat and cold; for example, the germ which causes typhoid can survive for a time in ice. Extreme heat is more quickly fatal to bacteria than extreme cold. Several methods of sterilizing depend on killing bacteria by heat: 1. Boiling for three minutes destroys all bacteria. 2. Sterilizing by steam under pressure in the 
autoclave. Thirty minutes' exposure is ordinarily sufficient to kill all germs. 3. Heating in dry air, or baking, which is not so efficient as steam sterilizing. 4 . Pasteurizing (named after the great French bacteriologist Pasteur), which means heating to $130^{\circ}-140^{\circ} \mathrm{F}$. for ten to twenty minutes. It destroys most diseaseproducing germs and is used for milk.

Light, especially direct sunlight, is very unfavorable to bacteria. Indeed, sunlight is one of nature's most valuable antiseptics. The germ causing tuberculosis, for instance, is killed by two hours' exposure to direct sunlight.

Bacteria differ in their relation to oxygen. Some kinds require it just as much as animals; others will not grow if it is present.

Some kinds of bacteria have developed means of resistance to unsuitable conditions for life by the formation of what are called spores. This process is not common among disease-producing germs, but frequent among those living in the outside world. When an organism is about to form a spore, a glistening speck appears at one end. This dot increases in size, becomes surrounded by a dense covering, and is now called a spore. In this form the germ has a remarkable power of resistance against heat, cold, drying, and antiseptics. When conditions again become favorable for the life of the germ the spore changes back to the ordinary form of the organism and goes on growing. 
Spore formation has been compared to the sprouting of seeds, which can remain alive for a long time, but show no signs of life until they are placed under favorable conditions. For example, in the cold pack method of canning the vegetables are steamed for three days in succession. On the first day all germs which do not form spores are killed, while those that produce them change

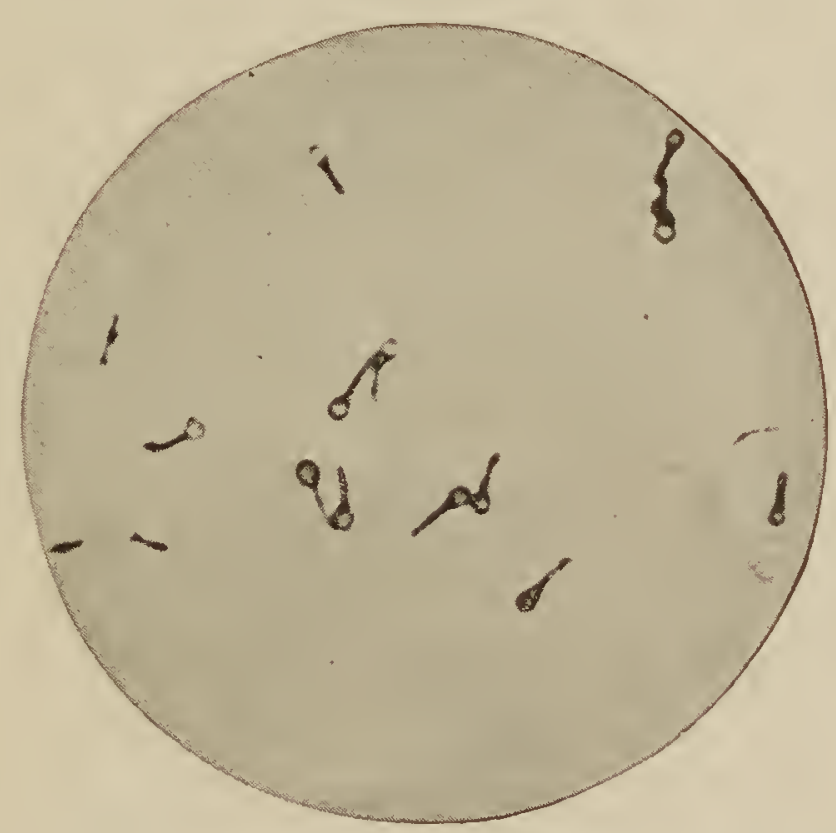

Fig. 2.-The bacillus which causes lockjaw forming spores. The light-colored swellings at the ends of the bacilli are the spores. This bacillus lives in the ground. (See Chapter XV.) (Kolle and Wassermann.)

into that form under the influence of heat. The jars are left at room temperature for twenty-four hours, and at this favorable temperature the spores change into the usual form of bacteria again. These are killed by heating on the second day, and sterilizing on the third day destroys any which may have escaped previously.

Bacteria are present almost everywhere in the outer 
world -in soil, water, food, clinging to particles of dust in the air; on plants, on the bodies of human beings and animals. They are not found where it is extremely cold, as in the arctic regions or on the tops of very high mountains.

Different kinds of bacteria grow side by side in the outside world and on the human body. In order to study any particular germ in the laboratory we must first grow it apart from all other kinds on suitable food material; then we must identify it by its appearance under the microscope and by other characteristics. The process of getting the germs which we wish to study is called "taking a culture." For this purpose we use a culture-tube (Fig. 3), which consists of a glass test-tube in which is a wooden stick or a wire, the end of which is wound with raw cotton. This is called a swab. The mouth of the tube is plugged with cotton. The tube is then sterilized, so as to kill all the bacteria on the swab and on the inside of the tube. Everything inside the tube remains sterile as long as the plug is kept in, because no bacteria can pass through the cotton. When it is desired to take a culture, the plug is removed carefully and held between the fingers, so that the end which goes in the tube does not touch anything and so take up germs. The swab is then carefully drawn out of the tube, taking care not to hit the edge of the tube, which is not sterile (see Fig. 4, A). The swab is then rubbed over the surface from which we wish to get the bacteria-a sore throat, 
wound, etc. - and the bacteria are wiped up on the cotton. The swab is then replaced in the tube, taking care that it does not come in contact with anything, and the tube

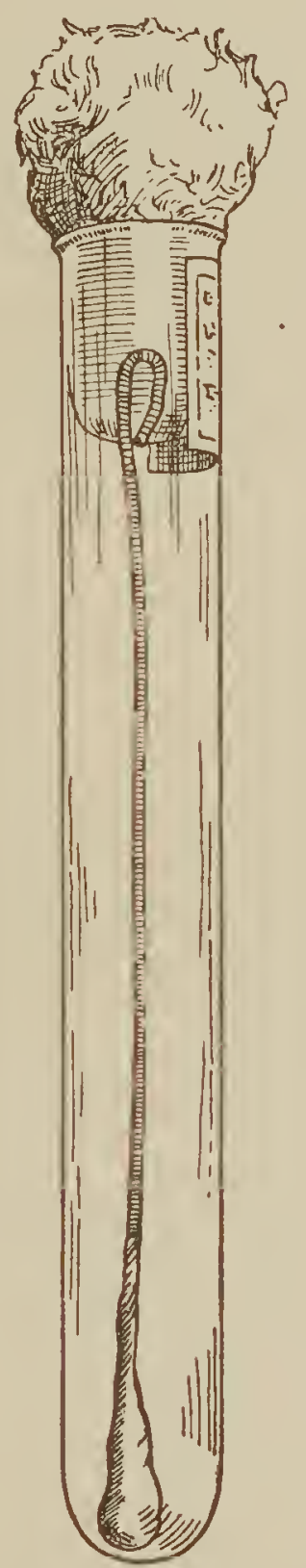

Fig. 3.-A culture-tube. The tube has been sterilized after the swab and plug have been put in; therefore everything inside the tube remains sterile as long as the plug is kept in (Warren).

labelled immediately with the patient's name, the date, and the place from which the culture was taken. The bacteria which we wish to examine are now in the tube, 


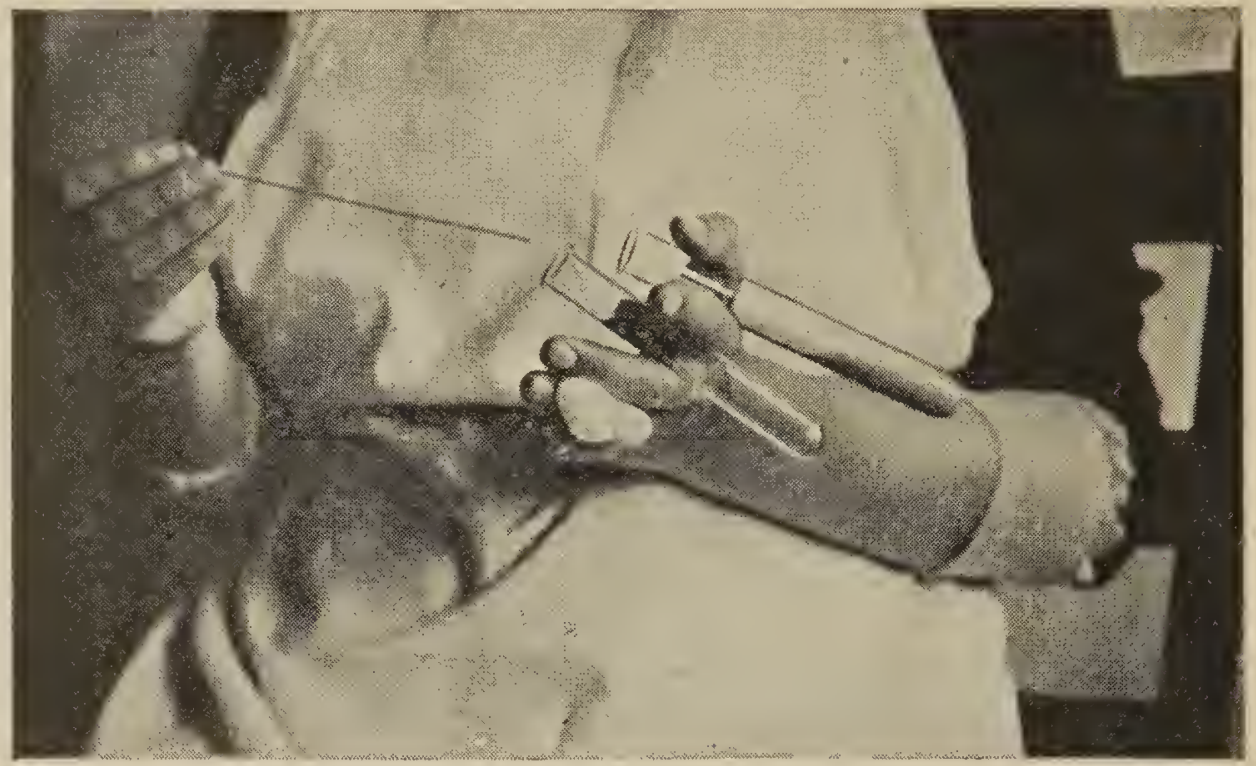

$A$

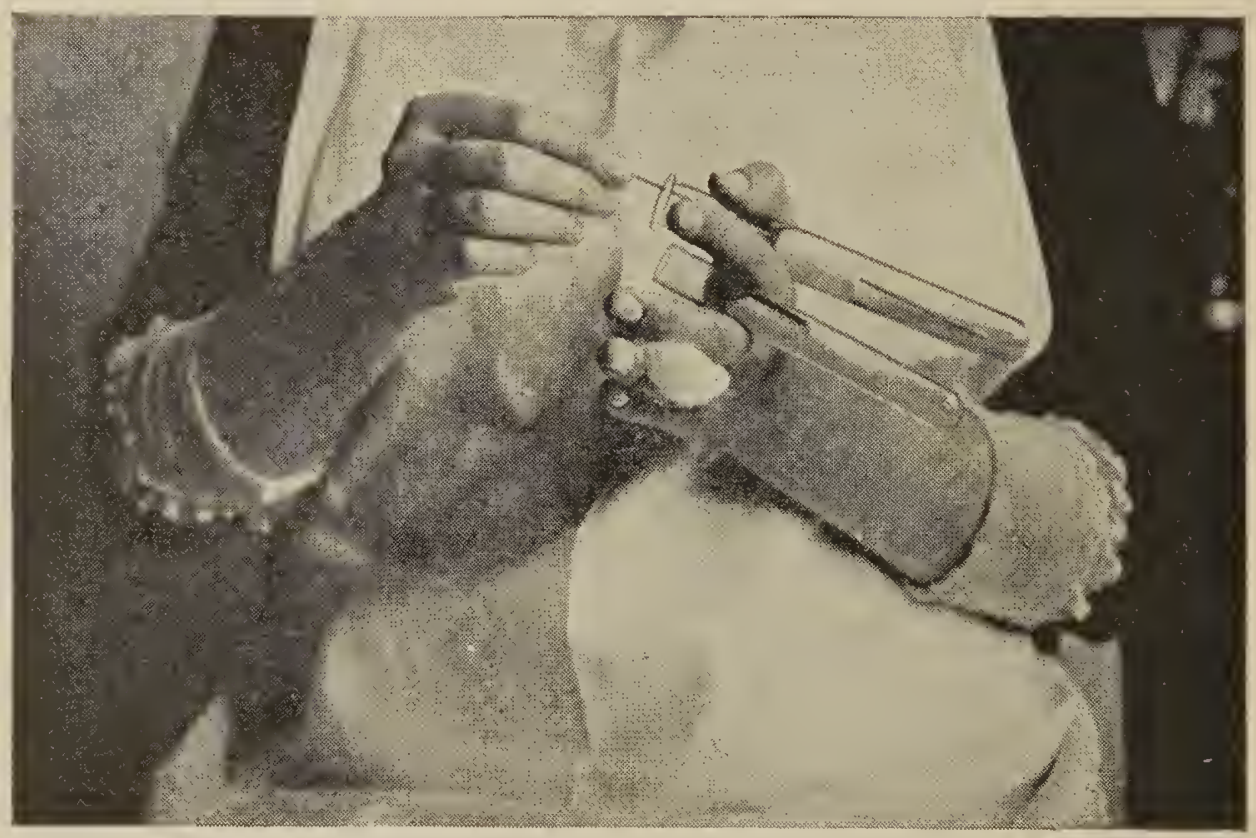

$B$

Fig. 4.-Making a culture: showing how the culture-tube and tube of food substance are held. The cotton plugs are put between the fingers so that the ends which go in the tubes do not touch anything. $A$. Removing the swab, carrying the bacteria, from the culture-tube. $B$. Transferring the bacteria from the swab to the surface of the sterile food substance.

and separated from all other bacteria, and the tube is sent to the laboratory for study. There are certain precautions which must be observed in taking cultures. 
If the culture-tube has been opened, or if the plug fits loosely, the tube should not be used, because bacteria may have been carried into the tube. The swab should be touched only to the spot from which the culture is desired, because otherwise we should take up germs which we do not wish to examine.

The nurse is sometimes obliged to take cultures, especially in dispensary and public health work, and she should therefore practice the method until she can do it accurately and quickly.

Having secured the material containing the desired bacteria, and separated them from other germs, the next step is to provide them with proper food and temperature so that they can multiply. The swab carrying the bacteria is wiped over the surface of sterile food substance, such as potato, in a test-tube, and the tube put in a special oven, which is kept at the temperature of the body. In twenty-four hours masses of bacteria are usually visible to the naked eye on the surface of the food substance. These masses, each of which is composed of millions of germs, are called colonies. Colonies of different bacteria vary in appearance. Some look like dewdrops, others are white and glistening, like the head of a white pin; still others have various colors. When bacteria grow in broth they cause a cloudiness. 

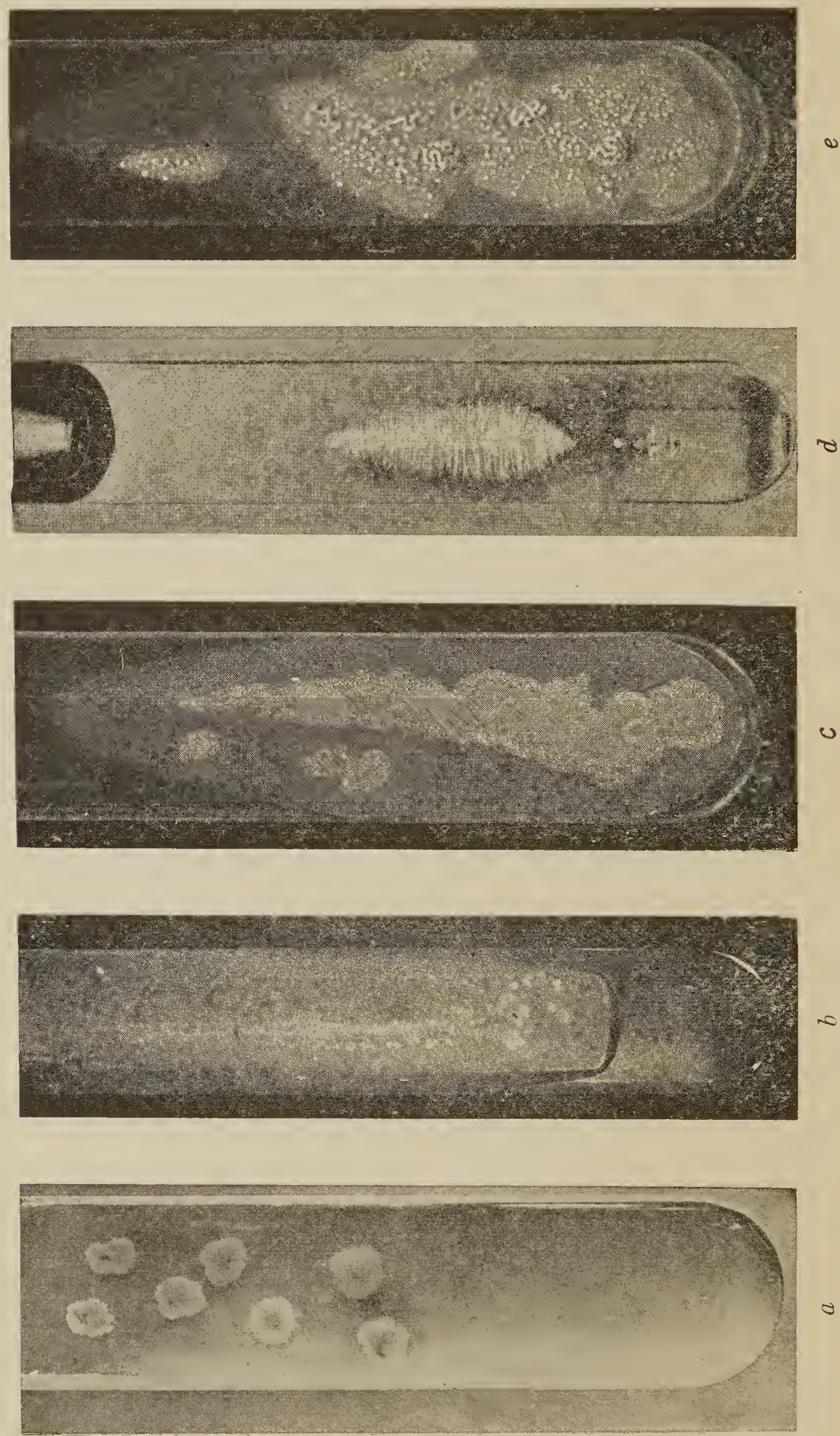


\section{DEMONSTRATIONS}

If possible, use the projectoscope to demonstrate bacteria on slides; otherwise use the microscope.

Show tubes of various media.

Demonstrate the culture-tube and method of taking a culture from the throat.

Show any cultures on hand in the laboratory, for demonstration of colonies, with explanation of the sources of the cultures.

Show a bottle of vaccine (typhoid or other) to impress the large number of bacteria that may be present in a cubic centimeter of fluid.

Fig. 5.-Colonies, or masses of bacteria, growing on food substances in test-tubes. Each colony is made up of hundreds of thousands of bacteria. Notice that each kind of germ grows in a different way. $a$, Colonies of a coccus often found in the nose and throat (F. T. Lord; photo by L. S. Brown). b, Colonies of a coccus frequently present in pus (streptococcus, see Chapter VI) growing for two days. Some of the colonies are separate; others have grown together into a single mass (Fränkel and Pfeiffer). c , Growth of bacilli in a single mass (Curtis). $d$, Bacilli growing in gelatin. This germ cannot grow where oxygen is present, and therefore does not form colonies on the surface of the gelatin (Fränkel and Pfeiffer). $e, A$ heavy growth of tubercle bacilli several months old. Tubercle bacilli grow more slowly than most bacteria (see Chapter VII) (Curtis). 


\section{CHAPTER II}

\section{THE WORK OF BACTERIA IN THE OUTSIDE WORLD: BACTERIA IN RELATION TO FOOD}

Those whose work lies constantly with disease, as doctors and nurses, are inclined to have a one-sided view of bacteria. They think of them all as evil and as enemies of human life, whereas only a few kinds, comparatively, cause disease. The greater number are harmless to man, and the work of most bacteria is good, and in fact necessary to human life. Bacteria may, therefore, be divided into two great groups according to their activities, the harmful and the harmless. The first kind live normally on or in the bodies of human beings and cause disease. The second kind live in the outside world and are harmless to man. It is these which we shall study in this chapter. We see their work all around us in nature, for it is the breaking up of dead animal and vegetable matter, which we know as decay or putrefaction. We usually think of putrefaction as an unclean, disgusting process, as it certainly is in some relations, but it is really nature's way of purifying the earth. The complicated materials of the plant or of the animal body are broken up after death into water, gases, and simple substances that plants can use 
for food. For instance, when a dead animal is buried in the ground, bacteria enter the body and cause it to disintegrate. The gases and water that are formed pass off into the soil, and the other substances which the bacteria produce from the animal's body are suitable food for plants. In this way the dead animal body disappears, and the materials of which it was made up are used over again to nourish plants; for it is one of the great laws of nature that no particle of matter shall be lost or wasted, but only changed into other forms. It is through the work of bacteria that the accumulation of dead animal and vegetable matter is prevented and the earth kept fit for living things. Without their activity life would be impossible.

The conditions most favorable for putrefaction are those which we saw in the last chapter are most suitable for the growth of bacteria. A moderately warm temperature, about that of hot summer weather, is best. Moisture is also necessary, for, as every one knows, no perfectly dry substance ever decays. We all know how quickly things decay or spoil in hot, damp weather. The process goes on best in the dark, and can be decreased or even stopped by sunlight.

As has been said, bacteria are present almost everywhere in nature. The number in the soil is very large, especially if it contains much decaying animal or vegetable matter, as in so-called "rich" earth, or if it has been polluted with sewage. Vegetables which are to be 
eaten raw should, therefore, be carefully washed. One disease-producing germ, the bacillus of lockjaw or tetanus, is found in the soil and is liable to get into wounds if they are contaminated with dirt (see Fig. 2).

There are bacteria which live normally in water. They are present in drinking-water and are harmless, as they cannot grow in the human body. We take in considerable numbers of them every day. Water, however, which has been polluted with sewage may contain disease-producing bacteria, the most common of which is the bacillus that causes typhoid fever.

The air contains small numbers of bacteria, not free in it, but riding around on dust particles. The germs causing tuberculosis and pneumonia, for instance, may be carried some distance in this way.

One cannot be an efficient housewife without knowing something about bacteriology, as it has many important relations to household life and to various industries, especially those connected with food and its preservation. It lies at the foundation of the great modern industries of canning, cold storage, and dairying. Bacteriological methods are applied every day by the housewife in the preparation and preservation of food, and by the farmer in the care of milk.

The spoiling or decay of food is caused by the growth of bacteria in it. Tainted meat, rancid butter, rotten eggs, decaying fruit and vegetables are all the result of the work of bacteria. The thrifty housewife heats (and 
thus sterilizes) left-over food which she is afraid will not "keep" until it can be eaten.

In canning, the object is to kill the bacteria already present in the food, and afterward to prevent others from growing in it. The principles of canning fruit and vegetables are just the same as those of surgical sterilization, that is, the destruction of all bacteria present by heat, and protecting the material from the entrance of other germs. In the older method of canning, the fruit or vegetables are boiled, the jars, covers, and rings are sterilized by steaming in water, the jars are filled to overflowing, and sealed air-tight while boiling hot. In the newer "cold pack" method, the fruit or vegetables are put into the jars cold and are sterilized by steaming in a boiler on three days in succession. The reason for the repeated heating is to kill any spores that may be present (see Chapter I). This method preserves the color and flavor better than the method of boiling.

Pickling, either in brine or vinegar, preserves food because bacteria cannot grow in a strong salt or acid solution. Large amounts of sugar also prevent the growth of bacteria; this is the principle of putting up fruit cold in a thick syrup. Dried meats, vegetables, and fruit do not spoil because they contain too little moisture for the growth of bacteria. In the process of smoking meat or fish it is not only dried, but certain antiseptic substances pass into it from the smoke.

The principle underlying cold storage is that food can 
be preserved indefinitely if it is kept at such a low temperature that bacteria cannot develop. The bacteria present in the food when it was put in cold storage are not necessarily killed, but they cannot grow. The wholesomeness of food is not affected by the process, but the flavor is not so good.

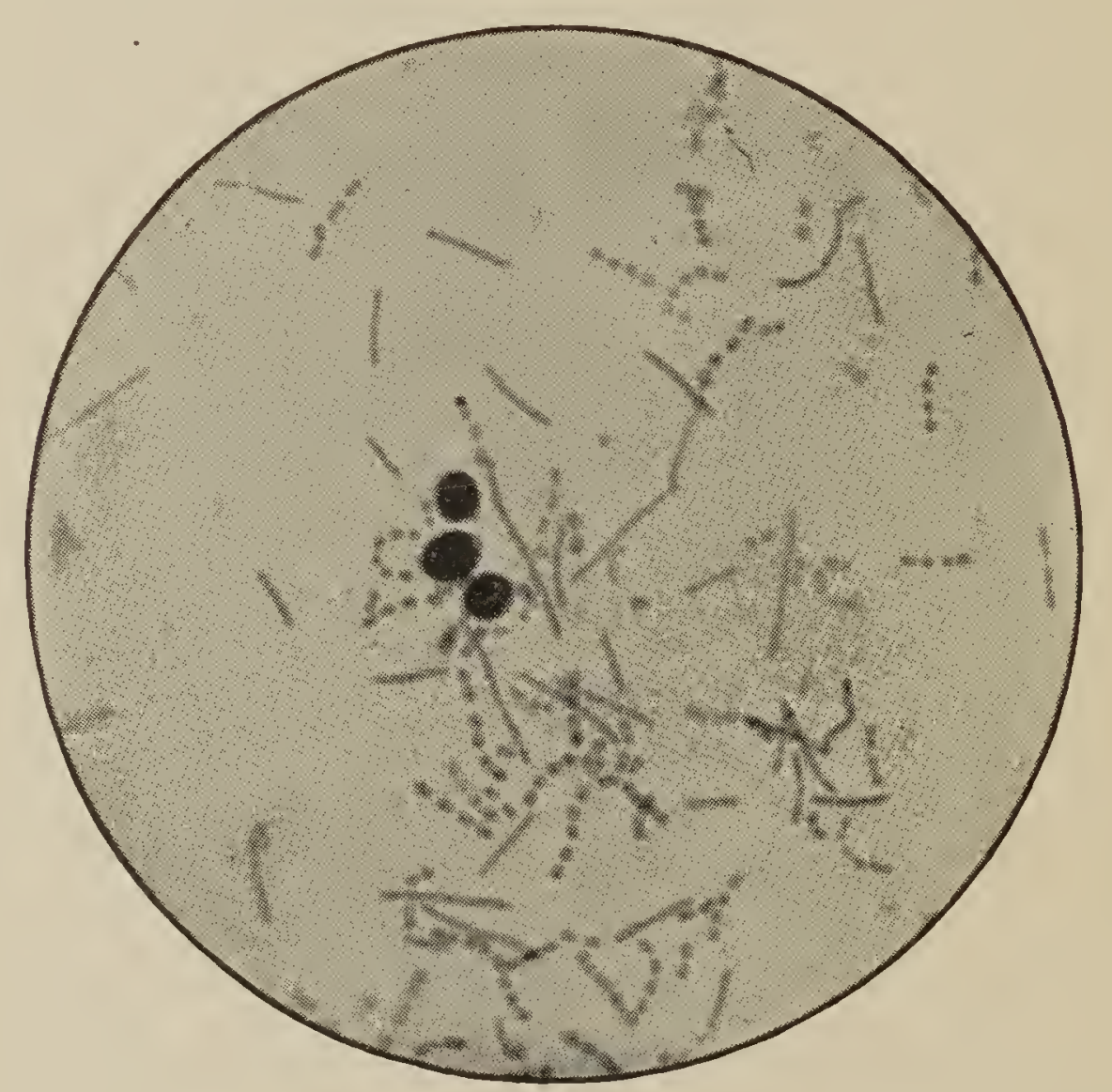

Fig. 6.-Bacilli and cocci in sour milk; these bacteria are harmless. (Park and Williams.)

The souring of milk is caused by the growth in it of a special germ, the lactic acid bacillus (see Fig. 6), which is harmless. Milk containing few bacteria sours less quickly than that in which they are abundant.

Milk is an excellent substance for disease germs to grow in. The bacteria causing typhoid, summer diar- 
rhea, and sore throat, as well as others, may multiply enormously in milk without changing its appearance or taste. Many epidemics have been caused by contaminated milk supplies.

Milk as it is drawn from a healthy cow contains a few germs, but it acquires many more from the cow's body, the dirt in the barn, the hands of the milker, etc. Some of this contamination is unavoidable, but it can be greatly reduced by care in the cleanliness of the cows, milkers, barns, cans, etc., which is now observed in all good dairies. When it has just been drawn very clean milk contains about 100 bacteria per cubic centimeter. By the time milk reaches the city customer, which is twenty-four hours at least, the number of bacteria ranges from 10,000 in the very best milk to millions per cubic centimeter in bad milk. Good milk averages about 100,000 bacteria in a cubic centimeter. These bacteria are usually harmless in themselves, but if milk contains a large number of them when it is fresh it shows that it has been produced under uncleanly conditions, and would therefore be more likely to contain disease germs if there were chance for contamination.

Pasteurization is the process which is used for the preservation of milk. It consists in heating milk to $140^{\circ} \mathrm{F}$. for thirty minutes, which kills from 95 to 99 per cent. of the bacteria in it. It destroys the germs of most diseases, including those of typhoid, summer diarrhea, and diphtheria. All the milk sold by large city 
firms has been pasteurized. It is dangerous to give a young child "raw" or unpasteurized milk because the bacteria present in it may cause digestive troubles.

Good milk is so important that boards of health in many places regulate the conditions under which it shall be produced and sold. The farms on which it is produced are inspected, and sanitary conditions enforced in the buildings, among the employees, in the care of the cows, and handling of the milk. Milk from sick animals cannot be used, nor can the milk be marketed if there is a case of infectious disease among the family or employees on the farm. No milk is allowed to be sold which contains more than a certain number of bacteria in each cubic centimeter. It must be kept in the refrigerator in the store and sold only by the bottle.

In the household, milk should be kept covered and cold. The mouth of the bottle should be wiped with a clean cloth before the milk is poured out unless the cap fits down over the top. Milk bottles should never be taken into a sick room. If one is uncertain as to the cleanliness of milk, it is best to pasteurize it.

Bacteria can pass through the shell of an egg, and some few are usually present in the egg even before it is laid. To make eggs keep longer they are often coated with a substance called "water-glass," which fills up the pores in the shell and prevents the entrance of bacteria. 


\section{Demonstrations}

Leave an agar plate uncovered on the table during class to collect bacteria from the air.

Take a culture from drinking-water collected in a sterile tube.

Make a culture from a specimen of soil.

Make a culture from the hospital milk, collected in a sterile tube.

Show cultures of typhoid and dysentery bacilli in sterile milk (without litmus) and compare with a tube of uninoculated sterile milk. 


\section{CHAPTER III}

BACTERIA IN RELATION TO THE HUMAN BODY AND THE PRODUCTION OF DISEASE. INFECTION. HOW BACTERIA ENTER THE BODY TO PRODUCE DISEASE

As we have seen in the last chapter, there are certain bacteria which can grow only when in contact with the bodies of men or animals. These are the bacteria which produce disease.

Diseases may be divided in a general way into two classes. The first class are those due to causes arising within the body. They are called constitutional diseases, for example, diabetes. The second class are those caused by living organisms which enter the body from outside. These are called infections. They include a large number of conditions, some mild, others severe and even fatal. Diseases which are caused by the passing of living organisms directly from person to person are said to be contagious.

The healthy human body harbors millions of germs on the skin, in the mouth, and intestine; in short, on every surface that comes in contact with the outside world or with food. Some of these bacteria are harmless and never cause disease under any conditions; but others may under certain circumstances gain entrance to the deeper parts of the body and cause those changes which 
we call an infection. Even these harmful bacteria may often live on the surface of the body without producing any disturbance of health. For instance, the germs causing diphtheria, tonsillitis, and pneumonia may frequently be obtained from healthy throats, and we all carry on the skin the bacteria which are the cause of boils and abscesses. The deeper parts of the body and the internal organs are sterile in health, but in disease they may contain bacteria:

The skin carries large numbers of bacteria, picked up from the various things with which it comes in contact. It is impossible to make the skin absolutely sterile even with the most thorough scrubbing and the application of antiseptics. The germs in the outer layers of the skin can be removed, but it is impossible to get rid of those in the deeper layers. Therefore rubber gloves are worn in surgical work, as they can be boiled and'made absolutely sterile.

The air which is breathed in contains, as we have seen, particles of dust, some of which have bacteria attached. The air around persons who have been coughing or sneezing contains a mist of sputum, nasal secretion, and saliva droplets, which carries germs. It is plain, therefore, that we breathe in considerable numbers of bacteria daily. The inside of the nose is especially adapted for dealing with these germs. It is made up of a complicated scroll-like arrangement of bones, covered with mucous membrane. As the air passes over 
these surfaces it is not only warmed and made more agreeable to breathe, but the bacteria-laden dust sticks to the moist surfaces, so that only a small part of it reaches the lungs.

The mouth contains constantly numerous kinds of germs. Bacteria grow readily in a neglected mouth, as conditions of warmth and moisture are favorable, and bits of food around the teeth provide nourishment. The decay of the teeth is caused by bacteria, and cavities swarm with them. The tartar which collects around the gums is composed partly of bacteria, and the fur on the tongue is a mixture of bacteria, bits of food, and castoff cells from the tongue. The mouth would contain more germs than it does if it were not for the saliva, which acts as a continuous mouth-wash. The bacteria are swallowed with the saliva, and many are killed by the acid gastric juice. The importance of brushing the teeth carefully and of removing bits of food between the teeth with dental silk is apparent, also the necessity of going regularly to the dentist.

The stomach normally contains few bacteria on account, as has been said, of the disinfectant action of the gastric juice; but putrefying food and large numbers of germs brought constantly to the stomach from a dirty mouth may cause digestive disturbances.

The intestine contains enormous numbers of bacteria, and billions are thrown off every day in the feces. It has been estimated that a grown person excretes daily 
about 128,000,000,000. About one-third of the solid matter of the bowel movement is composed of bacteria. They are more abundant in the large than in the small intestine. The chief kind of bacteria found in the intestine is the colon bacillus (see Fig. 7). It is harmless in the bowel, but if it gets into other organs, as the bladder, it may cause inflammation.

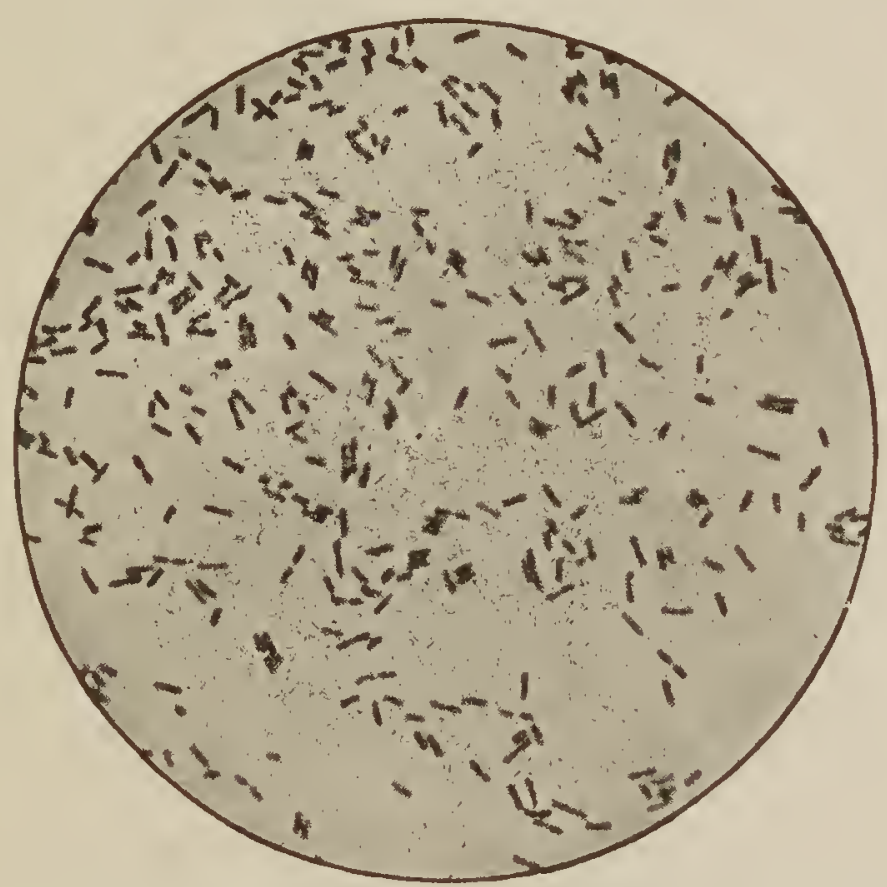

Fig. 7.-Colon bacilli, the commonest kind of bacteria in the intestine. Short, fat bacilli, showing much difference in length. Magnified 1100 times. (Park and Williams.)

Under conditions which will be studied later, bacteria may gain entrance to the tissues of the body and grow in them, injuring them and producing symptoms. When this happens it is called an infection. The word "infection" has a very broad meaning, and is used for conditions that vary greatly in severity. Some infections are so mild that they cause almost no discomfort, others are 
fatal. A pimple, for example, is a trivial infection of the skin; a boil is a more troublesome one, while erysipelas is a severe infection of the skin. Many common diseases are infections, for instance, tuberculosis, typhoid fever, pneumonia, meningitis, etc. Bacteria may also get into a surgical wound or one caused by accident, so we may have infections following these conditions. This idea of infection is one of the most important in medicine and nursing, and has numberless practical applications. It is, therefore, absolutely necessary for the nurse to understand its meaning in the beginning of her work.

There are certain routes or pathways by which bacteria enter the body and cause infections. The most important of these pathways are through the skin, the respiratory tract (nose, throat, and lungs), the mouth, and the genital tract (vagina and uterus).

The unbroken skin is a perfect protection against bacteria; they cannot get through it. If, however, the skin is injured or torn, bacteria may enter the underlying tissues. Here they find favorable conditions for growth, and they multiply, causing an inflammation, usually with the formation of pus. Breaks and injuries of the skin which are so small that they are overlooked may offer a place of lodgment for germs. The danger of neglected accidental wounds and cuts is that they may be the starting-point of a serious infection.

Bacteria floating in the air enter the body through the 
respiratory tract. The germs of tuberculosis, influenza, common colds, and pneumonia are scattered through the air attached to particles of dried sputum. They are also thrown out by the patient during coughing or sneezing, and may be breathed in by anyone nearby. Those bacteria which are not held back in the nose, as described above, may lodge in the back of the throat, in the lining of the windpipe or the bronchial tubes, or in the lungs.

Bacteria may enter the body through the mouth in various ways. Contaminated food and drink are the cause of certain diseases which affect chiefly the intestine, notably typhoid fever and dysentery. Food may be prepared by persons who have on their hands the germs of typhoid or dysentery, and the bacteria are thus transferred to the food. Similarly, if food is prepared or handled by a consumptive, the tubercle bacilli may be transferred from the hands, contaminated with sputum, to the food. The importance of clean hands in the cooking, handling, or serving of food cannot be too much emphasized. They should always be washed thoroughly before preparing or serving a meal. Some states require that all applicants for places as waitresses in hotels or restaurants be examined for general cleanliness, typhoid, tuberculosis, and syphilis, and only those who pass the test satisfactorily be employed.

Flies may distribute bacteria over food by crawling on it. These insects are attracted not only to food, but 
to filth of all kinds, particulary feces, and from the latter may carry germs on their feet to the table. It is required in many communities that food exposed for sale shall be protected from flies during the summer months.

Food that is stale contains germs of putrefaction which may cause disturbances of the stomach and bowels. Bacteria grow well in most foods, so that if a number of hours pass between the time the food has been contaminated and when it is eaten the few bacteria present at first may have increased enormously, especially if the food has been left at room temperature. Ordinary cooking, particularly baking, does not always kill the bacteria in the center of a large mass of food. Germs may be alive in the inside of a large piece of meat even after roasting, or in the middle of a large dish of food that has been baked, as pudding.

The practice of putting the fingers and all sorts of things in the mouth, so common among children, and many grown people too, leads to many infections. The common children's diseases are often acquired in this way. It has been said that "disease germs lead a handto-mouth existence." If the hands were kept strictly away from the mouth and always washed thoroughly before meals many infections would be prevented.

By the use of common drinking-cups and of spoons and forks that have not been thoroughly washed germs may be carried directly from one person's mouth to 
another's. The use of common drinking-cups in public places is prohibited in most states.

The vagina and uterus do not normally contain disease-producing germs, but during childbirth bacteria may be carried in by carelessness, and cause puerperal fever. The uterus after childbirth is an excellent place for the growth of germs, and in your work in obstetrics you will see that most of the elaborate preparations for a confinement case have for their object the prevention of infection.

\section{Demonstrations}

Make a culture from the hands of a member of the class by having her pass them over a sterile agar-plate.

Cough against a sterile agar-plate held 1 foot from the mouth.

Make a culture from a specimen of normal feces. Show a broth culture of the colon bacillus, noting particularly the odor.

Have a nurse drink from sterile water in a sterile cup. Take a culture from the rim where the lips have touched. 


\section{CHAPTER IV}

\section{HOW BACTERIA ARE CAST OFF FROM THE BODY}

AND CARRIED FROM PERSON TO PERSON .

WE have seen that there are certain definite pathways by which germs enter the body. There are also certain definite ways in which they are thrown off. They are cast off in the excretions and secretions, the most important of which in this connection are the feces, urine, sputum, nasal discharge, and saliva. The particular excretion in which the bacteria causing the infection appear depends on the disease. In diseases affecting the intestines, as typhoid fever and dysentery, they are present in the bowel movements. The urine contains bacteria in infections of the kidneys and bladder, also in some other diseases, notably typhoid fever. In infections of the lungs, for example, consumption and pneumonia, the sputum contains the bacteria causing the conditions, sometimes hundreds of millions being thrown off in a single day. The saliva is infectious in diseases of the throat, as tonsillitis and diphtheria. The nasal secretion contains the disease germ in common colds, grip, and also in measles. All abnormal discharges, such as pus, secretions from sores, ulcers, infected eyes, etc., contain the germs which are causing the trouble. It is very important for the nurse to know 
the particular way in which the germs are cast off in each infection, so as to guard against carrying the disease by the discharges.

Bacteria that cause disease can, as a rule, live only in the human body. They do not find conditions favorable for life in the outside world, and there most of them die rapidly. Multiplication outside the body occurs only in the case of a few disease germs, as the growth of typhoid or diphtheria bacilli in milk. Disease germs, therefore, pass from one person to another with only a short stay outside the body. The most important way in which infection is transmitted is by actual contact, either directly with the infected person or indirectly with his excretions, or with things that have been recently contaminated with them. For example, the germs of diphtheria, tonsillitis, or a common cold may be transferred directly from one person to another by kissing on the lips, an example of actual contact with an infected person. A nurse may get typhoid fever or dysentery by soiling her hands with the bowel movements of a patient sick with the disease, and neglecting to scrub them before going to her meals. A careless consumptive may contaminate the floor and furniture of his room with sputum, and a child playing around the room may get the germs on his hands and so into his mouth. Many other examples of ways in which bacteria may be carried from person to person, either directly or indirectly, will occur to everyone. 
Contact is the important method of infection. This point cannot be too strongly emphasized, because there is a common idea that infection may be carried through the air in some mysterious way. This was the belief in the early days of bacteriology, but it has since been proved untrue. Only a few bacteria have the power of motion, and that only in liquids, and no bacteria can rise from a moist surface. They are merely carried passively from one person or thing to another. Even in cases in which the method of spreading of an infection seems almost impossible to explain some unsuspected point of actual contact will be found.

Infection may be stopped completely with the individual patient in almost every case by the immediate and thorough disinfection of his excretions and of the articles used by him. To remove germs from a room that has been occupied by a patient with a contagious disease careful wiping of the walls, floor, and everything in the room with a cloth wrung out of disinfectant solution is far more efficient than fumigation, which is too often done in a haphazard way, and gives a false sense of safety.

If strict precautions against the transfer of germs are taken, different contagious diseases can be cared for in the same ward, and no patient catch the disease of the other. This is a test of the intelligence and carefulness of the nurse. Clean surgery can be done anywhere, provided that everything coming in contact with the 
wound is sterile, and clean obstetrics is being done every day in the worst tenements of great cities, while the most elaborately fumigated operating room or maternity hospital will not prevent infection if hands, instruments, dressings, etc., are not sterile.

A person who has recovered from an infectious disease may continue to give off the germs of the disease for months or even years afterward. Also, persons who have been in close contact with those suffering from an infectious disease, as nurses and members of the family. may acquire the germs, and yet not develop the disease. About 3 per cent. of those who have had typhoid fever continue to pass typhoid bacilli in the feces, and persons who have been associated with diphtheria cases often have diphtheria bacilli in their own throats, although they remain well. Such persons are called "carriers," because they carry dangerous germs which they frequently distribute to people around them, but they are not sick themselves. Carriers have often proved to be the cause of outbreaks of different infections, and, in fact, stand next in importance as a means of spreading disease to actual contact with a patient. Not only typhoid and diphtheria, but dysentery and probably also cerebrospinal meningitis and infantile paralysis are spread by carriers. The only way to tell whether a person is a carrier is to examine him for the particular germ suspected; for example, to take a culture from the throat of a possible diphtheria carrier, and one from 
the feces for typhoid or dysentery. The importance of carriers in spreading infection is being realized more and more, and will be taken up more fully in the chapter on typhoid and dysentery.

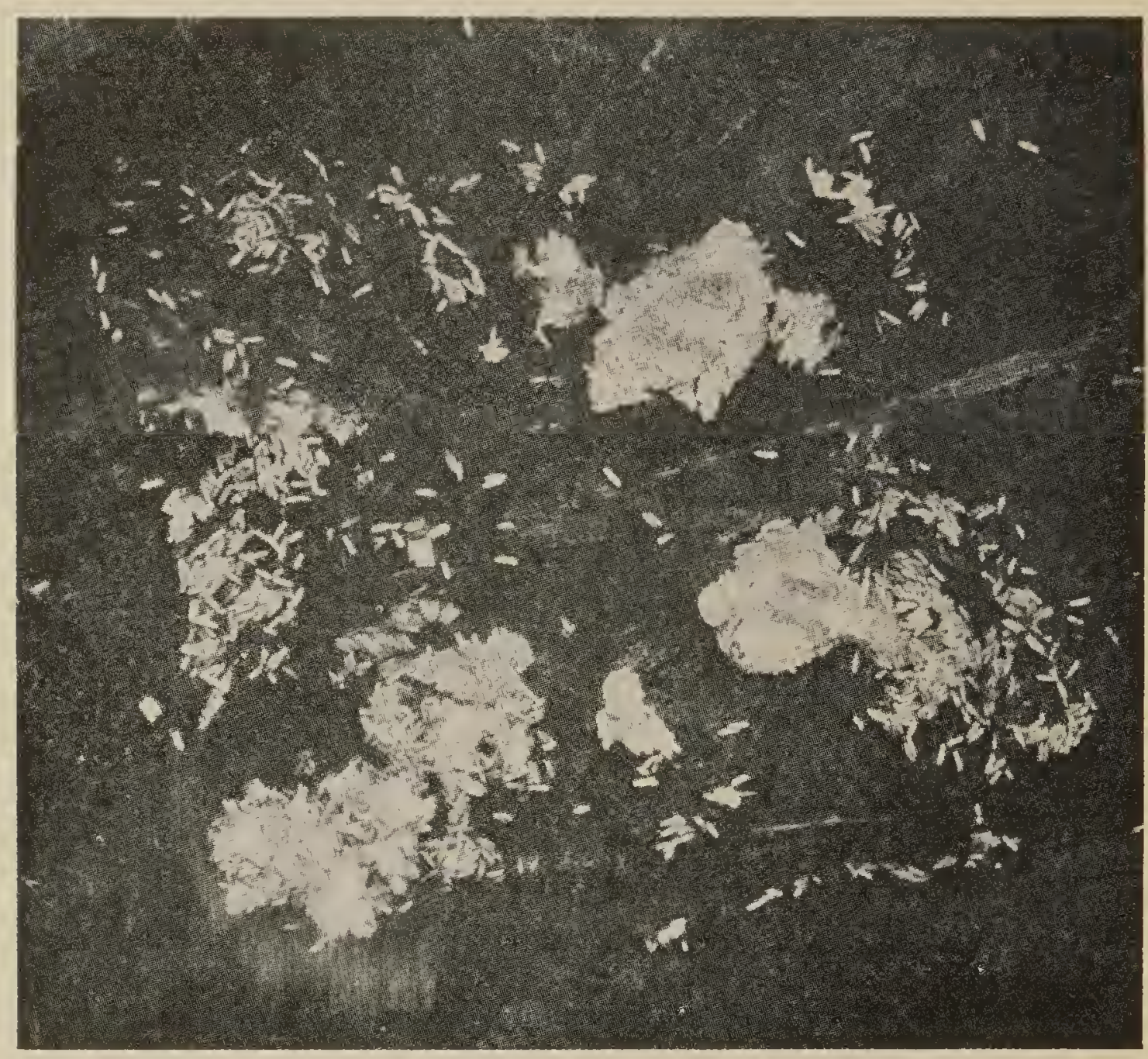

Fig. 8.-Eggs of the house-fly on the surface of a manure pile. Natural size. (From Newstead.)

Micro-organisms may also be carried by insects. The common house-fly is an important means of distributing the germs of typhoid, dysentery, and summer diarrhea. The eggs of the fly are laid in manure or garbage, and require about ten days to grow into flies (see Fig. 8). The insect has a very keen sense of smell and is attracted to 
all kinds of filth and also to food. It goes from feces, perhaps of a typhoid or dysentery patient, to the diningroom, where it drops into the milk or crawls over the butter. It has tiny hairs on its legs which wipe up the feces or other material over which it travels (see Fig. 9). It has been proved by experiment that a single fly may carry over 6,000,000 bacteria. The fly also eats the filth

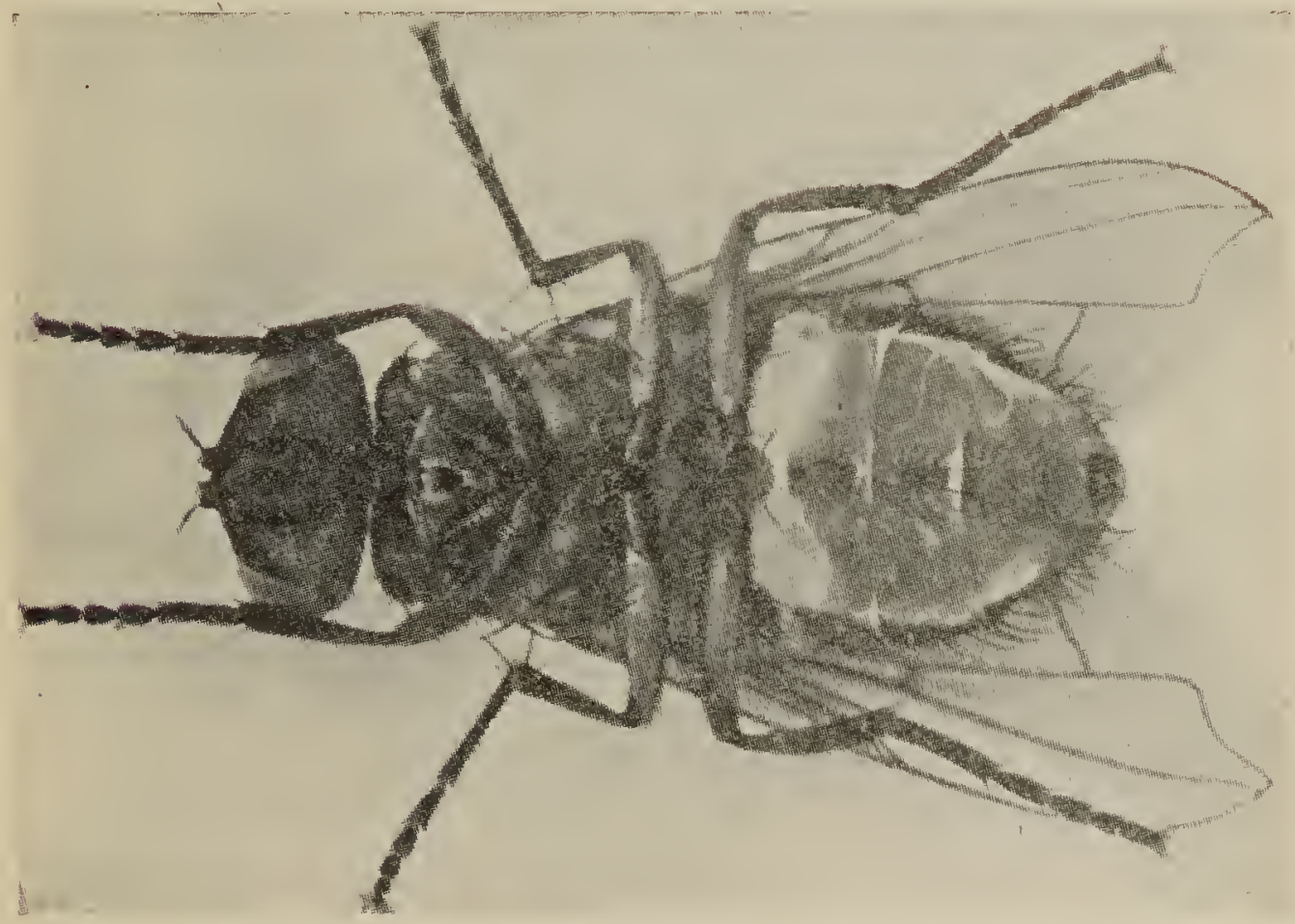

Fig. 9.-The house-fly, under surface. Note the hairs on the legs and body. (Photograph by N. A. Cobb. Copyright by National Geographic Society of Washington, D. C.)

over which it passes, and excretes it again from its intestine as fly specks.

It is no wonder that campaigns against flies have been undertaken in the last few years by progressive communities. Pits in which manure is deposited should be screened. Garbage should be kept tightly covered and should be collected frequently. No accu- 
mulations of filth of any kind should be permitted. Toilets, kitchens, and dining-rooms should be thoroughly screened. Food exposed for sale should be protected by netting or glass during the fly season. As to the actual killing of flies, it is particularly important to destroy the first ones of the season.

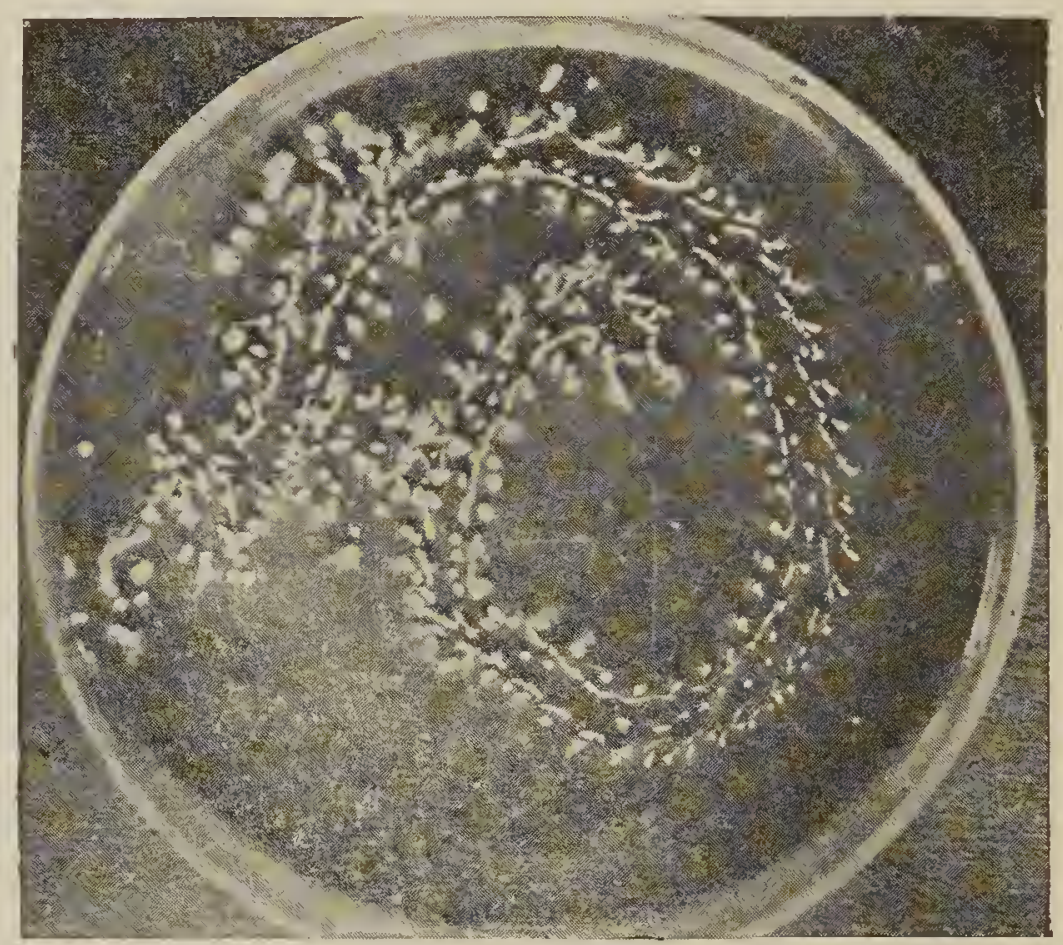

Fig. 10.-Colonies of bacteria arising from fly tracks on a plate of sterilized food substance. The path of the fly in its travels can be traced by bacteria left from its feet. A colony has grown at each place where the germs were deposited. (Magruder.)

The organism causing malaria develops in the stomach of a particular kind of mosquito, and is injected into the blood of the victim when the mosquito bites. If a mosquito of this variety bites a person suffering from malaria the malarial organism, which is present in the patient's blood, is sucked up by the mosquito, and after undergoing development in the mosquito may be injected into another person. 
It has recently been discovered that the organism of "trench fever," an infection common among soldiers at the front, is carried by body lice (Fig. 12).

The methods to prevent the spread of infection in hospitals, or anywhere else, must be clear after what has been said on how germs are taken into and cast off from

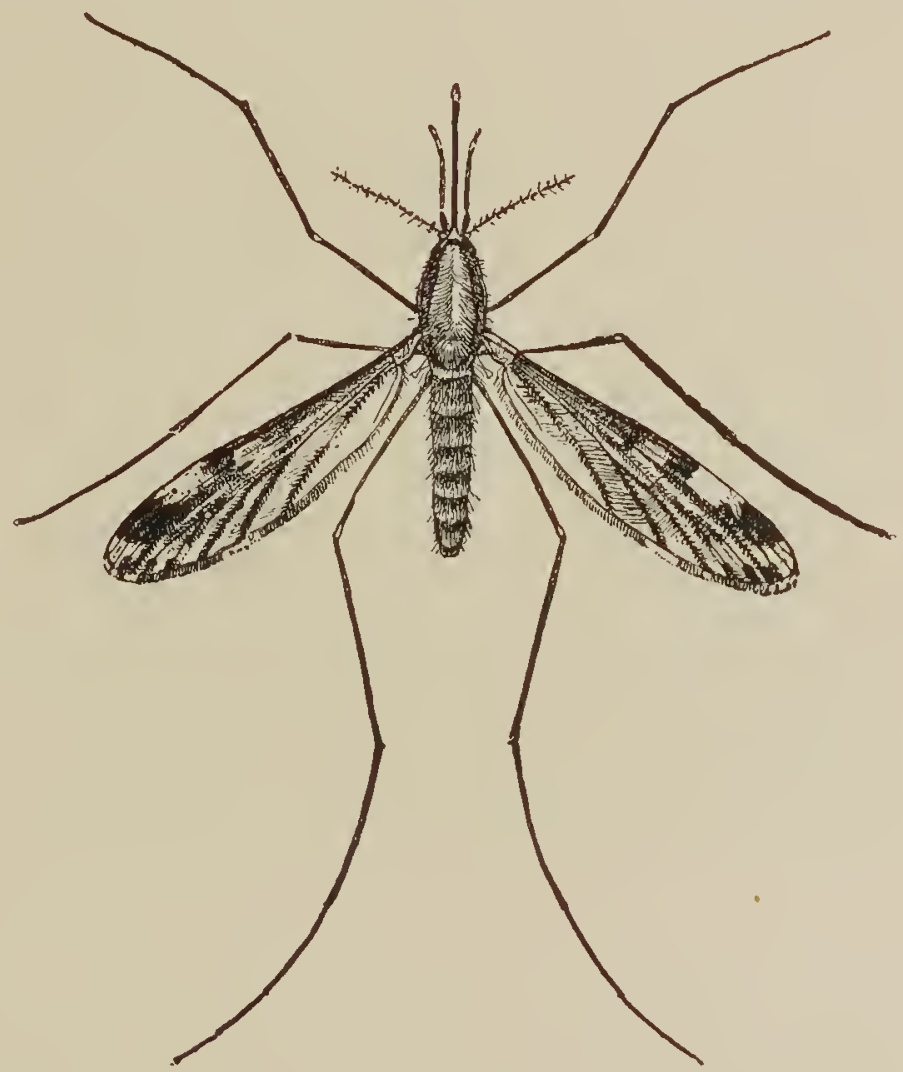

Fig. 11.-The mosquito which carries the organisms of malaria. (Howard.)

the body, and passed from person to person. No hardand-fast rules can be laid down to cover all cases, but in each particular situation the nurse must use her intelligence and her knowledge of bacteriology. The chief ways in which bacteria are carried around a ward have been summed up by a famous physician as "food, fingers, and flies" - and the most important of these is 
fingers. The nurse must train herself so that it is second nature for her to wash her hands thoroughly after handling bed-pans or anything dirty, and always before preparing the patient's food or going to her own meals, and never to touch any contaminated thing unnecessarily. Patients who help serve the food should be made to wash their hands before going into the diningroom, and no patient who is not neat should be allowed

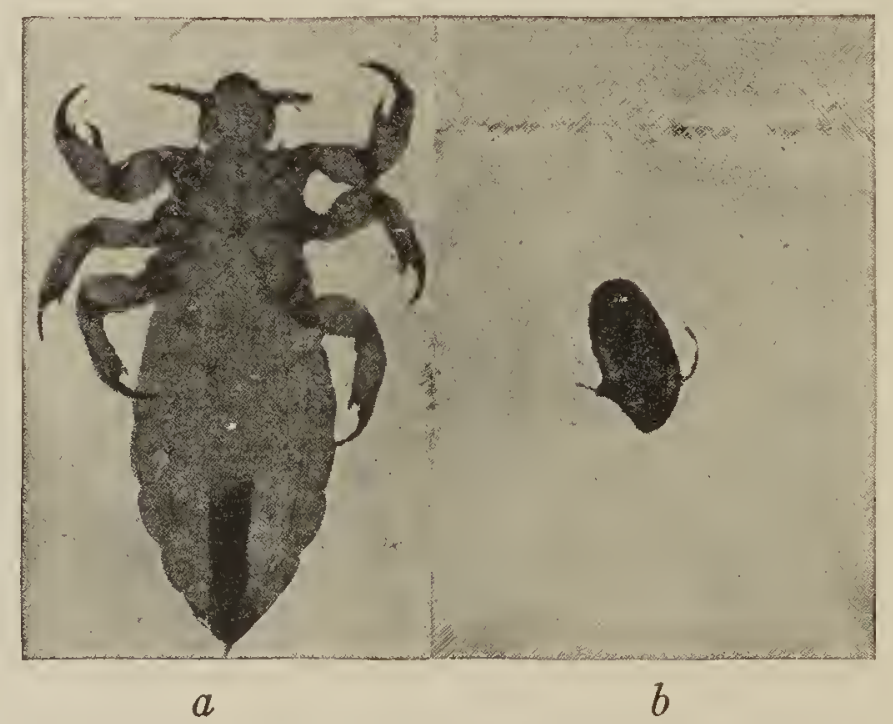

Fig. 12.- The body louse, enlarged ten times: $a$, Male; $b$, egg or nit. (From Beattie and Dickson's "A Text-book of General Pathology," by kind permission of William Heinemann, publisher.)

to assist. Bed-pans, sputum cups, and soiled dressings should be kept covered and disposed of as soon as possible. All articles contaminated by patients' excretions should, of course, be disinfected. The best methods of disinfecting discharges, bed linen, etc., are described in text-books of nursing. As to the prevention of infection of the nurse herself, it is a good rule to remember while on the ward never to put the fingers near 
the face, and to scrub the hands thoroughly on leaving the ward.

The number of infections arising on a ward where there are chronic patients is to some extent a measure of the cleanliness of the conditions in the institution and of the carefulness of the nursing. A number of cases of sore throat, dysentery, or pneumonia occurring one after another on a ward means that the germs are being passed around in some way that could be prevented by suitable measures. In the case of dysentery it may be that there are carriers of the germs who are helping to prepare or serve the food, or that the feces of dysentery patients have not been protected from flies, and that the latter are contaminating the food. In the case of sore throat, patients may be using towels or drinkingclps in common, or the dishes which they use have not been thoroughly washed.

\section{OUTSIDE EXERCISES}

If there has been a recent outbreak of infection in the institution, discuss its origin and ways of transmission.

L. O. Howard's "Reduction of Domestic Flies" or the Bulletins of the United States Department of Agriculture on House-flies may be used for demonstration in class of the anatomy and habits of flies, or for outside reading.

Discuss with the class the methods of disinfection of excretions, linen, etc., used on the wards; the methods of caring for food, etc. 


\section{CHAPTER V}

HOW BACTERIA INJURE THE BODY. ACUTE AND CHRONIC INFECTIONS. CONDITIONS FAVORING INFECTION

BACTERIA injure the body not by their mere presence within it, but through poisonous substances which they form. These are distributed throughout the body in the blood, and they cause symptoms by injuring the different organs. In very slight infections, such as a pimple, the amount of these poisons is too small to have any effect on the system. In the case of a boil, for instance, the poisons are sufficient to cause slight disturbances of the bodily functions. The person feels "out of sorts," has a slight headache, loses his appetite, and perhaps may have a little rise of temperature and a quickened pulse. In a severe infection, such as pneumonia, these poisons cause great changes throughout the body, affecting every organ. The temperature is raised, the pulse is rapid, and may be irregular and weak, the respirations are increased, the appetite lost, the bowels affected, the amount of urine reduced, there is muscular weakness, and the effect of the poison on the nervous system shows itself in headache, dulness, or perhaps delirium. 
Each kind of germ produces its own particular poison - that of the diphtheria bacillus is different from that of the tubercle bacillus, etc.

In an infectious disease there is a struggle between the invading bacteria, on the one hand, and the body on the other. We shall study later something about the means which the body uses in fighting bacteria. If it is successful in overcoming the germs, the patient recovers. If, on the contrary, it is overwhelmed by the bacteria and their poisons, the patient dies. Many infections are so mild that the body has no difficulty in overcoming them. In some infections, such as pneumonia or diphtheria, the struggle between the body and the bacteria is short and sharp, and the result definite, that is, the patient either dies or recovers. These infections are spoken of as acute. With other infections the fight may drag on for years, as in consumption, with times of improvement, in which the body gains on the bacteria, and of relapse, when the latter have the upper hand, and so it is uncertain for a long time whether the patient will get well or not. These long-drawn-out infections are called chronic. A few infections are so overwhelming from the start, as certain cases of meningitis, blood-poisoning, and scarlet fever, which may be fatal within twenty-four hours, that the body has no chance, and yields without a struggle.

All infectious diseases follow a definite course. There is first an incubation period (that is, one of development), 
then the onset of symptoms; next a stage of fever, followed in the case of recovery by dropping of the temperature, and finally convalescence.

Everyone knows that a person who has caught an infectious disease does not develop it immediately. A certain time is necessary for the bacteria to get started on their career sufficiently to cause symptoms. This is the incubation period (we are familiar with the incubator for hatching eggs), during which the germs are multiplying in the body. The patient usually feels well during this time. The length of the incubation period varies in different diseases from a few days to weeks, each disease having its own time. For scarlet fever and diphtheria it is two to six days; for measles, eleven to fourteen days; for typhoid, two to three weeks. It is not known how long it is for tuberculosis.

At the end of the incubation period symptoms begin to appear, and the person feels that he is "coming down" with something. The onset is sudden in some diseases, as pneumonia, the patient often being seized while in apparent good health. In other diseases the onset is gradual, as in typhoid, and the patient may be ailing for a week or more before he is sick enough to go to bed.

Finally, fever and other symptoms develop, and the patient takes to bed. After a longer or shorter time (each infection has its own length of time) the temperature falls, suddenly usually in pneumonia, gradually in most other diseases, and convalescence then begins. 
Infections may be classed as acute or chronic. An acute infection lasts a few days or weeks, and follows the definite stages above outlined. In chronic infections, on the other hand, the different stages cannot be sharply distinguished, and the disease is prolonged through months or years, ending in death or gradual recovery. Tuberculosis and syphilis are the commonest chronic infections.

Everyone is more or leśs exposed to various infections, but only a few take them. It is evident, therefore, that there must be certain conditions which favor infection. One of the most important of these is the age of the individual. There is a group of "children's diseases" which grown people do not usually catch even if exposed to them; for example, mumps, whoopingcough, chicken-pox, etc. On the other hand, young children do not take some diseases that are common in later life. Old people are more liable to have certain infections, particularly pneumonia, than younger persons, and with them a slight infection may have serious results. People in poor physical condition are more likely to be attacked by infections than are those in vigorous health. Unhygienic conditions of life, unsuitable or insufficient food, overwork, too little sleep or exercise, all help to make a person an easy prey for bacteria. Overcrowding in tenements or institutions also favors the transfer of germs directly from one person to another on account of close association. The 
frequency of infectious diseases among the poor of cities is the result of undernutrition, long hours of work in unventilated and overcrowded shops and factories, and unhygienic life in tenements. Some prison camps in Europe during the present war have become breeding-places for tuberculosis on account of the huddling together of the mén, without opportunities for cleanliness, or for separation of the sick, combined with underfeeding of the prisoners.

Chronic diseases not caused by bacteria, such as cancer, diabetes, and some nervous diseases, also make a person more liable to infections, which often end the patient's life.

Parts of the body in which there is poor circulation or interference with the nerve supply are easily attacked by bacteria. Every nurse knows the care which must be taken of swollen or paralyzed limbs, and the watchfulness necessary to prevent bed-sores in parts the circulation of which is interfered with by pressure. Under such circumstances a scratch or small break in the skin may be the starting-point of an extensive ulcer.

\section{DEMONSTRATIONS}

Illustrate the course of acute infections with the temperature charts of a pneumonia or typhoid, or any other acute disease which may be available. 
STAPHYLOCOCCUS AUREUS AND STREPTOCOCCUS, THE BACTERIA MOST COMMONLY FOUND IN PUS. INFLAMMATION

THE germs most frequently found in pus are the Staphylococcus aureus and the streptococcus. These bacteria are particularly associated with infections fol-

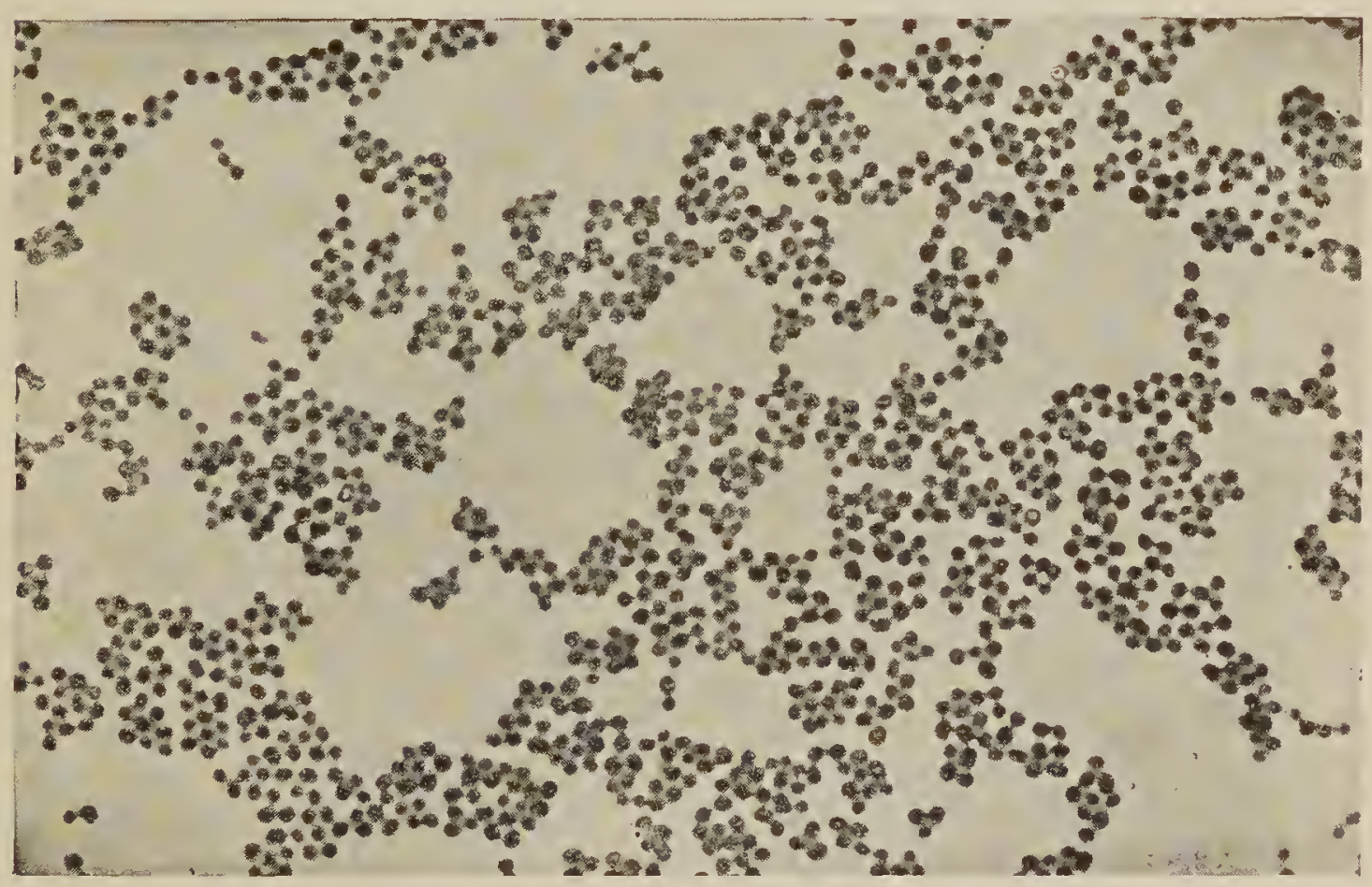

Fig. 13.-Staphylococcus aureus, magnified 2000 times. The cocci occur in bunches (Wright and Brown).

lowing injuries and accidents, operations, and confinement. They are the commonest germs encountered in medical practice, and are found in the most varied conditions and diseases. They are the most common cause 
of inflammation accompanied by the formation of pus, but by no means the only one, as other germs may cause suppuration. Both the staphylococcus and the streptococcus may give rise to different effects in different persons and under varied conditions. The Staphylococcus aureus, for instance, may in one person cause a trifling abscess of the skin, while in another it may enter the blood and produce abscesses in the internal organs.

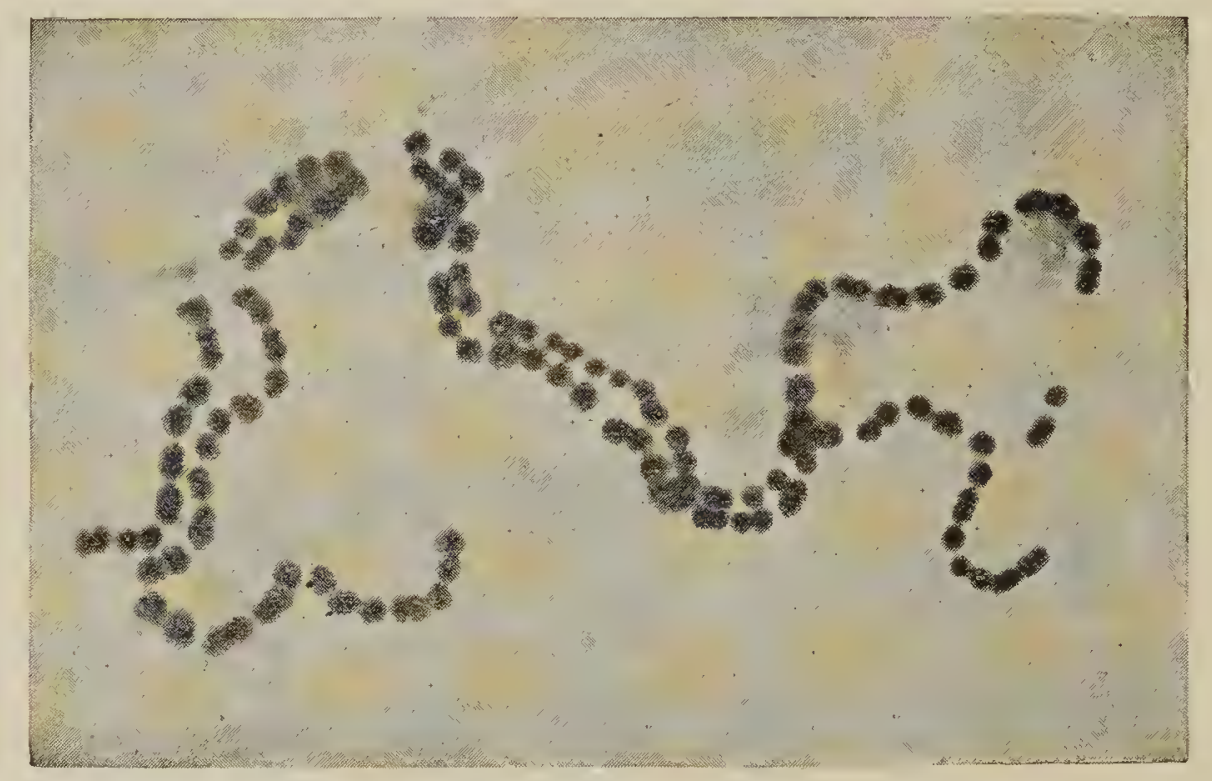

Fig. 14.--Streptococcus, magnified 2000 times. The cocci are arranged in chains (Wright and Brown).

The streptococcus may be the cause both of a mild sore throat and of a fatal peritonitis after operation. It is for this reason that care is taken in surgical and maternity wards to isolate patients with even mild and apparently unimportant infections. The germs may be almost harmless to the first patient, but if transferred to a second through carelessness they may cause a serious infection. 
The staphylococcus and streptococcus were among the earliest disease-producing bacteria to be discovered. Staphylococci in pus were first demonstrated by the French bacteriologist Pasteur in 1880.

The Staphylococcus aureus is a very common and wide-spread germ. The syllables "staph-yl-o" come from a Greek word meaning cluster, and the name is given because the cocci grow in groups like a bunch of grapes. It is called "aureus" (golden) because in cultures it forms a bright yellow coloring-matter. It is widely distributed in the outside world and on the bodies of human beings and animals. It is always present on the skin. It grows easily and quickly in the laboratory. It is very resistant to drying, and can, therefore, remain alive for a considerable time (several months under favorable conditions) outside the body. It is harder to kill, either by heat or antiseptics, than most disaaseproducing bacteria. It is the germ most commonly found in abscesses, boils, and infected wounds. As a rule it does not produce a dangerous inflammation, but in many cases it is very hard to get rid of.

The streptococcus is so called because it grows in chains, "strepto" coming from a Greek word meaning chain. This germ is also widely distributed in nature, but grows more slowly and is in every way more delicate than the staphylococcus. It is frequently found on the skin and in healthy throats. The conditions caused by it vary greatly in severity, some being mild, 
others grave and even fatal. It is the germ most dreaded in surgery and obstetrics, for it causes most of the fatal infections after operation and most cases of puerperal fever. In so-called "clean" surgical cases, in which there is no pus before operation, germs may be carried into the wound on the hands of the surgeon, or on instruments or dressings which have not been perfectly sterilized, or from the patient's own skin, which has not been thoroughly disinfected before operation. Infection following operation on a "clean" case shows that there has been carelessness on some one's part either in preparation for or in carrying out the operation.

In confinement cases the bacteria may be carried into the vagina and uterus from the skin or mucous membrane which has been insufficiently cleansed, or on dressings or instruments that are not sterile, or on the hands of the doctor or nurse, which have not been carefully disinfected. Such infections are, therefore, preventable in practically every case, but are all too frequent. Childbirth is, next to tuberculosis, the most frequent cause of death among women between fifteen and forty-five years. About 7000 deaths from puerperal fever are reported each year in the United States, and this is far below the true number from this cause. Even if infection following childbirth is not fatal, it may lead to years of invalidism, or make necessary a gynecologic operation.

The streptococcus is also the cause of erysipelas, and 
of many cases of tonsillitis and of blood-poisoning or septicemia.

We have seen in the last chapter that when bacteria invade the body they cause certain symptoms by the action of their poisons on the various organs. They also injure the tissues at the place where they enter the body or where they locate. These changes we are already familiar with as inflammation. Inflammations of various parts of the body are familiar in every-day experience, as boils, infected scratches or cuts, sore eyes, etc. Every kind of germ causes inflammation when it invades the body.

There are two grades or degrees of inflammation, acute and chronic. An acute inflammation is one which lasts a number of days; a chronic one, weeks or months. A boil, for instance, is an acute inflammation of the skin, while ulcers are chronic inflammations.

The changes present in every acute inflammation are redness, swelling, heat, and pain. These may be observed by anyone in an abscess or an inflamed joint. All of these changes cannot usually be demonstrated in chronic inflammations.

Inflammation is usually accompanied by the formation of pus, but not always so. A mild inflammation may heal without the formation of pus, and in some severe inflammations, such as erysipelas, no pus is formed. Bacteria are the cause of inflammation in the great majority of cases, but it is possible to have inflam- 
mation caused by irritating substances when no bacteria are present. Poison-ivy, for instance, can produce an acute inflammation of the skin.

Many diseases are acute or chronic inflammations of the internal organs caused by different bacteria. Pneumonia, for example, is an acute inflammation of the lung, due to a particular germ, the pneumococcus; while consumption is a chronic inflammation of the lung, produced by the tubercle bacillus. The patient with pneumonia either recovers or dies within a short time, while the consumptive struggles along for months or years. Meningitis is an inflammation of the coverings of the brain and spinal cord, which may be caused by various bacteria, and may be either acute or chronic.

The ending "itis" usually means "an inflammation of" -as bronchitis, an inflammation of the bronchial tubes; peritonitis, an inflammation of the peritoneum.

\section{DEMONSTRATIONS}

Show cultures of Staphylococcus aureus and streptococcus, with explanation of their sources.

Make cultures from the hands and throats of members of the class for demonstration of colonies of Staphylococcus aureus and streptococcus. 


\section{CHAPTER VII}

\section{THE TUBERCLE BACILLUS AND TUBERCULOSIS}

TUBERculosis is the most frequent of all infectious diseases, and it causes more deaths than any other form of sickness except heart disease. Its prevalence throughout the world and the number of deaths from it are startling. One-fourth to one-third of all deaths between the ages of fifteen and thirty-five are caused by the disease in some form. In the United States in 1915 there were 98,194 reported deaths from it, 85,993 being from tuberculosis of the lungs.

That is the dark side of the picture. The other one is, that if taken in time tuberculosis is one of the most curable of chronic diseases. If treated in the very early stages, 70 per cent. of cases of tuberculosis of the lungs can be cured, or at least the progress of the disease stopped. Tuberculosis is also becoming less frequent now that every one knows that it is infectious, and people in general are living more hygienic lives, particularly in regard to fresh air. The reduction in the death-rate from it in New York City since 1886 has been 40 per cent. In the entire United States the reduction between 1904 and 1915 was more than 25 per cent. In addition, special agencies for fighting the diseas hay been organized during the last few years in

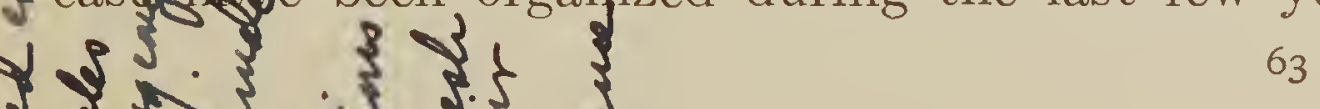


every civilized country. These include state sanitariums and free clinics for tuberculosis patients, open-air schools, and tuberculosis nurses. This campaign has already had remarkable results, and there is reason to

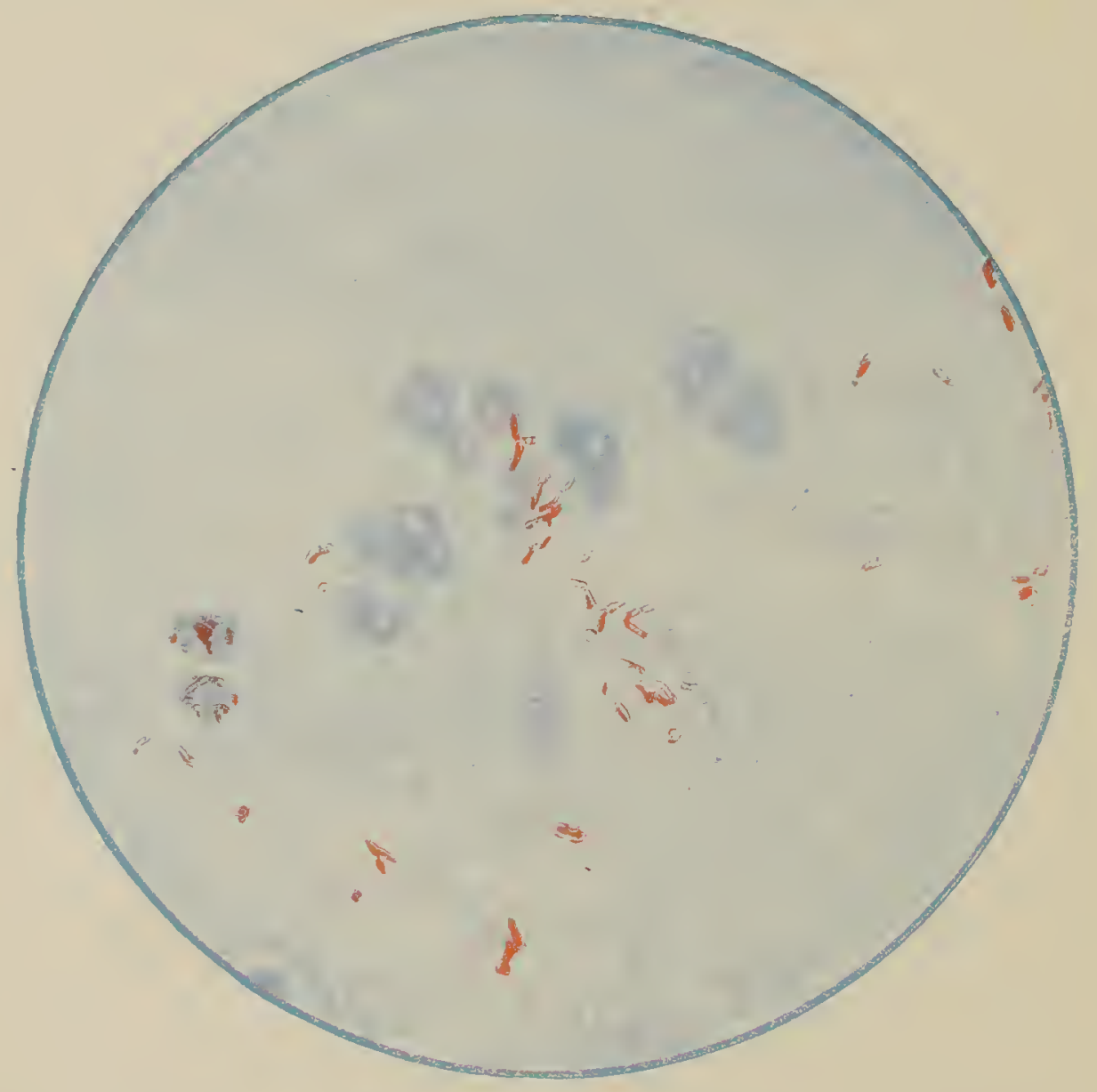

Fig. 15.-Tubercle bacilli in sputum, magnified about 1000 times. The bacilli have been stained with a red dye (see p. 67). The bacilli are curved and some of them appear like a row of beads. Note how many tubercle bacilli are present in a very small amount of sputum (a fraction of a drop) (Ohlmacher).

expect that in a hundred years from now tuberculosis will be a comparatively rare disease.

The tubercle bacillus was discovered in 1880 by Robert Koch, a German physician. This was one of the most important discoveries in medicine in recent times. 
The tubercle bacillus is the cause not only of consumption, or pulmonary tuberculosis, but also of other forms, which are often called by different names: "scrofula," which is tuberculosis of the lymph-glands of the " neck; hump back and Pott's disease, or tuberculosis of ? the spine; "white swelling" of the knee-joint; "cold : abscesses" of the ribs and other situations.

Every organ in the body may be attacked by the tubercle bacillus, but in some it is much more frequent than in others. In grown people the lungs are the organs most often affected; while in children tuberculosis of the lymph-glands, bones, joints, intestines, and the brain and its coverings are more common.

The tubercle bacillus varies from other disease-producing bacteria in several ways. It grows slowly in the laboratory, requiring about two weeks before its colonies are large enough to be seen with the naked eye, while colonies of most other bacteria can be seen in twentyfour hours (see Fig. 5,e). It can remain alive in the outside world for a longer time than most germs. In dried sputum which is kept in the dark it may live for six to eight months. In particles of dried and powdered sputum, which may float through the air as dust, it may remain alive for eight to ten days. It is also very resistant to dry heat, and in dried sputum can withstand a temperature of $200^{\circ} \mathrm{F}$. for one hour. Exposure to sunlight, however, in the presence of plenty of fresh air kills ythe bacillus rather rapidly.

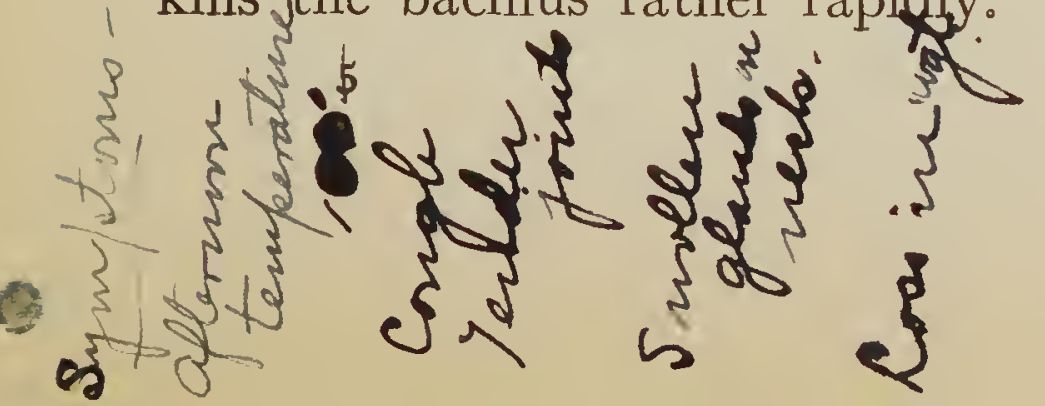


The bacillus may remain alive for months on carpets, woodwork, and furniture that have been contaminated by a careless consumptive, especially if the room is - dark and damp. 'Tuberculosis may, therefore, sometimes become a "house disease," as in case of the famous "lung block" of New York City, which was a block of filthy, densely populated tenements, from which in nine years there were reported to the health department 265 cases of tuberculosis.

The excretions of the tuberculosis patient are the means by which the disease is spread, and the most important of these is, of course, the sputum. The sputum of consumptives contains an enormous number of bacilli (see Fig. 15). It has been proved that a single patient who is raising considerable sputum may throw off in twentyfour hours $500,000,000$ to $3,000,000,000$ bacilli. If the sputum is allowed to dry in open sputum cups or on handkerchiefs, floors, bedclothing, etc., the germs, which can remain alive for some time under these conditions, will be blown off by air currents and carried around as particles of dust, which may be breathed in by a susceptible person, carried to the lungs, and there produce the disease. The danger from tubercular sputum cannot be overestimated. Infection may also take place by means of droplets of sputum and saliva laden with germs that may be thrown out during coughing to a distance of 3 to 4 feet. In ordinary talking, however, the danger from infected droplets is very slight. 
The bacilli may be taken into the digestive tract in a number of ways. Food may be contaminated by handling with fingers soiled with sputum, or it may be infected by flies which have crawled over tubercular sputum. The common drinking-cup or imperfectly washed spoon or fork may also carry the germs. Children playing in the street or on the floor may soil their fingers with tuberculosis dust and then put them in their mouths.

The ways in which tubercle bacilli are cast off from the body depend naturally on what organs are affected. In tuberculosis of the lungs the sputum is the chief source of infection. In tuberculosis of the kidneys and bladder the bacilli may be present in the urine in large numbers. The germs are present in the feces in tuberculosis of the intestine, and in the pus from tubercular abscesses.

In examining a patient's excretions for tubercle bacilli it is unsatisfactory to make a culture, as is done in case of most other bacteria, because tubercle bacilli grow so slowly. Therefore a drop of sputum, or whatever material is to be examined, is stained with dyes in such a way as to bring out the tubercle bacilli, and the germs are hunted for under the microscope. To collect sputum for examination the first that the patient raises in the morning should be obtained, as it is more likely to contain the bacilli. The patient should expectorate directly into a wide-mouthed bottle containing a little 
antiseptic solution (carbolic or formalin). Care should be taken that the outside of the bottle is not contaminated with sputum, and the bottle should be tightly corked.

Tuberculosis "runs in families," but is not inherited. Children in these families are not born tubercular, but they become infected at an early age in the home through association with tubercular relatives, who take care of them or play with them, or they may contaminate themselves with tubercular excretions in all sorts of ways. In a study of 679 children in Boston who were exposed to direct infection at home from tubercular relatives, it was found that 36 per cent. showed signs of tuberculosis of the lungs. The number of tubercular school children in Boston has been estimated at 5000 .

The importance of infection in childhood for the development of tuberculosis in later life has been recognized only recently. It is a remarkable fact that tubercle bacilli may remain alive in the lungs for years without causing tuberculosis, until something affects the health of the person, when they begin to multiply, and the disease develops. In this way tubercle bacilli, taken into the lungs in childhood, may cause no trouble until the young person comes under some unusual strain which reduces the strength for a time, as in entering a factory or shop or the army, when the symptoms of tuberculosis appear. It is probable that a large proportion of cases of tuberculosis which develop in grown 
people are the result of an infection acquired in childhood.

The majority of people have been at some time slightly infected with the tubercle bacillus, as signs of it are found in the lungs in many autopsies on persons who have died of other diseases, and who never had any symptoms of tuberculosis. The disease develops in only a small proportion of those who have been infected; in others the bacilli are held in check by the natural forces of the body, and finally die out. Certain influences favor the development of tuberculosis, the most important of these being indoor life, with insufficient fresh air, sunshine, and exercise; poor food; too frequent childbearing; and alcoholism.

The early symptoms of tuberculosis of the lungs are loss of weight, tired feeling, slight fever in the afternoon, loss of appetite, and a hacking cough with perhaps a little sputum. Sometimes also tuberculosis starts in like an ordinary cold, which, however, does not get well. Any of these suspicious symptoms should send a person to the doctor at once for a thorough examination.

Every progressive community is taking special measures to control tuberculosis. The most important of these are: the education of the public by means of exhibits, posters, talks, etc., as to the infectiousness of the disease, the ways in which it is spread, and how to avoid it; outdoor schools for children threatened with tuberculosis; separate dispensaries and sanitariums for 
tubercular patients; oversight of discharged patients in their homes by tuberculosis nurses, and the isolation of advanced cases in special hospitals. The removal of advanced cases from their homes and their care in special institutions will do more than any other single measure for the stamping out of the disease, because it is these patients who are the greatest sources of infection on account of the large amount of sputum which they excrete.

Every tubercular patient must be taught how to live hygienically so as to help along his own recovery; and he must also be taught how to take care of his sputum so that he will not be a danger to others. This training should be carried out in the sanitarium or hospital. He also needs care, oversight, and encouragement in his own home. The hygienic training and the aftercare of the patient are largely given over to the nurse, and form one of the most important and hopeful branches of public health nursing.

\section{Demonstrations}

Show a culture of the tubercle bacillus, and tubercle bacilli in the sputum, if possible, from a patient in the hospital.

Show a Kaiserling specimen of tuberculosis of the lung.

Charts and other material from a tuberculosis exhibit will add much to the interest of the lecture.

La Motte's "The Tuberculosis Nurse" is recommended for outside reading. 


\section{CHAPTER VIII}

\section{PNEUMONIA, INFLUENZA, GRIP, AND COLDS}

Pneumonia is an acute inflammation of the lung. It ranks with tuberculosis in the number of deaths which it causes, about 10 per cent. of all deaths in the United States today being due to it. Old people and young children are especially liable to it. It occurs after infectious diseases, as measles and whooping-cough, and it frequently ends the life of patients who are suffering from chronic diseases not due to bacteria, such as cancer, Bright's disease, and some nervous diseases.

There are two chief kinds of pneumonia, lobar and bronchopneumonia. In lobar pneumonia a whole lobe of the lung is inflamed; in bronchopneumonia there are small patches of inflammation scattered through the lung.

Lobar pneumonia is caused by a special germ, the pneumococcus ("pneumo-" from the Greek word for lung). Bronchopneumonia may be caused by a number of different bacteria. When simply "pneumonia" is spoken of, lobar pneumonia is usually meant, and is what will be studied in this chapter. "Double" pneumonia means that both lungs are affected. "Pleuropneumonia" means that the pleura, or covering of the lung and lining of the pleural cavity, is also inflamed. 
The pneumococcus always grows in pairs, and thus shows another arrangement in which cocci may be seen under the microscope. It is called a diplococcus ("diplo-" from a Greek word for double). Compare it with the staphylococcus, which always appears in bunches, and the streptococcus, which grows in chains. Each pneumococcus is slightly pointed. The pneumococcus is a delicate organism, growing with some difficulty in the

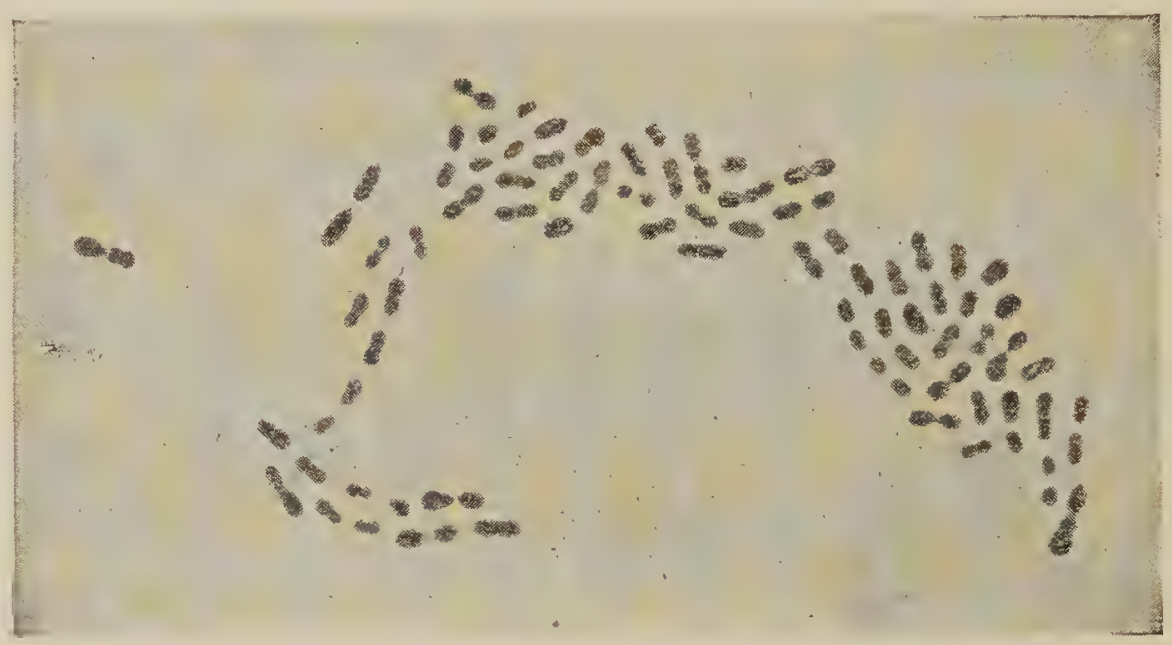

Fig. 16.-Pneumococci, magnified 2000 times. The cocci are irregular in shape, but it can be seen that they grow in pairs and that the ends of the cocci are often pointed. Compare with the staphylococcus (Fig. 13) and the streptococcus (Fig. 14) (Wright and Brown).

laboratory, and easily killed by drying. It cannot live long outside the body except, as we shall see, in the moist sputum of a pneumonia patient, but is ordinarily passed directly from person to person.

The sputum of a pneumonia patient contains the pneumococcus in great numbers, just as the sputum from a. consumptive contains the tubercle bacillus. The pneumococcus may live in moist sputum for ten days. 
The nurse must be as careful to destroy the sputum irom pneumonia as that from tuberculosis, and the same precautions must be taken to disinfect bed-linen, dishes, and everything soiled by sputum.

A person who has recovered from pneumonia may carry the pneumonoccus in his throat for weeks, or even as long - as three months. If such a person coughs or sneezes without covering his mouth in a car or theater or any crowded place he will distribute the germs to his defenceless neighbors, who, in turn, may develop the disease. The practice of coughing or sneezing "into the open" is quite as dangerous and disgusting as spitting on the floor.

Those who have been closely associated with a pneumonia case, as the nurse and members of the family, may also have the pneumococcus in their throats, although they never develop the disease. These persons are carriers, as described in Chapter IV, and they may scatter the germs in the same way as a convalescent from pneumonia. A person may remain a carrier of pneumococci for more than a month. Pneumococci must be very widely distributed, for patients who have not been off a ward for weeks and old people or invalids who have not. been away from home for a long time often develop pneumonia.

These, then, are the three chief ways in which pneumonia is spread: directly by the sputum of a pneumonia patient; by convalescents who still have the germs in their throats, and by healthy carriers. Every one knows that 
tuberculosis is an infectious disease, and special precautions are taken in every case to prevent its spread. Pneumonia is just as much an infectious disease as tuberculosis, and does almost as much damage, but the responsibility

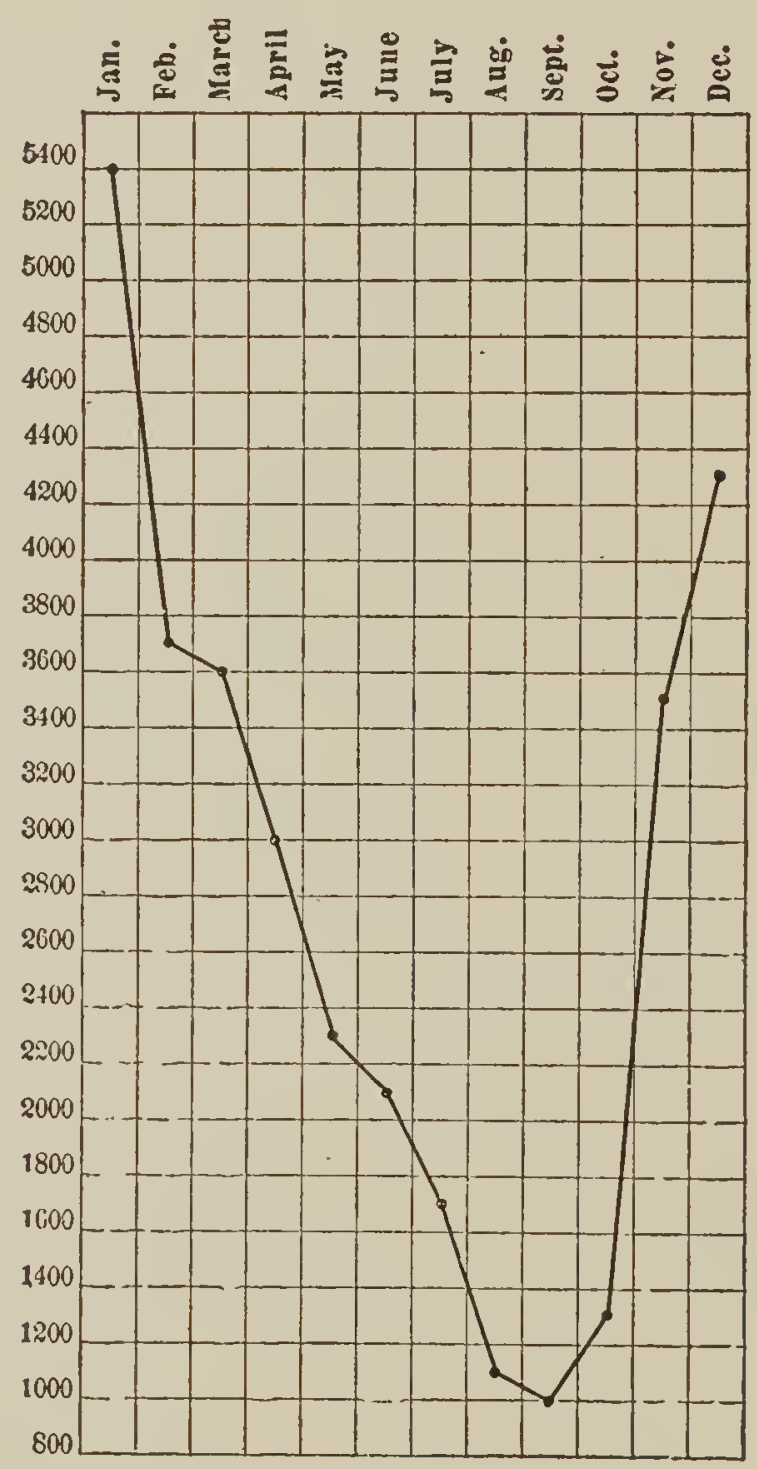

Fig. 17. - Chart of 35,828 cases of pneumonia, showing the number occurring in each month. The greatest number occur in the winter and spring (Hare).

of preventing infection from it is only beginning to be realized.

Epidemic Influenza.-Influenza is an extremely contagious disease, probably caused by a small organism 
called the influenza bacillus. The infection occurs in great epidemics which sweep over the entire world at intervals of years. Such an epidemic started in Europe in the summer of 1918, and reached the United States early in the fall, spreading rapidly from the eastern ports to the west and south, and causing a large number of deaths both among the general population and in the army camps.

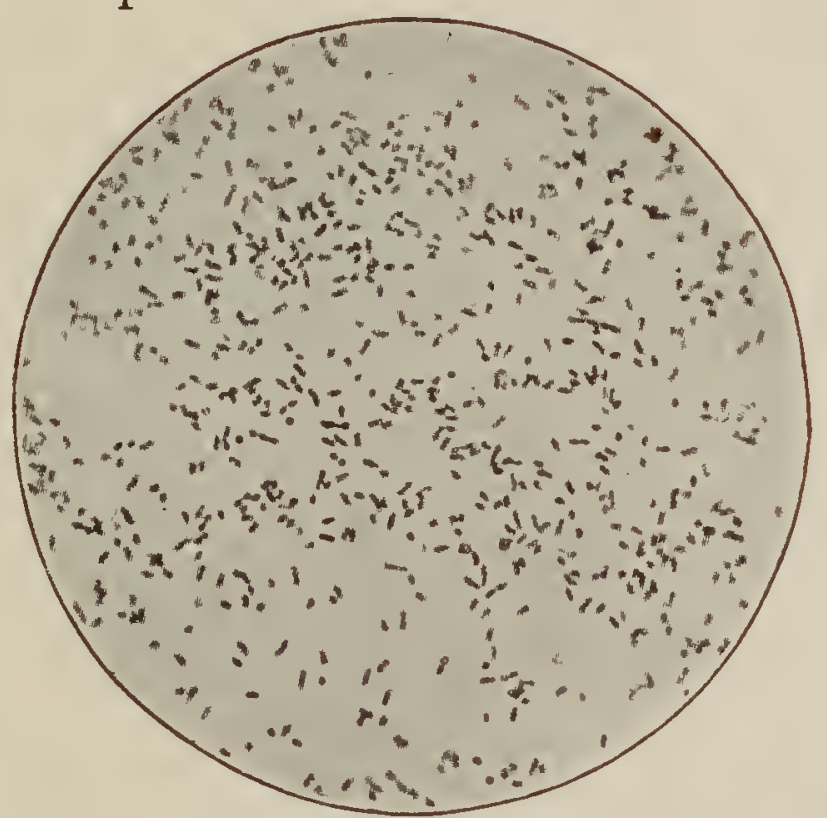

Fig. 18.- Influenza bacilli, enlarged 1000 times. The bacilli are usually short, although some long forms are seen in this picture. They sometimes occur in pairs (Král).

Influenza is a very serious disease because it is often accompanied by a bronchopneumonia which may be fatal. The disease is spread by "droplet infection," that is, by the spray of sputum, saliva, and nasal secretion thrown out during coughing and sneezing. It may also be carried by articles recently soiled with these secretions.

The influenza bacillus is one of the smallest of the 
known disease-producing bacteria (see Fig. 18). It is a delicate organism, and dies quickly outside the body. It is very sensitive to drying, although in dried sputum it may remain alive for twelve to forty-eight hours. It is easily killed by disinfectants. Infection, therefore, takes place directly from person to person, or by means of articles on which the secretions are still fresh and moist.

The nurse in charge of a case of influenza must take extreme care of articles soiled by the patient's sputum, saliva, and nasal secretion. Pieces of gauze or old cloth should be used instead of handkerchiefs, and should be burned after use. The bed-linen and clothing should be disinfected before washing. The patient should have a separate set of dishes, which should be boiled after using. The nurse should wear a gauze mask covering the nose and mouth. This should be changed as often as it becomes wet, and should be boiled before using again.

Grip.-This is an infection, but it is not definitely known what germ is the cause of it. It is very contagious, and is spread by the sputum, saliva, and nasal secretion.

Common Colds. - A cold is an acute inflammation of the lining of the nose and throat, caused, probably, by a number of different bacteria acting together, among which are the Staphylococcus aureus, streptococcus, and pneumococcus. The nasal discharge and saliva carry the germs, and the ways in which the infection is spread are 
many-coughing, sneezing, kissing, carelessness about handkerchiefs, hands soiled with nasal secretion, imperfectly washed dishes, the common use of towels and drinking-cups, etc.

Colds are not serious in themselves, but if they occur frequently they reduce a person's vitality, so that he may become the victim of a more serious infection, as pneumonia or tuberculosis. A person who is subject to colds should consult a doctor, for they may be due to enlarged tonsils, adenoids, or something which prevents him from breathing through the nose, which should be remedied.

Pneumonia, grip, and colds often occur as epidemics in the winter and early spring, and decrease during the summer. The main reason for this is that there is more chance for the direct transfer of bacteria from person to person, particularly by coughing and sneezing, when people are crowded together in cars, schools, theaters, and other public places with the windows closed. In summer, when windows are open and ventilation is better, there is less chance for breathing in infected droplets.

\section{DEMONSTRATIONS}

If possible, show a culture of the pneumococcus and make a culture from pneumonic sputum.

Show Kaiserling specimens of lobar and bronchopneumonia.

If a member of the class has a cold, take a culture from the nasal secretion. 


\section{CHAPTER IX}

TYPHOID FEVER, DYSENTERY, AND SUMMER DIARRHEA OF INFANTS

TyPHoID fever is a preventable disease, due to unsanitary conditions in a community. In places in which sanitary conditions, particularly in regard to sewage

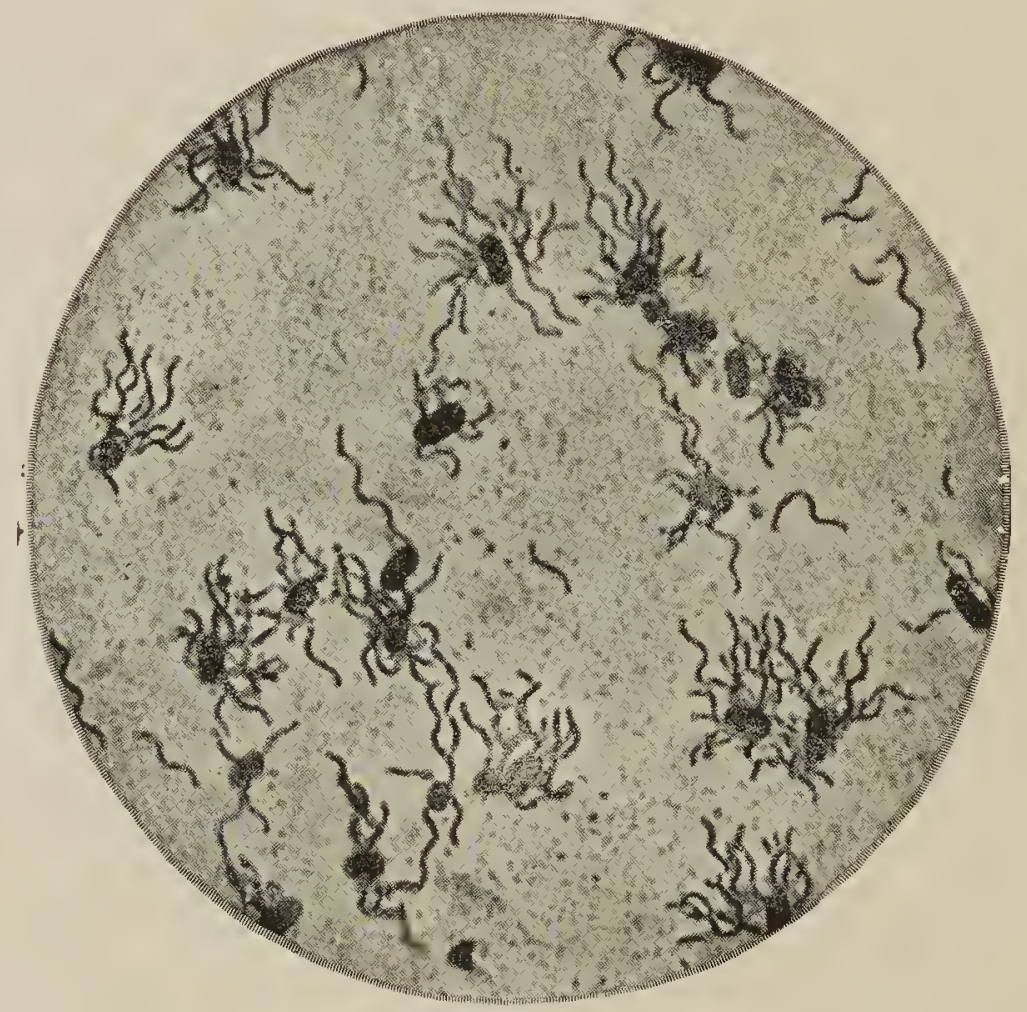

Fig. 19.-Typhoid bacilli, six hours old, magnified 1000 times; showing the thread-like outgrowths by means of which the bacilli move through liquiids (Fränkel and Pfeiffer).

and water- and milk-supplies are poor, typhoid is frequent; while in communities where these are good the disease is rapidly decreasing. It is in general more frequent in the country than in the city, and in the southern 
than in the northern states. In 1915 there were in the United States 8332 reported deaths from typhoid fever. As only 7 to 10 patients in every 100 having the disease die from it, the enormous number of cases may be estimated.

\section{No. of deaths}

from typhoid to each 100,000 of population.

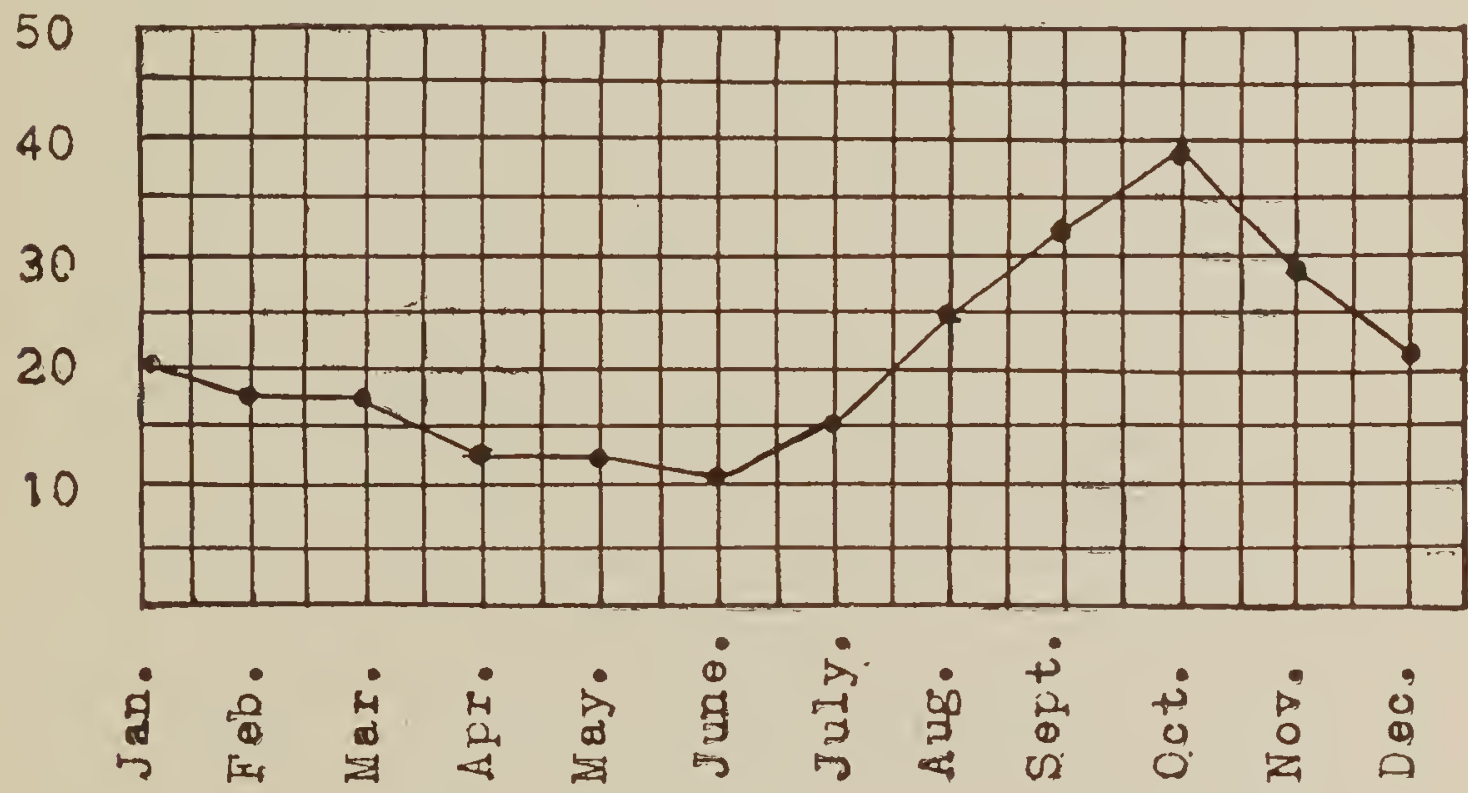

Fig. 20.-Deaths from typhoid fever in the entire United States according to months. The number rises steadily from June, when there are fewest deaths, to October, when they are most numerous. Note that the disease increases with the fly season.

The typhoid bacillus grows easily and quickly in the laboratory. It has the power of motion in liquids, due to hair-like outgrowths, which beat through the fluid. The bacillus develops chiefly in the human body, but it is also found in the outside world in water polluted by sewage from typhoid cases, and it can grow very readily in milk. It is quite hardy outside the body and can survive for 
some time in water, milk, oysters, etc. It is easily killed by drying and disinfectants, and in milk is destroyed by pasteurization.

It enters the body through the mouth, usually by means of infected food or drink, as water or milk containing the germs, food that has been handled by persons with the bacilli on their hands, raw vegetables for which sewage has been used as a fertilizer, or shell-fish which have grown in water polluted with sewage. About three weeks pass between the time of infection and the development of the disease. The bacillus is present in the blood during the first week of the disease. Typhoid is a disease affecting the whole body, but ulcers of the small in estine are practically always present.

The source of infection is the feces and urine of the typhoid patient. Each case comes from some previous case; that is, the bacilli from the excretions of the first case are in some way, often hard to trace, taken into the mouth of the second patient. This is a very disagreeable fact, but it is necessary to face it. The bacilli are cast off in the feces and urine, often in enormous numbers, more than $1,000,000,000$ in a single movement. They may also continue in the excretions for weeks or months after recovery. Disinfection of the feces and urine should be kept up as a routine for at least two weeks after recovery.

The ways in which the bacilli are spread are as follows: first by water. The means by which the typhoid bacillus 
gains entrance to the water is this: the undisinfected wastes of the patient are thrown into the earth closet, which may be situated near a well or close to a stream which forms part of a city water-supply (see Fig. 21). Then the bacteria are carried by the ground-water from the vault into the well or stream. In the latter event, a single case of typhoid fever in the country may give rise to many in a city at a long distance. A celebrated epidemic in a Pennsylvania town was caused in this way. A man living beside a mountain stream, which supplied a town a number of miles away, had typhoid in November. His excretions were thrown, without disinfection, into the earth closet. In the spring, after a thaw, an epidemic of typhoid suddenly broke out in the town, and was traced to the water-supply, and finally back to the single typhoid patient on the mountain. There were 1104 cases in the epidemic and 114 deaths. The bacilli in this case remained alive over the winter and were washed into the stream during the spring thaw. Typho'd bacilli do not multiply in water as they do in milk, but they can remain alive for some time in it. Millions of bacilli may be thrown into the water-supply at one time, so that, even if only a small percentage survived, they would still be enough to cause many cases.

Infected milk is responsible for many outbreaks of typhoid. As has been said in Chapter II, the typhoid bacillus grows rapidly in milk without changing its appearance or taste. The germs may get into the milk from 
the hands of the dairyman or milkman, in case he or any of his family have typhoid, or from washing the cans or bottles in infected water, or from using milk bottles in the typhoid patient's room, as is frequently done among ignorant people. A striking epidemic due to infected milk occurred in Jamaica Plain, Mass., in 1908. A large number of typhoid cases appeared in that district within a few days of each other. Investigation by the health department proved that all persons affected received milk from a certain dealer, and that he was suffering from a mild form of typhoid. During the early stage of the disease, before the diagnosis was made, he had still been able to attend to his work, and in so doing had transferred the typhoid germs on his hands to the milk, in which they had multiplied rapidly. There were 410 cases in this outbreak, all originating from one person, and spread by the milk-supply. Epidemics have also been traced to ice cream made from milk containing typhoid bacilli, proving that some of the bacilli remained alive even after freezing the milk containing them.

Another very important method of spread is by direct contact with the patient. This is the way in which nurses and members of the patient's family contract the disease; that is, they soil their hands while caring for the patient, and neglect to wash them before going to meals, or else put their fingers in their mouths. If a nurse catches typhoid from a patient, it is at least strong evidence that she has been careless. Other examples of 
direct transfer of the bacilli come readily to mind: a convalescent fingers a piece of food and passes it on; a washerwoman handles clothing soiled with typhoid excretions; the mother of the family may have to nurse the patient and prepare the family meals, vibrating between the sick room and the kitchen. Infection by direct contact is much more frequent than was formerly thought. It is advisable for a nurse to wear rubber

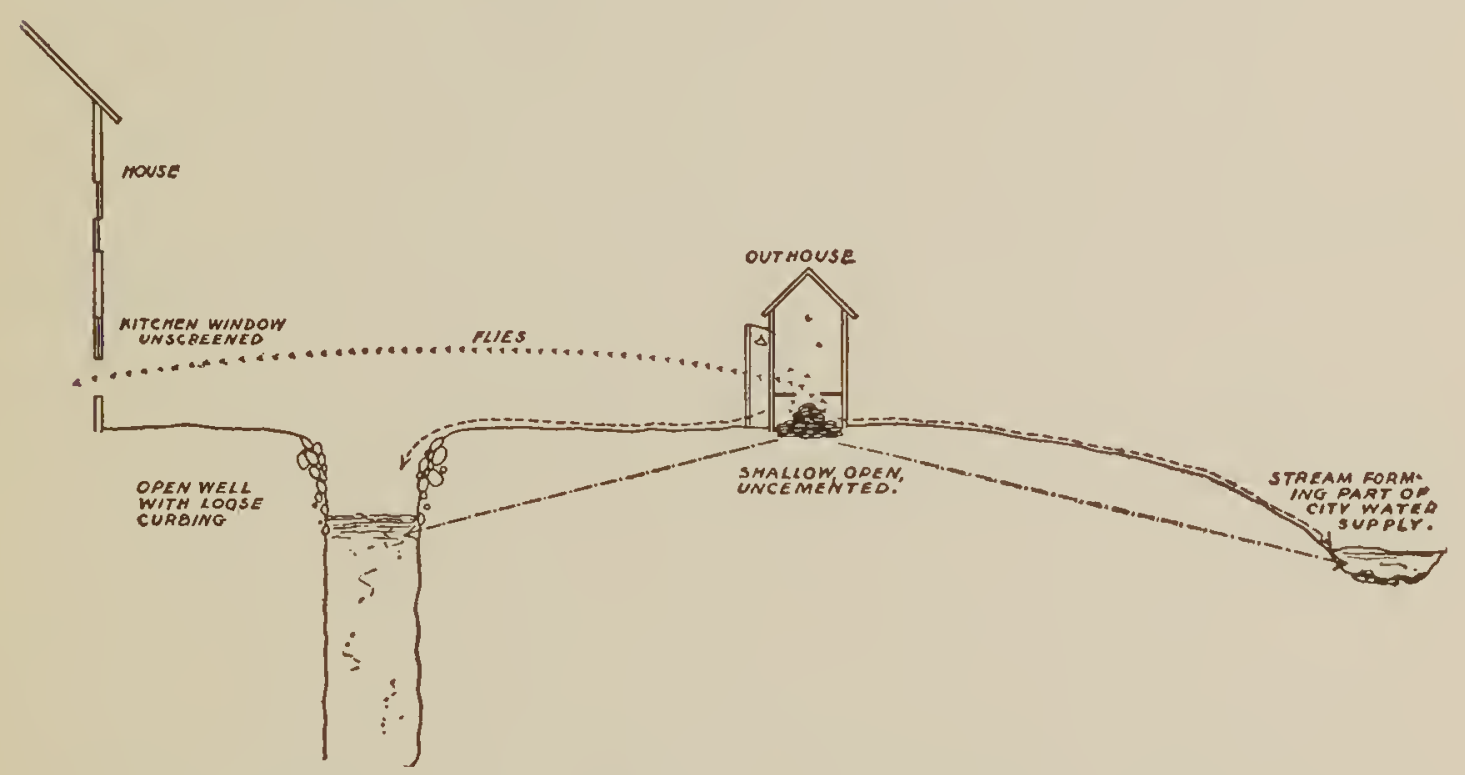

Fig. 21.-Diagram showing how an unsanitary outhouse can be a source of contamination for a city water-supply, a household well, and a kitchen.

gloves and a rubber apron when waiting on a typhoid patient or disposing of the excretions.

Flies are also very important in the spread of the bacilli (see Chapter IV). Typhoid cases are most numerous in the fly season. These insects contaminate their feet with the typhoid feces, then crawl over food, depositing the bacilli on it, or drop into milk and start a culture. Typhoid bacilli have been grown from flies 
caught near water-closets used by typhoid patients in tenement houses, and it has been shown that the germs may remain alive on the bodies of flies for twenty-three days.

The disease is also spread by carriers. In about 3 per cent. of persons who have recovered from the disease the bacilli remain in the gall-bladder, from which they are carried to the intestine with the bile, and thrown off in the feces. A typhoid carrier is a continuous source of danger, especially if living in an institution or having anything to do with the preparation of food. Outbreaks of typhoid due to carriers are being reported quite frequently in the medical journals. Out of 1515 reported cases of typhoid in Massachusetts in 1916, at least 140 were known to be due to carriers. The most famous carrier in this country is a New York cook, who in less than five years' time had caused outbreaks of typhoid in seven households in which she had worked, the number of cases traced to her being 26. A person may remain a carrier for as long as thirty years.

It is clear from what has been said that the utmost care must be taken to disinfect the feces and urine of the typhoid patient and everything that could possibly be contaminated with them, as bed-linen, clothing, wash-water, etc. The dishes used by the patient should be boiled. If all the wastes of each patient could be thoroughly disinfected, typhoid fever would become infrequent in a comparatively short time. This disinfec- 
tion is the duty of the nurse, who has a great responsibility not only for the welfare of the individual patient, but for the protection of the community.

A method for the prevention of typhoid has come into use in the past ten years. It is called antityphoid inoculation or immunization, and consists in the hypodermic injection of typhoid vaccine, which is dead typhoid bacilli in salt solution. This method will be discussed in Chapter XIV, but it may be said here that inoculation protects against the disease for about three years, that it is very efficient, and is compulsory in the army and navy, in many institutions, and in progressive training-schools for nurses.

The blood of a typhoid patient gives a test called the "Widal reaction," after the French physician Widal, who discovered it. The reaction is also given by persons who have had the disease at some time in the past and by those who have had antityphoid inoculation. A "positive Widal reaction" means, therefore, that the person either has typhoid at the present time, or has had it, or has been immunized against it. This reaction is used as a routine in the diagnosis of typhoid.

The decrease of typhoid in any community depends on the enforcement of a number of sanitary measures by the public authorities. A pure water-supply is a necessity. The state must control the banks of streams from which public water-supplies come in order to prevent pollution by sewage. If wells are used, they 
should be at a long distance from outhouses, should be dug deep, and the sides tightly cemented to keep surface-water out. The tops should also be covered.

Sewage, on the other hand, must be properly disposed of to prevent it from getting into water-supplies. In cities and towns where there is a sewage system all the sewage can be treated at one plant by scientific methods, ' and made entirely harmless and inoffensive. In the country, however, each householder has to solve his own problem, and sanitary conditions are often far worse here than in the city. The ordinary shallow open earth closet is most objectionable, as leakage can take place from it, and it is open to flies. It is possible, however, to make sanitary vaults with water-tight masonry walls and protected from flies.

The milk- as well as the water-supply should be controlled by the health authorities. Farms which sell milk should be required to come up to certain standards in regard to the care of the cows, cleanliness of the employees, and methods of handling the milk. The conditions under which milk is sold should also be supervised by the health boards. These measures have been discussed in Chapter II.

Known typhoid carriers should be under the supervision of the health authorities, and should not be allowed to engage in any employment requiring the handling of food or drink.

Typhoid cases should, if possible, be treated in hos- 
pitals, where the chances of contact infection are less and the conveniences for disinfection better.

Antityphoid inoculation should be more generally practised (see Chapter XIV).

For one's own individual protection certain precautions should be taken. If one suspects that the watersupply is polluted, drinking-water should be boiled. The common household water-filters are untrustworthy. Milk should be pasteurized in the home unless one is sure that it has been produced and distributed under clean conditions. When traveling one should not drink city water in places where there is much typhoid. One should not drink milk at a restaurant unless it is served in the original bottle and has been pasteurized.

The Dysentery Bacillus.-This somewhat resembles the typhoid bacillus. It causes the dysentery of grown people; also the summer diarrhea of infants, which is so frequent among babies under poor sanitary conditions during hot weather. The bacillus causes ulcers of the large intestine and the feces contain blood and mucus.

The bacillus is cast off in large numbers in the bowel movements. It can live from four to nine days on cloth at room temperature, and on food substances, such as bread, for one month. It grows in milk without changing its appearance or taste.

The dysentery bacillus is spread in the same way as the typhoid bacillus: by direct contact, carriers, and flies; and what has been said about the methods of 
spread of typhoid and measures for its prevention applies also to dysentery. In insane hospitals, or other institutions where there have been cases of dysentery for several years, there will be a number of recovered persons who are still passing the bacilli from the intestine, and it is an easy matter for them to transfer the germs from their hands to food or milk if they work in

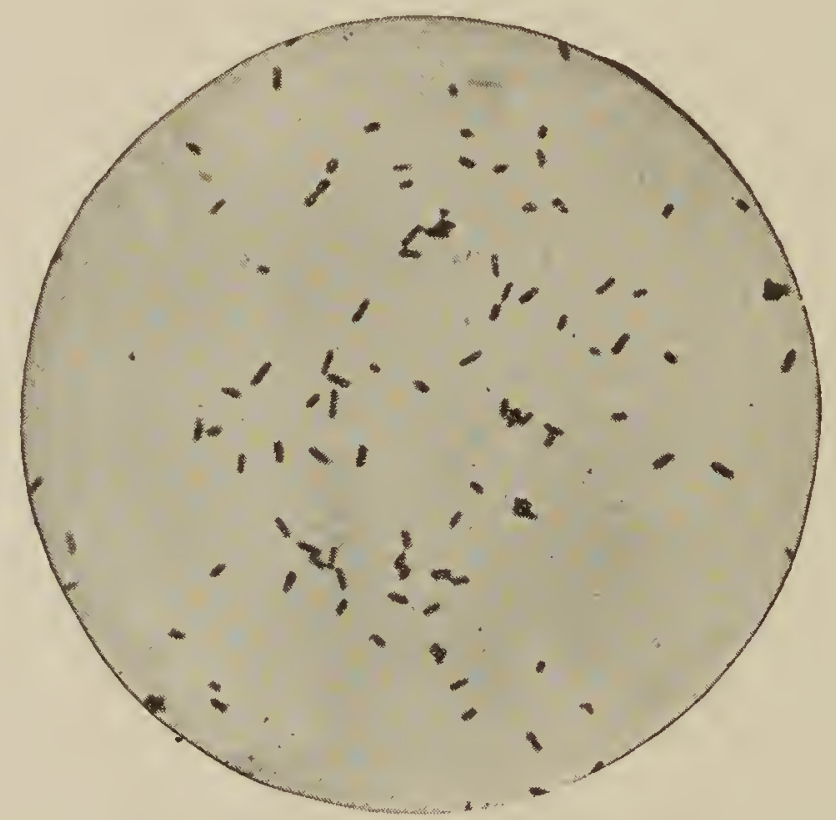

Fig. 22.-Dysentery bacilli, enlarged about 1000 times. Many of the bacilli are so short that they appear like cocci (Kolle and Wassermann).

the kitchen or dining rooms. Also flies coming from toilets used by such persons will infect the food. Nurses who are careless about washing their hands frequently contract the disease from the patient, or they may contaminate other patients' food.

In the case of children, the method of spread is the same. The baby's milk is contaminated by flies which have been in contact with the bowel movements of a 
previous case, or the feedings are prepared by some one who has the bacilli on her hands. The unhygienic conditions in tenements and the ignorance of mothers favor such ways of carrying the bacteria.

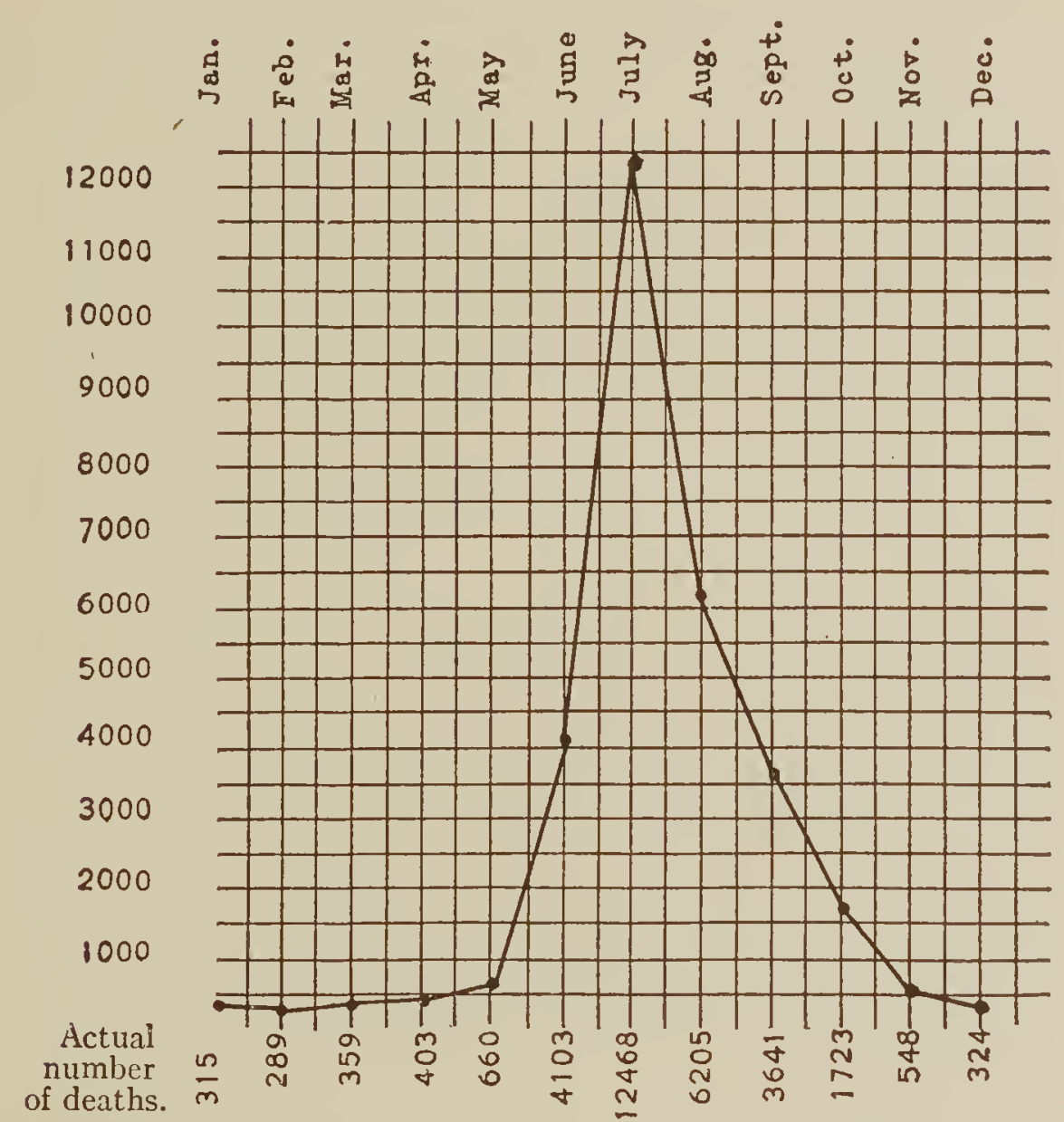

Fig. 23.-Number of deaths from diarrheal diseases in New York City for ten years in children under five, according to season. The reasons for the enormous increase in the summer months are the heat, which favors the growth of bacteria in the milk and reduces the resistance of the children; and the presence of flies, which spread the infection.

The same care must be taken to disinfect the discharges of a dysentery patient, and things soiled by them, as in the case of typhoid. In fact, these measures should be carried out in all cases of intestinal infections, even if they are not proved to be caused by the 
dysentery bacillus. Babies' milk should always be pasteurized and protected from flies. Nursing bottles and nipples should be sterilized by boiling after each use; the feedings should be prepared by a person with clean hands, and the bottle, after it is prepared, kept away from flies and dirt. The baby's crib and carriage should be screened during the fly season. The diapers of infants suffering from diarrhea should never be left around, but should be sterilized at once. Old linen, which can be burned when it is soiled, should be used if possible.

\section{Demonstrations}

Show a culture of the typhoid bacillus, also the motile organisms under the microscope.

Show Kaiserling specimens of typhoid and dysenteric ulcers.

Demonstrate a Board of Health Widal outfit, emphasizing the questions on the card as to milk dealer and handling of food.

Show a culture of the dysentery bacillus. 


\section{CHAPTER $\mathrm{X}$}

\section{DIPHTHERIA AND TONSILLITIS}

THE diphtheria bacillus grows on the tonsils and walls of the throat, causing the usual form of diphtheria. It also grows in the nose, producing "nasal diphtheria," and in the larynx, causing what used to be known as "membranous croup." The bacillus forms a grayish-white membrane where it grows, which is characteristic of the disease.

The diphtheria bacillus was discovered in 1883-84 by two German physicians, Klebs and Löffler, and is sometimes spoken of as the Klebs-Löffler bacillus. The bacilli have a characteristic appearance under the microscope (Fig. 24). They are curved and have dots at the ends and often bars through the middle. After they are twenty-four hours or more old they swell up into curious shapes, resembling clubs, dumb-bells, and exclamation points. The bacilli grow quickly and well in the laboratory, so that it is usually possible to tell in twelve hours from the time a throat culture is started whether or not diphtheria bacilli are present. In the moist condition the bacillus is easily killed by heat, but when dry, especially when contained in pieces of the diphtheric membrane, it is much harder to destroy. It may remain alive 
for several months in bits of membrane which are coughed out by the patient and allowed to dry on articles, such as furniture, toys, etc.

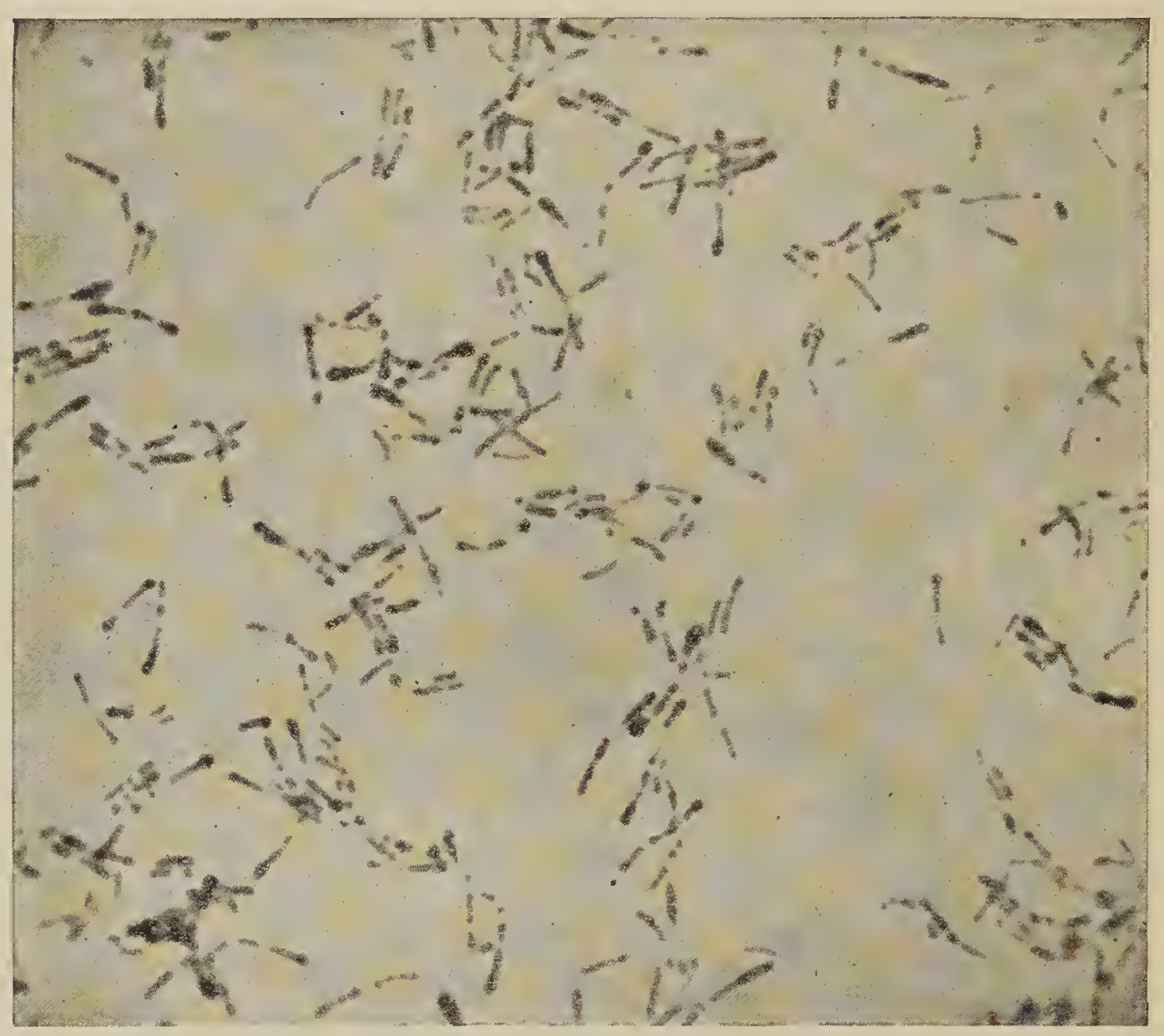

Fig. 24.-Diphtheria bacilli, enlarged 2000 times. Note the great irregularity in form; no two bacilli are alike. Barred, beaded, clubshaped, dumb-be!!, and exclamation-point forms. This appearance of diphtheria bacilli is characteristic. Compare with tubercle bacilli (Fig. 15), colon bacilli (Fig. 7), and typhoid bacilli (Fig. 19).

The bacilli are found in the throat in all cases of diphtheria, and in the saliva and nasal discharge. They may remain for weeks in the throat or nose after all symptoms have disappeared and the throat looks normal. They are often found, too, in the throats of those who are 
associated with a diphtheria patient, as members of the family, nurses, and schoolmates. In them the bacillus may cause no symptoms, yet when transferred from them to other persons it may cause the disease. These persons are, of course, "carriers." In one investigation among 129 doctors, nurses, and medical students having charge of diphtheria patients the bacilli were found in the throats of 62 .

The diphtheria bacillus is another example of an organism which nay remain in the body of the patient for some time after he has recovered from the disease, and which may be spread by healthy carriers. Compare it with the pneumococcus and the typhoid and dysentery bacilli.

Health departments usually require two "negative" cultures (that is, cultures which do not show the diphtheria bacillus) from both the throat and nose before releasing a person from quarantine.

The bacilli may be transferred directly from the patient to a healthy person by coughing into his face, kissing, etc. They are found on articles used by the patient, and the disease may be spread by means of these. The bacilli have been grown from a handkerchief eleven weeks after it had been used by a patient.

Persons suffering from a mild or unusual form of the disease may spread the infection. Some slight sore throats are due to the diphtheria bacillus, but this can be proved only by taking a culture from them. Hence a culture should be made from every case of sore throat, es- 
pecially in schools and institutions, as one cannot always tell simply by looking at a throat whether it is a case of diphtheria or of ordinary tonsillitis. In children's wards the nurse should be on the watch for nasal discharges, especially those which irritate the nostrils or are tinged with blood, as these may be due to the diphtheria bacillus. In many children's wards a throat and nose culture is made as a routine on each new patient.

The most frequent method of spread of diphtheria is, however, through healthy carriers, who may be the schoolmates of the pupil who has been taken sick with diphtheria, members of the family, or the nurse who has had the care of him. These people are more dangerous than the patient or convalescent, because they go about freely; and it is they who are the hardest problem in the control of the disease, on account of the difficulty of detecting and of isolating them. Carriers keep diphtheria alive in the schools, in which it is spread by various childish practices, putting pencils in the mouth, using each other's handkerchiefs, passing around candy, and taking turns on chewing gum. The number of diphtheria cases in cities rises when the schools open in the fall. To find out the frequency of diphtheria carriers in the schools the Boston Board of Health took cultures from the noses and throats of all the public school children in a single district (Brighton). Among 4178 scholars they found that 55 , or 1.3 per cent., had diphtheria bacilli in the throat or nose. 
We have a very efficient cure for diphtheria in diphtheria antitoxin, which is the blood-serum of a horse that has been given hypodermic injections of broth in which diphtheria bacilli have grown. It will cure the disease if given early and in sufficiently large doses, and it will also prevent its development in persons exposed to it. Hence it is given not only to the patient but also to the nurse and members of the family. The use of antitoxin is taken up in Chapter XV.

Diphtheria used to be one of the most serious and dreaded diseases, but its spread has been controlled and the death-rate from it much lessened by the enforcement of public health measures, combined with the use of antitoxin. The chief measures used by Boards of Health to control the disease are: inspection of school children; taking cultures from all suspicious throats, and keeping the child out of school until it is decided whether or not he has diphtheria; taking cultures from the throats of all members of a family in which a case of diphtheria has developed, and quarantining them, as well as the patient, if they are carrying the bacilli; releasing the patient and those associated with him from quarantine only when their throats are "negative" for diphtheria bacilli; giving antitoxin to all who have been in close contact with the patient; special public health nurses for contagious diseases, and compulsory removal of the patient to a contagious disease hospital if he cannot be thoroughly isolated at home. 
Tonsillitis.-Ordinary tonsillitis and sore throat are caused by the streptococcus, Staphylococcus aureus, and

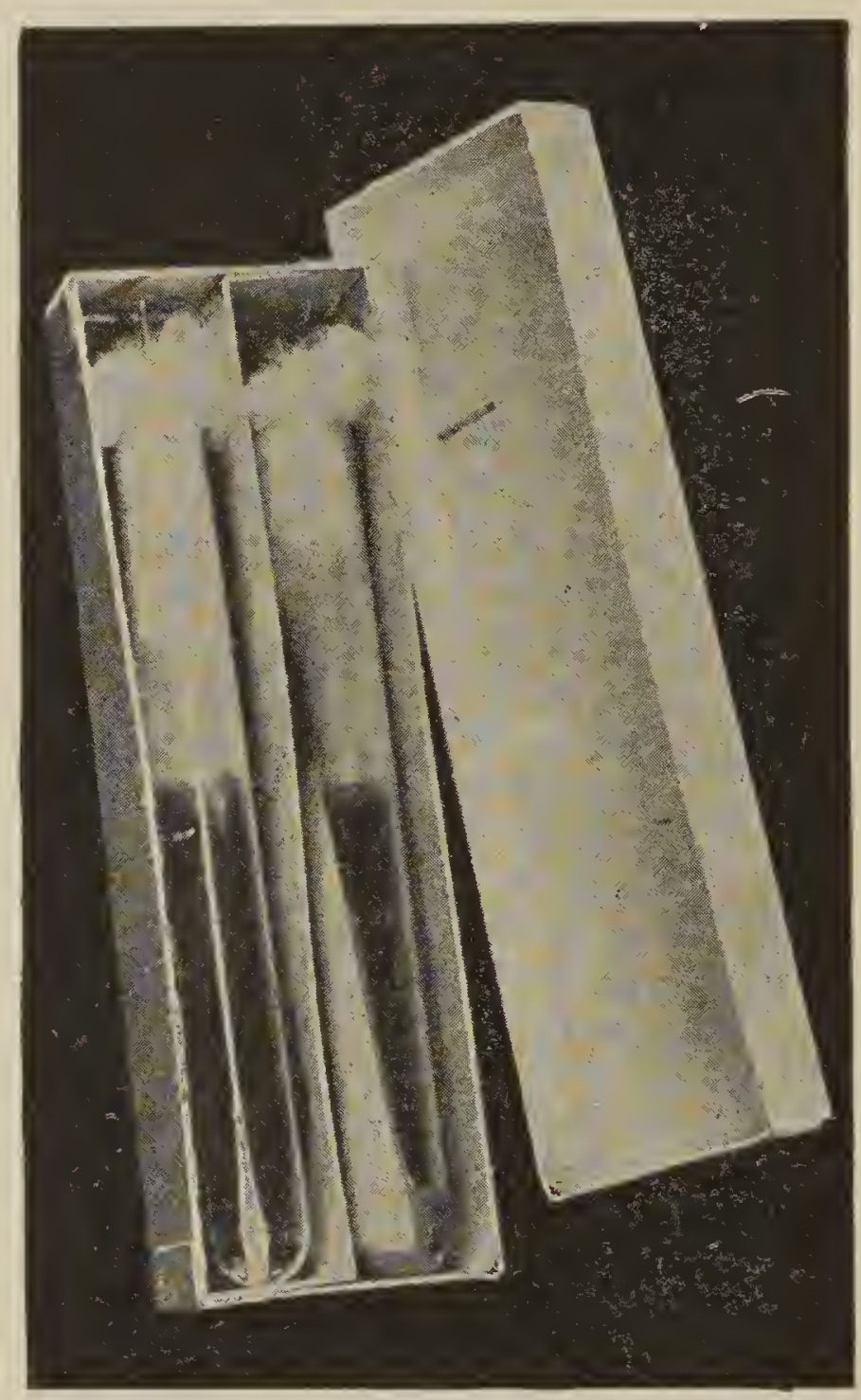

Fig. 25.-A Board of Health outfit for diphtheria diagnosis, consisting of a box containing a culture-tube and a tube of food substance. The swab is rubbed over the patient's throat and then immediately over the surface of the food substance, so that no time is lost in starting the culture. The substance on which diphtheria bacilli grow best is beef blood-serum (obtained from the slaughter-house) which has been coagulated by heat (McFarland).

sometimes by the pneumococcus. They are spread in the usual ways of nose and throat infections: by direct transfer of the bacteria, as in kissing or coughing; or by 
articles contaminated with the patient's saliva or nasal discharges, as drinking-cups, forks, spoons, handkerchiefs, etc.

Frequent attacks of tonsillitis or sore throat are important not only in themselves, but from an inflamed throat or tonsils bacteria may be carried to other parts of the body and set up an inflammation there. Cases of rheumatism, inflamed joints, and diseases of the heart valves may be due to bacteria, particularly streptococci, which have come from inflamed tonsils. A person who is subject to sore throats should see a doctor and take measures to get rid of the infection.

\section{Demonstration}

Show a culture of the diphtheria bacillus, and demonstrate a Board of Health diphtheria outfit. 


\section{CHAPTER XI}

CONTAGIOUS DISEASES: MEASLES; SCARLET FEVER; WHOOPING-COUGH; MUMPS; CHICKEN-POX

THERE is a group of diseases called in a general way the contagious diseases, because they are especially easily transmitted from person to person by contact (contagious, from the Latin verb "to touch"). The most frequent of these are measles, scarlet fever, whooping-cough, mumps, and chicken-pox. The causes of a number of the contagious diseases have not yet been discovered with certainty. These infections most often attack children and occur in epidemics. Several, as scarlet fever, measles, and chicken-pox, are associated with rashes of different kinds. Second attacks are very rare; that is, one attack usually protects the person for life (see Chapter XIII).

Measles is the commonest of all diseases caused by living organisms; but, in spite of this fact, the organism which causes it is still unknown. It may be that it is too small to be seen with the highest powers of the microscope. It has been proved, however, that the organism is present in the secretions of the nose and throat and also in the circulating blood. It is probable that infection occurs by breathing in the droplets thrown 98 
out by the patient in coughing and sneezing. The organism does not live long outside the body.

The first symptoms, which resemble an ordinary cold, appear from nine to eleven days after the person has been exposed, and the rash breaks out on the thirteenth or fourteenth day. The patient may give the disease from the time the very first symptoms appear. It is not known how long the patient continues to be infectious, but it is usually at least ten days.

Measles itself very seldom causes death, but complications are frequent, and may be very serious or fatal. The most common of these are bronchopneumonia (see Chapter VIII) and an abscess in the ear. Measles may also reduce the resistance of a child so that it falls a victim of tuberculosis (see Chapter VII). In England and Wales in 1909 measles and its complications caused 12,618 deaths. It is also a frequent and severe disease where large numbers of army recruits are brought together for the first time.

Scarlet Fever.-The organism causing scarlet fever is not yet definitely known, although recently (1917) a bacillus, somewhat like the diphtheria bacillus in appearance, has been discovered in the tonsils of scarlet fever cases, and may be the cause of the disease. The secretions from the nose and throat contain the organisms, whatever they may prove to be. The flakes of skin shed during "peeling" will carry the disease if they are contaminated with these secretions. The organism 
can remain alive for some time outside the body on things soiled by the secretions of the throat and nose, as toys, clothing, etc. It probably enters by the moath to produce the disease, which develops from two to four days after infection.

The patient may give the disease from the onset of the symptoms and for a long time, even after peeling is over. Like diphtheria and typhoid, scarlet fever may be spread by mild unrecognized cases. Six weeks is usually set as the length of isolation, but ten weeks is safer, and no patient should be released from quarantine if there is any discharge from the nose or ears.

Whooping-cough is caused by a small bacillus which is present in the lining of the bronchial tubes and is cast off in great numbers in the sputum. The bacillus grows slowly and with difficulty outside the body. It is transferred directly from person to person by breathing in droplets of sputum thrown out during coughing.

The disease is very contagious. It develops about a week after the child has been exposed. The patient may spread the disease as long as he continues to cough.

Whooping-cough is more serious than is generally supposed. It may be followed by bronchopneumonia or tuberculosis, and on account of these complications it is a frequent cause of death in children under five. Every effort should be made to protect young and delicate children from infection.

Mumps.-The organism of this disease and the ways 
in which it is spread are still undiscovered. The disease develops from seventeen to twenty-one days after infection.

Chicken-pox.-The cause of this disease, also, and the ways in which the organism enters and leaves the body are still unknown. The organism probably does not live long in the outside world. The incubation period (see Chapter V) is about two weeks, and the patient may give the disease even before the eruption appears.

There are certain general measures which should be carried out in every case of contagious disease.

Special care must be taken of the secretions of the nose and mouth, as these undoubtedly contain the organisms of measles and scarlet fever, and quite probably also of mumps. The same precautions must be taken with the sputum in whooping-cough. Old muslin or gauze should be used instead of handkerchiefs, and burned after use. The mouth and teeth must be kept clean. The bed- and body linen must be disinfected before being sent to the laundry. Separate dishes should be provided, and boiled after using. The doctor and nurse should wear long gowns and caps which completely cover the hair. The hands should be scrubbed whenever they become contaminated with the patient's secretions, and always on leaving the sick room.

At the end of quarantine the patient should be given a thorough bath, the hair washed, and fresh clothing 
put on in another room. The floor, wood work, and furniture of the sick room should be washed with soap and water, and the walls wiped down with a cloth wrung out of $1: 1000$ bichlorid solution. Toys and books should be burned. The mattress should be steamcleaned if possible, but if not, it should be put out in the sun for several days and beaten. Fumigation of the room is unnecessary, and thorough washing with soap and water is more important than disinfectants.

In preventing the spread of the contagious diseases, isolation from the very beginning of the symptoms is important. In most contagious diseases the patient can give the disease from the time of onset of the first symptoms, and measles, at least, is more contagious in the early stages than later. Too often isolation is not begun until the disease is well developed, and other children have already been infected. All children having any suspicious symptoms should be isolated immediately without waiting until a definite diagnosis can be made. Daily medical inspection of school children, as carried out in cities, is doing much to prevent the spread of contagious diseases. Pupils showing any suspicious signs are sent home, where they are kept under supervision until the diagnosis is decided. Real isolation of a contagious patient in the case of a large family in crowded quarters is impossible, and, therefore, in such circumstances the patient should be sent to a contagious disease hospital, if this is at all possible. 
Some unintelligent parents think that every child must have the milder contagious diseases, and make no effort to protect their children, or even expose them knowingly. This is altogether wrong, for no one can tell beforehand whether or not a case will be light. It may develop severe or even fatal complications. Particularly in regard to measles and whooping-cough most people are still too careless, both as to limiting the spread of infection and as to the care of the child to prevent complications. 


\section{CHAPTER XII}

\section{SYPHILIS AND GONORRHEA: THE VENEREAI DISEASES}

SyphiLis and gonorrhea are two very wide-spread infectious diseases which are connected, directly or indirectly, with sexual immorality, and are spoken of as the venereal diseases. The amount of suffering and loss which they cause is enormous, and, in fact, they are quite as great a medical and social problem as tuberculosis. Their prevention and control form one of the most serious tasks in the care of an army. These diseases are more frequent and are more far-reaching in their results than is generally realized. The nurse is brought into frequent contact both with the actual diseases and with their results in nervous and mental disorders, internal diseases, obstetrics, and gynecology.

All prostitutes are infected with one or both of these diseases, and everyone who lives an immoral life is sure to contract them sooner or later. These persons infect others, most often their wives and children.

Syphilis is a chronic infection that may affect any organ in the body. It is caused by a corkscrew-shaped organism, the Spirocheta pallida. Spirochetes are micro-organisms which are very much like bacteria. The spirochete of syphilis is called "pallida" (pale) because it ap- 
pears colorless under the microscope. It has the power of movement. It grows only with great difficulty and under special conditions outside the body. It is one of the most recently discovered organisms, being known only since 1905 .

The Sipirocheta pallida gains entrance to the body through breaks in the skin or mucous membranes, most often on the genital organs, occasionally on the lips, and causes an ulcer. Within a few weeks after infection the

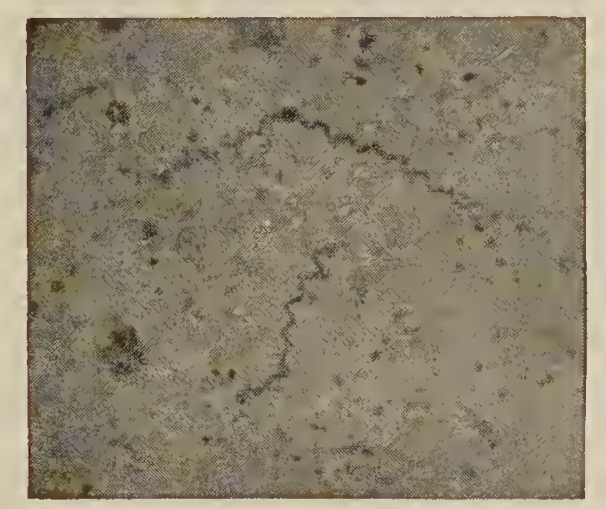

Fig. 26.--Spirocheta pallida, magnified 1500 times, from the discharge from a syphilitic sore (photo by I. S. Brown).

organisms get into the blood and are carried to every organ in the body, a rash appears, and there are sores in the mouth. The discharges from the ulcers and sores contain the organisms, and the disease may be spread at this stage by the patient himself or by things contaminated with the syphilitic discharges, as clothing, towels, drinking-cups, etc.

These early symptoms disappear after a number of weeks, but the disease is not cured; it enters on the chronic stage. Like the tubercle bacillus, the Spirocheta 
pallida may remain alive in the body for many years without causing any symptoms. It may then attack any organ in the body. Syphilis may thus be the cause of various diseases which appear a long time after the first infection. It is a frequent cause of diseases of the heart and arteries. Locomotor ataxia is due to it, and so are 10 per cent. of all cases of insanity; among the latter general paralysis of the insane, or paresis, in which the spirochetes are in the brain substance.

Syphilis is also the cause of many miscarriages. If either of the parents is suffering from the disease the unborn child may be infected. This is called congenital syphilis (congenital meaning present at birth). Many of these children are born dead or die in infancy; some of those who live are diseased in various ways or are feebleminded. In one investigation of children of syphilitic parents it was found that 47 per cent. were miscarriages or died in infancy; of the remainder, one-third were healthy, and the other two-thirds were diseased either physically or mentally. Congenital syphilis is one of the most frequent causes of mental deficiency in children (feeblemindedness, imbecility, and idiocy).

Syphilis is spread most frequently by sexual intercourse during the early stages of the disease. It is also contracted occasionally through articles contaminated by fresh syphilitic discharges, as clothing and towels; or by cups, dishes, and pipes that have been used by a person having syphilitic sores in the mouth, or by dental instru- 
ments that have been used on a patient with syphilis of the mouth, and not sterilized. After the early symptoms have passed and the disease has become chronic, the syphilitic does not transmit the disease, and hence is no longer a danger to others. It is important to remember the difference in the infectiousness of the disease at different stages, for nurses often show a needless fear of chronic syphilitic patients.

The blood of a person who has syphilis, or has had it, gives a special test, the Wassermann reaction, named after the German physician who discovered it. Blood for the test is usually drawn from a vein at the bend of the elbow. A "positive" reaction is given as long as the organisms of syphilis remain alive in the body, which may be as long as thirty years after infection. If the brain or spinal cord is affected by the disease the reaction is generally given by the cerebrospinal fluid. Congenitally syphilitic children usually have a positive Wassermann reaction. The Wassermann reaction is done as a routine on every patient in most general and insane hospitals.

There is a drug, salvarsan, which kills the organism of syphilis just as quinin kills that of malaria. Salvarsan contains arsenic, and is given intravenously. If given in the early stages of the disease it will, in almost every instance, destroy the spirochetes and thus prevent the development of chronic syphilis. After the disease has become chronic the effect is not so certain. Every syphilitic should be given salvarsan, and should continue under 
further antisyphilitic treatment until it is reasonable to believe that he is permanently cured. This usually takes at least three years. Early and prolonged antisyphilitic treatment will in most cases prevent the later development of conditions due to syphilis, as diseases of the heart, arteries, and nervous system.

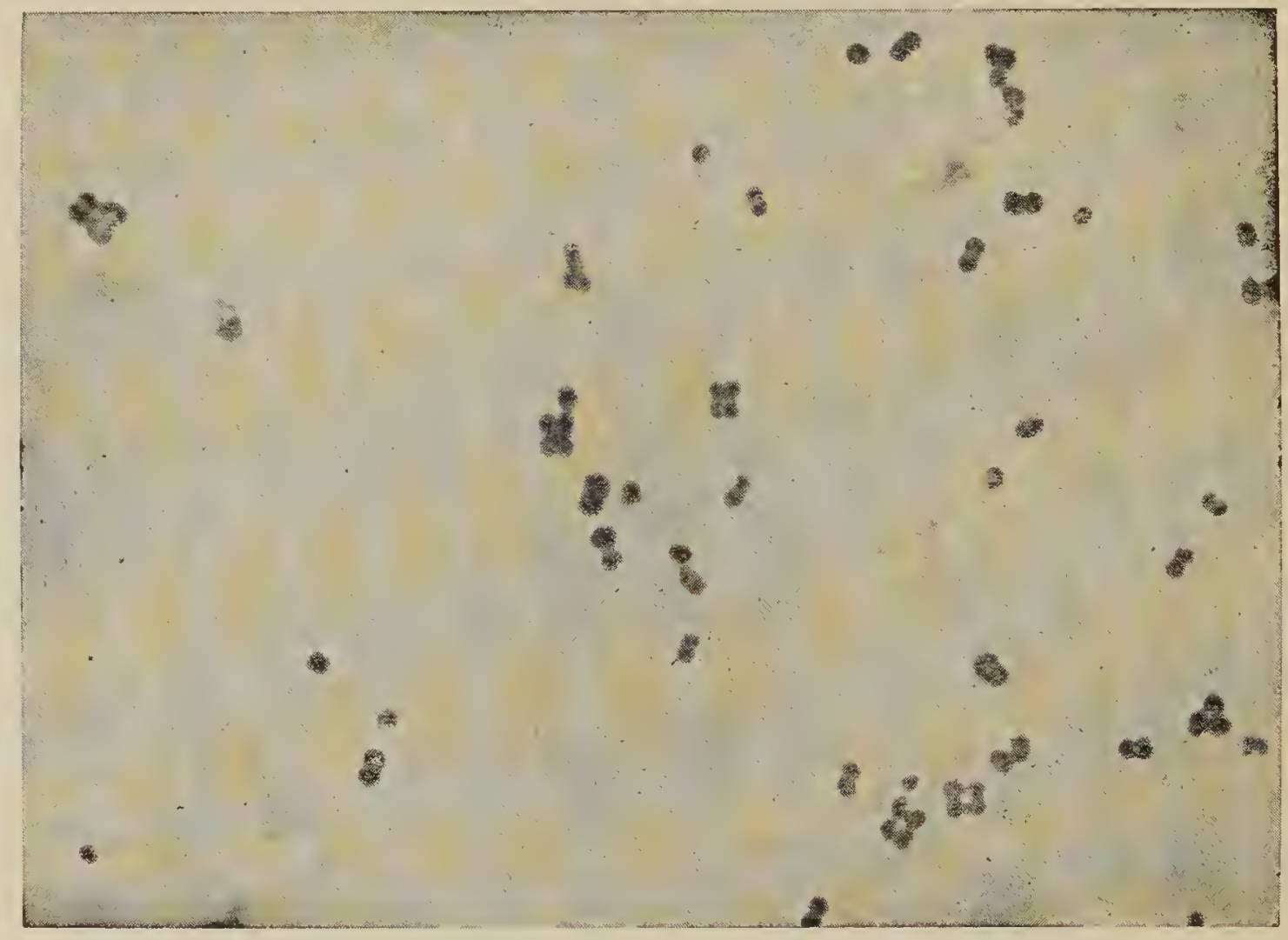

Fig. 27.-Gonococci, enlarged 2000 times. The cocci occur in pairs, sometimes two pairs together. They have somewhat the shape of beans (Wright and Brown).

Gonorrhea is an infection of the urethra and genital organs in both men and women, caused by a particular germ, the gonococcus. It begins as an acute inflammation and later becomes chronic.

The gonococcus was discovered in 1879 by a German physician, Neisser. It is a delicate organism, growing 
poorly in the laboratory and dying quickly outside the body: It has a characteristic appearance under the microscope, the cocci being shaped like beans, and always occurring in pairs. It is, therefore, a diplococcus, like the organism of pneumonia.

In women the gonococcus causes an inflammation of the vagina, uterus, fallopian tubes, and ovaries. This condition is quite common, and makes necessary many gynecologic operations. Gonorrhea in women is extremely difficult to get rid of, as the infection will suddenly start up again after it has apparently been cured. In most gynecologic clinics it is the custom to examine the uterine secretion of every patient under the microscope for the gonococcus.

If either husband or wife has gonorrhea the marriage is often childless.

If a woman who has gonorrhea gives birth to a child, the baby's eyes may become infected during the process of birth. The gonococcus causes a very serious inflammation of the eyes of newborn babies, which unless promptly and vigorously treated may within a few days cause blindness for life. It has been estimated that the gonococcus causes about 10 per cent. of all cases of blindness, and that there are in the United States 12,000 persons blind for this reason. The law requires that a drop of silver nitrate solution be put into each eye immediately after the child is born to prevent this infection, and also that any inflammation of the eyes of a newborn 
baby be reported to the Health Department within twenty-four hours. Some of the infections of the eyes of the newborn are caused by carelessness in washing the eyes, and are due to the Staphylococcus aureus, but it is impossible to distinguish the two kinds without examining the pus from the eyes under the microscope.

The gonococcus may cause an inflammation of the vagina in little girls. This sometimes breaks out in hospital wards or orphan asylums, and is very difficult to stop in spite of the greatest precautions.

The gonococcus is present in the discharge from the inflamed parts, the urethra, vagina, uterus, and eyes. The infection is spread in grown people chiefly by sexual intercourse, but it may be carried by articles soiled with gonorrheal discharges, as towels, wash-cloths, clothing, etc. The children of a family in which either of the parents has gonorrhea may be infected in this way.

The control of the venereal diseases is a more difficult problem than that of other infectious diseases. As long as prostitution exists, syphilis and gonorrhea will continue. There are, however, certain measures which will reduce the spread of these diseases, and on which there should be general agreement. Syphilis and gonorrhea should be reportable to the Health Department just as other infectious diseases are. The authorities should keep the patient under supervision and insist that he follow up treatment as long as necessary, and that he take precautions against infecting others. Laws which will break 
up prostitution as a business should be rigidly enforced. Salvarsan treatment, which is now expensive, should be put within the reach of all, and sufficient hospital accommodations should be provided for venereal patients. A knowledge by the public of the ways in which these diseases are spread, their prevalence and consequences, instruction of young people in sex hygiene, and the provision of good amusements are all important aids in the reduction of these infections. 


\section{CHAPTER XIII}

\section{HOW THE BODY PROTECTS ITSELF AGAINST BACTERIA. IMMUNITY}

We have seen that bacteria harm the body by producing poisonous substances which are carried about in the blood, and that the symptoms of an infection are due to the injury to the different organs caused by these poisons. Also, if the body is overcome by the poisons the patient dies, while if the body can protect itself against them the patient recovers. The question that we are going to take up now is, how does the body deal with the invading bacteria? or how is it that a patient recovers from an infectious disease? The answer, in a general way, is this: In the course of an infectious disease certain substances appear in the blood which are either injurious to the bacteria themselves or which counteract their poisons. These substances are adapted in each case to fighting the particular germ causing the infection. If the patient can produce these protective substances in sufficient quantity he gains resistance to the disease, the bacteria die out, and he gets well. If he cannot produce them, the bacteria gain the upper hand, the patient is overcome by their poisons, and dies.

Both the poisons formed by the bacteria and the substances produced by the body to counteract them are 
extremely complicated and delicate. It is only recently that anything has been known about them. They have not yet been obtained in pure form outside the body, and they are known and studied only by the effects which they produce in the bodies of men and animals.

The protective substances remain in the body for varying lengths of time after the patient has recovered from an infectious disease, the time depending on the disease. After diphtheria and pneumonia they disappear quickly, within a few weeks, whereas after typhoid they remain in the body for many years. As long as they continue in the body the person is unlikely to have the disease a second time, even if exposed to it.

This resistance to infection is called immunity, and the person who is resistant to an infection when exposed or, in other words, does not "catch it," is said to be immune to that infection. A person who has had scarlet fever or typhoid is usually immune to these diseases for the rest of his life; that is, second attacks are very rare, even though the person is in contact with the disease. After diphtheria and pneumonia, on the other hand, immunity is short, and second attacks are common.

Nature's way of producing immunity is allowing one to have a disease and recover from it. In the last few years, however, physicians have discovered methods of producing immunity artificially, that is, without having the disease. In the case of some infections it is possible to immunize the person before he has the disease, that is, 
to make him resistant to the disease when he is exposed to it, and thus prevent him from having it at all. This is spoken of as prophylactic or preventive immunization, and is practised on a large scale in the prevention of typhoid fever. When a person is already suffering from an infection, the amount of protective substances in the blood may in some cases be increased by giving the patient injections of dead bacteria of the same kind as are causing the trouble. In the case of a few infections also these protective substances can be produced in the blood of an animal. If the blood-serum of this animal is injected into a patient suffering from the infection it immunizes him quickly, thus cutting short the natural course of the disease. An example of this is the use of antitoxin in diphtheria! Again, it is possible in a very few infections to give the person the disease in an exceedingly mild form, which, however, will protect him from the usual severe form of the disease. This is done in vaccination against small-pox.

There are thus three ways of producing immunity besides the natural method of recovering from the disease:

The first is by injecting into the patient dead bacteria of the kind which one wishes to protect against. These dead bacteria are contained in normal salt solution, and the preparation is called a bacterial vaccine.

Second, by the injection into the patient of the bloodserum of an animal which has been immunized to the bacteria against which it is desired to protect the patient. 
This preparation is called a serum (plural sera), and in the case of diphtheria, "antitoxin."

Third, by the inoculation of the patient with the living micro-organisms, which give him the disease in an extremely mild form. This is done for two diseases only, small-pox and hydrophobia or mad dog bite.

The applications of each of these methods will be taken up in the following chapters.

The question whether a vaccine or a serum will give better results in any disease is one that must be worked out by experiment. It has been found that in some diseases vaccines are better, in others sera. Unfortunately, there are some infections, for instance, tuberculosis, for which neither a satisfactory vaccine nor serum has yet been prepared.

The prevention and treatment of infections by vaccines and sera is one of the most hopeful developments of medicine, and one which is constantly growing in importance, as physicians discover new applications of the principles of immunity. 


\section{CHAPTER XIV}

\section{BACTERIAL VACCINES}

THE treatment of infection by bacterial vaccines consists in giving the patient hypodermic injections of dead bacteria of the same kind as are causing the infection. If the infection is due to the staphylococcus, killed staphylococci are given; if to the colon bacillus, killed colon bacilli, etc. If the bacteria used in making the vaccine have come from the patient himself, the vaccine is said to be autogenous (from two Greek words: auto, meaning "self," and gen, "source"); if from some other source, it is called a stock vaccine. The treatment by bacterial vaccines, although often spoken of as "vaccination," is entirely different in every way from vaccination against small-pox, which is what is ordinarily meant by vaccination, and the use of the same word for both is unfortunate.

It seems strange at first thought that the very germs which are causing the infection can be used for their own destruction. The explanation, however, is that the injection of the dead bacteria stimulates the body to the production of protective substances, that is, substances which are injurious to the bacteria.

An autogenous vaccine is made as follows: A culture is taken from the place of infection (an abscess, infected 
wound, urine in cases of inflammation of the bladder, etc.). The organism causing the trouble is grown in large quantities. At the end of twenty-four or forty-eight hours the bacteria are put into normal salt solution and are killed by heating. The number of germs in each cubic centimeter of the solution is found by counting them under the microscope, and then the concentrated vaccine is diluted with salt solution until each cubic centimeter contains the desired number of bacteria (usually 500,000,000 to $1,000,000,000)$.

Many millions of bacteria are given at a single injection. In the case of vaccines there is no such definite dosage as with ordinary remedies. Each patient must be studied individually. The usually accepted full dose of the Staphylococcus aureus for curative purposes is $600,000,000$, and of other organisms 100,000,000. Larger doses are given for preventive immunization, as, for instance, against typhoid.

The vaccines most commonly used are the Staphylococcus aureus, streptococcus, gonococcus, typhoid, and colon bacillus. Staphylococcus aureus infections, such as boils and infected wounds, are very favorably influenced by vaccine treatment. The results with other vaccines are not so brilliant.

Vaccines are given in the same way as ordinary hypodermics. The upper arm, shoulder, thigh, and buttock are the usual places for injection. The skin and syringe should be prepared as for any hypodermic injection. 
The vaccine must be thoroughly shaken before use, as the bacteria settle to the bottom on standing. It should be injected deeply, as less pain and swelling are caused than by superficial injection. A different muscle should be used for each injection.

Vaccines should be kept in a cold, dark place. Under these conditions they will keep their strength for several months. Aseptic precautions must be used in opening a bottle of vaccine.

The time between doses varies with the condition of the patient. In localized infections with no temperature or constitutional symptoms, as a sinus or inflammation of the bladder, injections are usually given twice a week, and the doses are large. In severe infections, on the other hand, accompanied by fever, puerperal fever, for instance, small doses are given and repeated frequently. In other words, the sicker the patient, the smaller the dose and the more frequently repeated.

Vaccine treatment has been most successful in chronic infections, such as sinuses, infected wounds, ulcers, chronic cystitis, and in localized infections, as "crops" of boils. There is a difference of opinion as to its value in severe acute infections, as blood-poisoning, puerperal fever, etc.

Bacterial vaccines are used not only for the cure but also for the prevention of infection. The chief application of this is preventive or prophylactic inoculation against typhoid fever by the use of typhoid vaccine. 
The treatment consists usually in giving three doses of vaccine ten days apart, the first 500,000,000, the second and third 1,000,000,000 bacilli. It is important that the whole course of treatment be taken, as less than that will not protect. The injections are usually followed by considerable swelling and soreness of the arm. There are sometimes constitutional symptoms - headache, malaise, nausea, and occasionally a rise in temperaturebut these are not serious and they pass off in twenty-four hours.

This vaccination gives protection against typhoid for two to three years, and at the end of that time should be repeated. It is not an absolute preventive in every case, as typhoid has been known to occur following it. Therefore an inoculated person must not relax any precautions that he would otherwise take. An immunized nurse should be as scrupulously careful about washing her hands and taking all other measures to protect herself as if she were not inoculated. Antityphoid vaccination does not in the least take the place of other measures against typhoid, but is an addition to them. It will be impossible for some time to come to get rid entirely of sources of typhoid infection, particularly carriers, and antityphoid immunization protects against infection which we cannot avoid.

The results of antityphoid immunization have been remarkable. It is practised as a routine in the armies of the United States and Europe, and has practically 
done away with typhoid in them, whereas before the treatment was introduced typhoid caused an enormous number of deaths in war. In the Civil War it caused 29,336 deaths, and in the Spanish-American War in 1898-99 one-fifth of the soldiers in the camps had it, and to it were due 86 per cent. of the total deaths of the war!

Antityphoid inoculation is also required of all nurses connected with the Army and of all Red Cross units. It is the rule, too, in most nurses' training-schools, and is being carried out more and more wherever large numbers of people live together, as in insane hospitals, schools, prisons, etc. It is also strongly advised for all persons who travel, as they cannot always protect themselves against contaminated food and water; also for persons living in a place where typhoid is common. In fact, every intelligent person should wish to be inoculated. If one member of a family develops typhoid, the others should be immunized, and no unprotected person should be allowed to take care of a typhoid patient.

Preventive inoculation is also given in the Army against paratyphoid fever, which is caused by a bacillus somewhat like the typhoid bacillus ("para" meaning like), and which usually resembles a light attack of typhoid. The treatment has been successful in preventing the disease, which was formerly very frequent in armies. 
A vaccine of the influenza bacillus has been used in the recent epidemic, both for prevention and treatment. Preventive inoculations are given in this case on three days in succession.

\section{DEMONSTRÁTIONS}

Show any vaccines on hand, explaining the source of the culture, the condition for which the vaccine is given, dosage, etc.

An effort should be made to have senior nurses assist with antityphoid inoculations in the hospital, and measure out the doses. They should also observe any cases in which vaccine treatment is given. 


\section{CHAPTER XV}

\section{THERAPEUTIC SERA}

A THERAPEUTIC serum (plural sera) is, as has been said, the blood-serum of an animal, usually a horse, which has been injected with the bacteria against which it is desired to develop resistance, or with the poisonous substances formed by the bacteria. These sera are used both for the prevention and the cure of infections. There are three sera which are very efficient, those against the bacilli of diphtheria and tetanus (lockjaw), which are spoken of as antitoxins ("anti," against, and "toxin" from a Greek word meaning poison), and that against the germ causing cerebrospinal meningitis, the meningococcus. These sera have proved to be so valuable that they are used as part of the routine treatment of these diseases or for their prevention. Sera have been produced against some other bacteria, for example, the streptococcus, pneumococcus, and dysentery bacillus, but they are not so powerful as the three mentioned above, and their use is not general.

The protection given by a serum is usually short, lasting only a few weeks, but it is immediate, and is, therefore, extremely valuable, when the patient is already sick, in cutting short the course of the disease or making it less severe. The protection given by a bac- 
terial vaccine, on the other hand, is slowly produced, but usually lasts much longer than that given by a serum. In a general way, therefore, vaccines do not give as good results as sera if quick action is necessary, as when a patient has already developed a disease, but they are more efficient for producing a lasting resistance, as in the case of antityphoid inoculation.

Diphtheria antitoxin was one of the earliest discoveries in the study of immunity. It first came into use about 1894, and it has saved an enormous number of lives. Diphtheria used to be a very fatal disease. At the Boston City Hospital the death-rate before the days of antitoxin was 43.2 per cent., while since its use has become general the rate has dropped to 7.8 per cent.

The diphtheria bacilli, in an ordinary case of diphtheria, are not spread throughout the body, but remain limited to the throat, where they form a very powerful poison which is taken into the blood and injures the various organs, especially the heart, nervous system, and kidneys. "A patch of membrane the size of the thumb-nail may produce sufficient toxin to cause death." Antitoxin counteracts the toxin and prevents its harmful action on the organs. After they have once been injured by the toxin, however, antitoxin cannot bring them back to normal; hence the extreme importance of giving antitoxin early in the disease.

The method of making antitoxin is as follows: A horse is injected with gradually increasing amounts of broth 
in which diphtheria bacilli have grown and which contains their toxin (see Fig. 28). The horse is the animal chosen because it yields a large amount of blood on account of its size. The first dose is very small, not enough to make the animal sick, but at the end of the treatment it may take without symptoms a quart of broth at a single injection. When the horse has developed a large

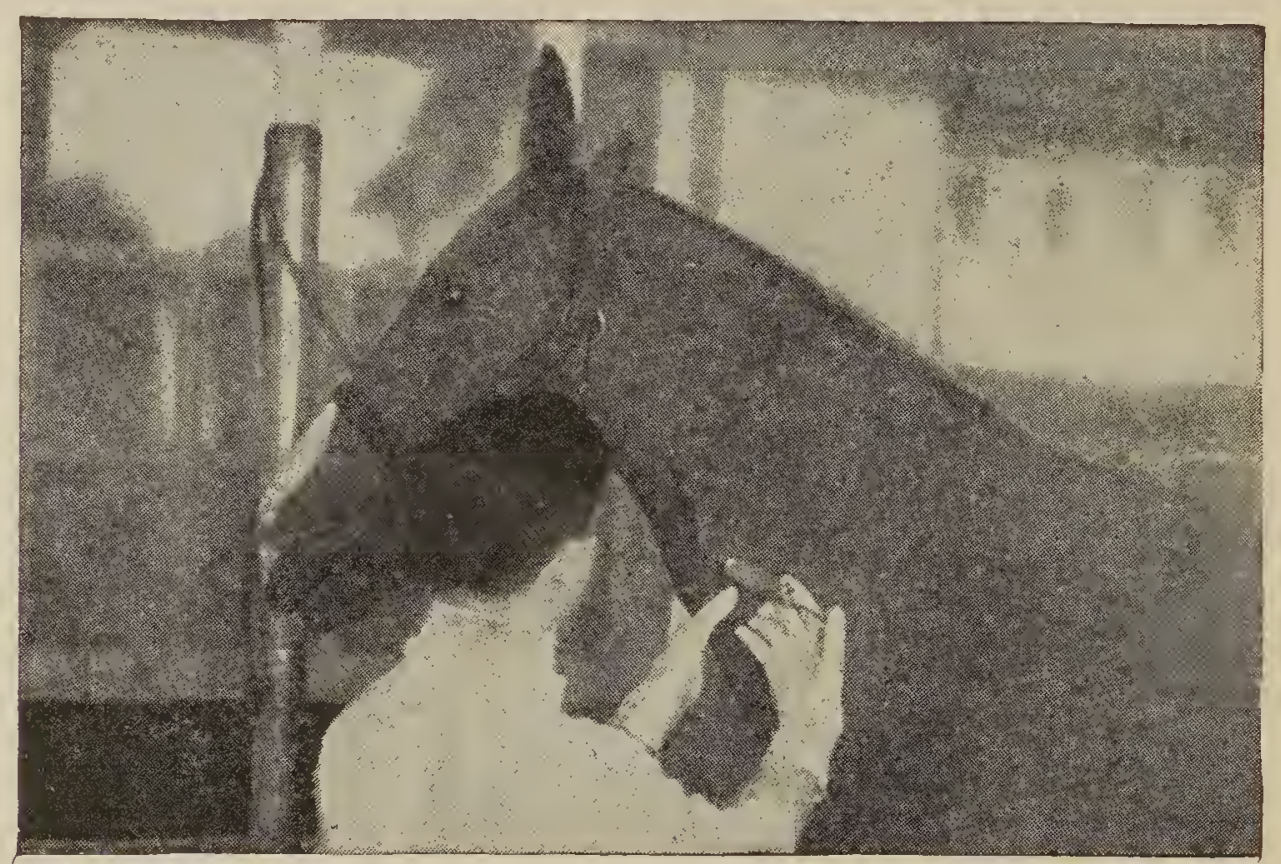

Fig. 28.-Injecting diphtheria toxin (broth in which diphtheria bacilli have grown) into the jugular vein of a horse. (Courtesy of H. K. Mulford Company, Philadelphia.)

amount of antitoxin in its blood, it is bled with aseptic precautions from the jugular vein, 6 to 8 quarts of blood being removed at one time (see Fig. 29). The blood-serum separates from the clot on standing and is the "antitoxin" used in medical practice. The bleeding is repeated about once a month as long as the animal has a good amount of antitoxin in its blood, this period varying from six months to several years. 
Antitoxin must be kept in a dark, cool place, as it gradually loses its strength when exposed to light and warmth. It is given in the shoulder or thigh, with the same aseptic precautions as for any hypodermic.

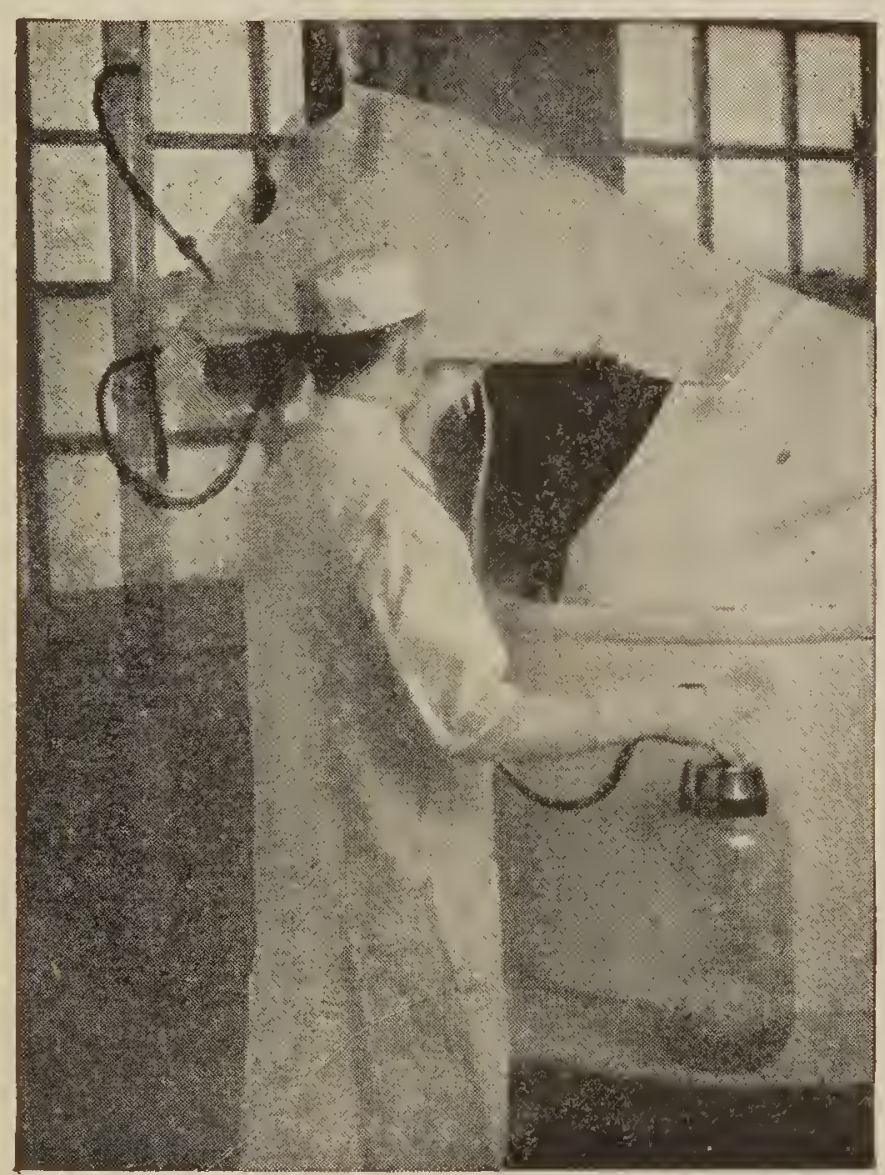

Fig. 29.-Bleeding from the jugular vein a horse that has been injected with diphtheria toxin. The blood contains diphtheria antitoxin. The blood-serum, after it has been separated from the clot, is the "antitoxin" used in medicine. (Courtesy of H. K. Mulford Company, Philadelphia.)

The "unit" of antitoxin is the amount which counteracts a certain standard amount of toxin. It is used in measuring the doses of antitoxin just as minims and drams are for ordinary medicines.

No hard-and-fast rules can be laid down about dosage. The amount of antitoxin given is determined by 
the seriousness of the symptoms and the stage of the disease at which treatment is begun. The sicker the patient and the later the stage of the disease, the larger must be the dose. The danger is not in giving too much, but too little. 3000 to 4000 units are usually given as the first dose in ordinary cases, and repeated every five to six hours until the patient improves. In cases in which there is considerable membrane 8000 to 10,000 units are given, and in very severe cases 50,000 to 100,000 units. If sufficient quantities of antitoxin are given early in the disease practically every case of diphtheria should recover. In a series of cases at the Philadelphia Hospital for Contagious Diseases all the patients receiving antitoxin on the first day of the disease recovered; among those treated on the second day the death-rate was 5.4 per cent.; while among those not treated until the third day or later the number of deaths was much higher.

Antitoxin also prevents the development of diphtheria in those exposed to the disease. Small doses (500-1000 units) are, therefore, given to members of the patient's family, the nurse, and others who have been in contact with the patient. This is called a prophylactic or preventive dose, and the protection given by it lasts about four weeks.

The use of ant toxin is sometimes followed by symptoms which are spoken of as the "serum sickness." A few days after antitoxin has been given a rash appears, 
sometimes resembling the hives; in other cases a diffuse redness, and there may be pains in the joints. These symptoms are not usually serious.

Tetanus Antitoxin.-- The bacillus causing tetanus or lockjaw (see Fig. 2) lives in the soil. It forms spores (see Chapter I) and is, therefore, very hard to kill by heat or antiseptics. It grows only where there is no oxygen. Wounds which are contaminated with soil, such as Fourth of July injuries and those received in trench warfare, are liable to become infected with the tetanus bacillus. This is one of the most deadly germs; one thousand of them, which is an exceedingly small number as bacteria go, in a wound may produce enough poison to cause death. Like the diphtheria bacillus, the tetanus bacillus forms a powerful poison or toxin. It acts especially on the nervous system, causing convulsions, to which death from the disease is due. The disease after it has once developed is almost always fatal.

An antitoxin for the tetanus bacillus is obtained in the same way as diphtheria antitoxin, that is, by.injecting horses with broth in which tetanus bacilli have grown and which contains their poison or toxin. The curative value of this antitoxin is much less than that against diphtheria, and after the symptoms of tetanus have appeared its hypodermic administration is of little value. It has been injected directly into the spinal canal in some cases, however, with good results.

The antitoxin has, however, immense value in pre- 
venting the development of the disease; in fact, tetanus can be prevented in almost every case by the routine practice of giving the serum immediately after all injuries that are liable to be followed by tetanus. It is, therefore, quite customary to give a dose of antitoxin as a precaution immediately to persons having wounds contaminated with dirt. In the early days of the war

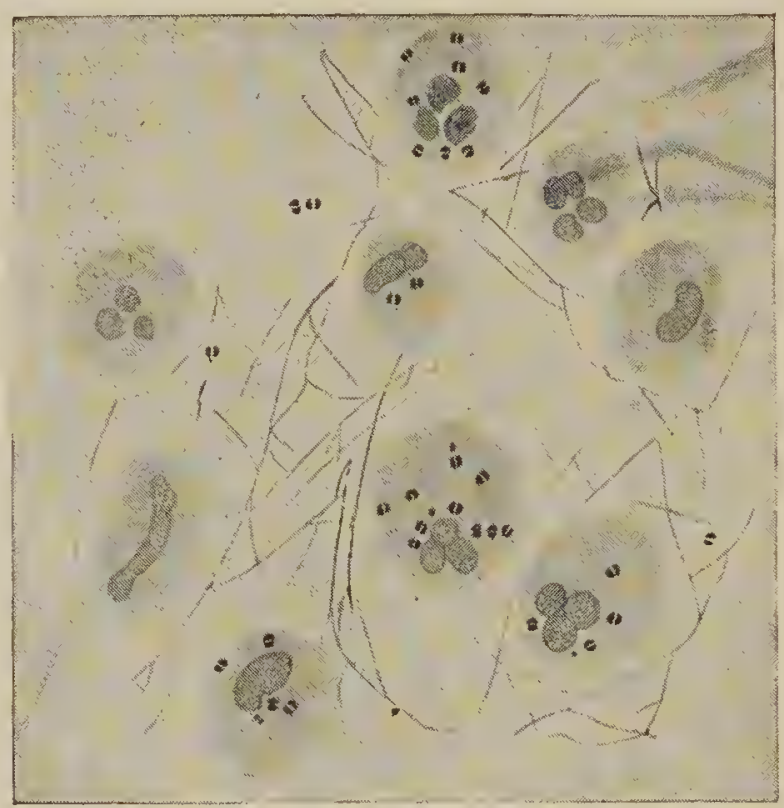

Fig. 30.-Meningococci in the leukocytes (or pus cells) from the cerebrospinal fluid in a case of cerebrospinal meningitis. The cocci occur in pairs and look like gonococci (see Fig. 27). The network between the cells is fibrin (Jordan).

there were many cases of tetanus, but now every wounded soldier is given antitetanus serum as soon as he reaches a surgeon, and as a result the disease is becoming rare.

Antimeningococcus Serum.-This is a serum used for the cure of cerebrospinal meningitis. The disease is an inflammation of the coverings of the brain and spinal cord, the meninges, accompanied by the formation of pus, and due to a coccus, called the meningococcus. 
The germ is delicate, growing poorly in the laboratory, and quickly killed by drying. It cannot live long outside the body. It is present in the cerebrospinal fluid of patients suffering from the disease, and is also often found in their nasal secretion and saliva. It is sometimes present in the throats of healthy persons who have been in contact with the disease, and these may become carriers. The way in which the disease is spread is not fully known, but it is probably through carriers.

The curative serum comes from a horse that has been injected with cultures of the meningococcus. The results of its use are most encouraging, as it has reduced the death-rate in the disease from an average of 75 to 30 per cent.

The serum is injected directly into the spinal canal by means of lumbar puncture; 30 to 45 c.c. of cerebrospinal fluid are allowed to run off, and then an equal amount of serum is injected through the same needle. The treatment is repeated daily for three or four days, and longer if necessary. As in the case of diphtheria antitoxin, the earlier the treatment is begun, the better the results.

\section{DEMONSTRATIONS}

Show an antitoxin outfit, and demonstrate its use. If possible, show also antitetanic and antimeningococcic sera.

If practicable, a visit to an antitoxin establishment should be undertaken. 


\section{CHAPTER XVI}

\section{VACCINATION AGAINST SMALL-POX}

SMALL-POX was the first disease to which immunity was obtained by artificial means. Vaccination was developed by practical experience, and was carried on successfully for many years before there was any knowledge of the scientific principles on which it is based.

The principle of vaccination is very complicated, but it may be stated in a general way as follows: The organism which causes small-pox in human beings also produces in cows a mild disease called cow-pox, which appears as an eruption on the udder. If the living organisms from the eruption of cow-pox are rubbed into the skin of a human being, a very slight infection, compared to small-pox, takes place, but this is sufficient to give protection from small-pox for a number of years. The principle is therefore entirely different from immunization with bacterial vaccines, in which the organisms injected have been killed, or immunization with sera, in which no organisms are injected, but the blood-serum of an immunized animal.

The relationship between cow-pox and small-pox was discovered by Edward Jenner, an English country doctor. He published his observations in 1798, after he 
had been studying and experimenting on the subject for twenty years. Jenner noted that persons working around cows which had cow-pox developed sores on their fingers like those on the cows' udders, and that these persons never caught small-pox during an epidemic. He introduced on a large scale the practice of inoculating people with the material from the eruption of cow-pox, which, in an improved form, is what we now call vaccination.

Before the days of vaccination small-pox was as common as measles is today, and was a very fatal disease. It is still very frequent in parts of the world in which vaccination is not practised. Owing to vaccination the disease has become rare in civilized countries; but if vaccination is neglected in any community small-pox will re-appear in the course of time. The efficiency of vaccination is shown by experiences in the Philippine Islands, in seven provinces of which there had been, before vaccination was carried out, more than 6000 deaths every year from small-pox (showing that there were about 25,000 cases). In the year following vaccination by the United States Army authorities of all the inhabitants (over $8,000,000$ ) there was not a single death from the disease.

The organisms causing small-pox have never been grown outside the body, but they have in all probability been seen under the microscope inside the cells of the skin in the small-pox eruption. These organisms are 
not bacteria, but are one of the lowest forms of animal life.

"Vaccine virus," or "lymph," is prepared in large quantities at special establishments by inoculating calves with the organism of small-pox or cow-pox. The skin of the abdomen is shaved and sterilized, and scratches are made just as in the vaccination of human beings. Into these scratches is rubbed material from the eruption of cow-pox, or sometimes of small-pox, which contains the living organisms. In a few days the calf develops sores similar to those following vaccination in a human being. The material from these is scraped out, mixed with glycerin to prevent the growth of ordinary bacteria, and put up in small glass tubes. The virus thus contains the living organisms from a case of cow-pox.

In vaccination, the skin of the part to be inoculated must be thoroughly cleaned with soap and water to get rid of ordinary bacteria, but if disinfectants are used they must afterward be removed; otherwise the organisms in the virus might be killed. Slight scratches are made, the virus gently rubbed into them, and allowed to dry. If the vaccination "takes," a sore appears on the third day at the place of inoculation, and goes through certain characteristic stages, leaving a scar. There is also a reaction on the part of the whole body lasting several days, shown by fever, loss of appetite, general discomfort, and headache. During this 
time substances are being formed in the body which will protect against small-pox.

Vaccination protects against the disease for a varying length of time, averaging about seven years. Every child should be vaccinated between the ages of six months and two years. Grown people should be revaccinated whenever the disease appears in the community, or if they are going to places where it is present.

\section{DEMONSTRATION}

Show tubes of virus. Senior nurses should help with any vaccinating done in the institution. 



\section{INDEX}

Abscess, 35, 58, 59

in ear, 99

tubercular, 65, 67

Antitoxin, diphtheria, 95, 114, 115, 122,123

dosage, 125

unit, 125

tetanus, 127

Arteries, diseases of, 106, 108

\section{BACILLI, forms of, 14}

Bacillus, colon, 37, 116, 117

diphtheria, 31, 35, 43, 45, 91, 123,127

dysentery, 30, 31, 39, 87, 93, 122

influenza, 39, 74, 121

Klebs-Löffler, 91

lactic acid, 30

scarlet fever, 99

tetanus, 19, 28, 127

tubercle, 25, 30, 31, 39, 79, 93, 117

whooping-cough, 100

Bacteria, appearance under microscope, 14

classification of, 14, 26

conditions of life, 15

disease-producing, 15, 17, 18, 26, $31,34,43$

distribution in nature, 19

food of, 15

growth in laboratory, 16, 20
Bacteria in air, 28, 35, 38

in soil, 19, 27, 127

in water, 28,80

in wounds, 38, 57, 59, 60, 117, $118,127,128$

light, effect of, 18, 27, 65

methods of study, 20

moisture, 17,27

movement, 14, 44, 79

multiplication, 16, 43

on human body, 34

oxygen, relation to, 18,127

size, 13

staining, 14

temperature for growth, 17, 23, 27

Blood-poisoning, 53, 58, 61, 118

Boils, 38, 59, 61, 117, 118

Bones, tuberculosis of, 65

Bronchitis, 62

Canning, 19, 28, 29

Carriers, 45

diphtheria, 45, 93, 94

dysentery, $45,51,87$

infantile paralysis, 45

meningococcus, 45, 129

pneumococcus, 73

typhoid, 45, 84, 86, 119

Cerebrospinal fluid, 107, 129

Chicken-pox, 55, 98, 101

Childbirth, 41, 45, 57, 60, 69 
Children's diseases, 40, 55, 98

Cocci, arrangements of, 14, 59, 72, 109, 128

Cold storage, 28, 29

Colds, 39, 42, 43, 76

Colonies, 23, 65

Contact infection, 43, 82, 87, 93, 96

Contagious diseases, 34, 44, 95, 98 care of, 101

control of, 102

Cow-pox, 130

Cultures,

in tuberculosis, 67

taking of, 20

throat, 91, 93, 95

to detect carriers, 45

typhoid, 83

Cystitis, 37, 118

Decay, 15,26

Diphtheria, 42, 53, 54

antitoxin, 95, 114, 115, 122, 123

dosage, 125

unit, 125

control of, 94,95

forms of, 91, 93, 100

immunity in, 113

membrane, 91, 123, 126

method of spread, 93

Diplococci, 78, 108, 109, 128

Diseases, classification of, 34

Drinking-cups, 40, 51, 67, 77, 105

Droplet infection, 35, 39, 66, 73, 75, $77,93,96,98,100$

Dysentery, 42, 43, 45, 51, 87

bacillus, 30, 31, 39, 87, 93, 122

method of infection, 88

prevention, 88

EGGS, 28, 32

Epidemics from milk supplies, 31 influenza, 75
Epidemics of contagious diseases, 98 of respiratory infections, 77 of typhoid, 81, 82, 84

Erysipelas, 38, 60, 61

Eyes, inflammation of, 42, 61, 110 gonococcus infection of, 109

FECES, bacteria in, 36, 42

disinfection of, 80,84

dysentery bacilli in, 87

protection from flies, $47,51,88$

tubercle bacilli in, 67

typhoid bacilli in, 80, 84, 89

Flies, dysentery from, 51, 87

eggs, 46

habits, 46,47

measures against, 47, 49

protection of food from, 39, 48, 67

typhoid, 46, 83

Food, contamination of, $39,49,51$, $67,80,87,88$

decay of, $28,36,40$

drying of, 29

growth of bacteria in, 40

handlers, 39, 80, 84, 86

smoking of, 29

Fumigation, 44, 45, 102

Garbage, 46,47

Gonococcus, 108, 117, 128

Gonorrhea, 104, 108

transmission of, 110

Grip, 42, 76

Gynecology, 60, 104, 109

Hands, cleanliness of, 39, 40, 43, $49,50,82,83,90$

Heart, diseases of, 63, 97, 106, 108 Hydrophobia, 115

ICE cream, 82

Immunity, 98, 112 
Immunity, artificial, 113

by vaccines and sera, 122

methods of producing, 114

prophylactic, 114

Immunization, antityphoid, 85, 87,

$117,118,123$

influenza, 121

paratyphoid, 120

preventive, 114, 117

small-pox, 114, 115

with sera, 122, 130

with vaccines, $116,123,130$

Incubation period, 53

in chicken-pox, 101

in diphtheria, 54

in measles, 54,99

in mumps, 100

in scarlet fever, 54, 100

in typhoid, 54, 80

in whooping-cough, 100

Infections, 34, 37

acute and chronic, 53

among chronic patients, 51

conditions favoring, 55

course, 53

pathways, 38, 43, 51

prevention, 49

symptoms, 52

Inflammation, 37, 38, 58, 59, 71, 76,

108

acute and chronic, 61, 62

signs and symptoms, 61

Influenza, 74

Inoculation. See Immunization.

Insanity, 104, 106

Intestine, bacteria in, 36 infections of, 89

tuberculosis of, 65

JENNER, 130

Joints, inflammation of, 61, 97 tuberculosis of, 65
KLEBS, 91

Koch, 64

LiCE, 49

Locomotor ataxia, 106

Löffler, 91

Lung, 39, 42, 62

Lymph-glands, tuberculosis of, 65

MaLaria, 48, 107

Masks, 76

Measles, 42, 54, 71, 98, 103

Meningitis, 62 cerebrospinal, 45, 122, 128

tubercular, 65

Meningococcus, 122, 128

Milk, care of, 32 control of milk-supplies, 32, 86 diphtheria bacillus in, 43 dysentery bacillus in, 87 growth of bacteria in, 16, 30, 47 number of bacteria in, 31 souring of, 30 typhoid bacillus in, 43, 78, 79,80

Miscarriage, 106

Mold, 13

Mosquito, 48

Mouth as point of entrance of infection, 39, 40, 67, 80, 82, 94, 100

bacteria in, 34, 36 care of, in contagious diseases, 101

syphilis of, 105, 106

Mumps, 55, 100

NASAL secretion, 42

care of, 101 in colds, 77

in diphtheria, 92, 94

in influenza, 76

in measles, 98 
Nasal secretion in meningitis, 129 in scarlet fever, 99,100 in tonsillitis, 97

Neisser, 108

Nervous system, 52, 56, 104, 106, $108,123,127$

Nose, bacteria in, $35,38,39,76,77$, 91, 93, 96

Obstetrics, 41, 45, 60, 104

Oysters, 80

Paralysis, general, 106 infantile, 45

Paratyphoid fever, 120

Paresis, 106

Pasteur, 18, 59

Pasteurization, 18, 31, 80, 87, 90

Peritonitis, 58, 62

Pickling, 29

Pneumococcus, 28, 35, 39, 62, 72, 93, 96, 109, 122

Pneumonia, 42, 51, 52, 53, 54, 55, 62

broncho-, 71, 75, 99, 100

immunity in, 113

lobar, 71

prevalence, 71

Poisons, bacterial, 52, 53, 112, 122 , 123, 127

Protective substances, 112, 116, 130, 133

Puerperal fever, 41, 60, 118

Pus, 42, 57, 58, 59, 60, 61, 67, 110, 128

RESPIRATORY tract, bacteria in, 38 , 39

Rheumatism, 97

Saliva, 36, 42, 76, 92, 97, 129

Salvarsan, 107, 111
Scarlet fever, 53, 54, 98, 99, 100, 113

Septicemia, 53, 58, 61, 118

Sera, therapeutic, 114, 122

Serum, antimeningococcus, 128 sickness, 126

Sewage, 27, 28, 78

disposal, 85, 86

from typhoid cases, 79, 80

Skin, bacteria on, 35, 59, 60, 99

infections of, 38, 61, 105

Small-pox, 114, 115, 130

Spine, tuberculosis of, 65

Spirilla, 14

Spirochæta pallida, 104

Spores, 18, 29, 127

Sputum, 35, 42, 43

care of, 50, 66, 70, 73, 76, 101

in influenza, 76

in pneumonia, 72

in tuberculosis, 65

in whooping-cough, 100

Staphylococcus aureus, 57, 59, 76, 96, 110, 116, 117

Sterilization by heat, 17 of skin, 35

Stomach, bacteria in, 36

Streptococcus, 25, 57, 58, 59, 76, $96,97,117,122$

Summer diarrhea. See Dysentery.

Surgery, 35, 44, 57, 58, 60

Syphilis, 55, 104

congenital, 106, 107

infectiousness, 107

treatment, 107, 111

Teeth, 36

Tetanus, 122,127

antitoxin, 127

Throat as point of entrance of infection, 97 bacteria in, 38, 39 cultures, $91,93,95$ 
Throat, diphtheria bacilli in, 35, Ulcers, syphilitic, 105 $42,45,92,123$ organism of measles in, 98 pneumococcus in, 35,73 streptococcus in, 59

Tonsillitis, 35, 42, 43, 61, 93, 96

Tonsils, 77, 91, 99

Toxins, 122, 123, 124, 125, 127

Tuberculosis, $54,55,56,115$ conditions favoring, 69, 77, 99, 100

control of, 64, 69

forms of, 65

infection in childhood, 68 prevalence, 63, 69

pulmonary, 42, 43, 53, 62

symptoms, 69

Typhoid fever, 42, 45, 54

control of, 85, 100, 119

immunity in, 113

method of infection, 43, 80

prevalence, 78

UlCERS, 61

dysenteric, 87

typhoid, 80

vaccine treatment, 118

Urine, 52

bacteria in, 42

tubercle bacilli in, 67

typhoid bacilli in, 80

Uterus, bacteria in, 41, 60, 109

Vaccination, 130, 131, 132

Vaccines, 114, 116, 123

antityphoid, 85, 118

Vagina, 41, 60, 109, 110

Vegetables, raw, 27, 80

Venereal diseases, 104, 110

Virus, vaccine, 132

WASSERMANN reaction, 107

Water-supplies, 78, 81, 87 control of, 85

Whooping-cough, 55, 71, 100, 103

Widal reaction, 85

Wounds, bacteria in, $38,57,59,60$, $117,118,127,128$ 


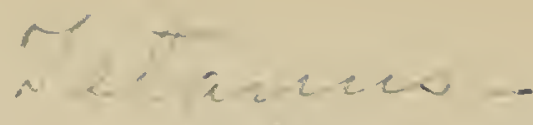

Disinfect - iodine

cut around to open to air.

inject tetanus toxin. 



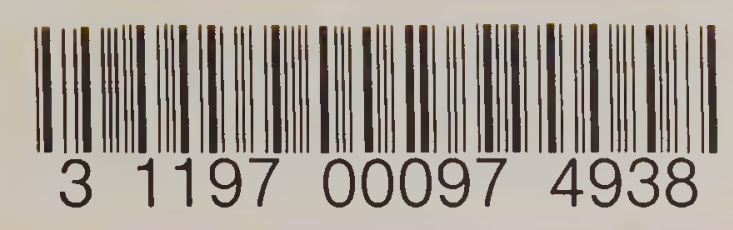


